\title{
SENSITIVITY OF THE HOUSE PRESSURE TEST FOR DUCT LEAKAGE TO VARIATIONS IN THE DISTRIBUTION OF AIR LEAKAGE IN THE HOUSE ENVELOPE
}

John W. Andrews

December 1998

$$
\begin{aligned}
& \text { RECEIVED } \\
& \text { FEB } 17 \text { 1999 } \\
& \text { OST! }
\end{aligned}
$$

Prepared for:

Office of Building Equipment

Office of Building Technology, State and Community Programs United States Department of Energy

Washington, DC 20585

Energy Efficiency and Conservation Division

DEPARTMENT OF APPLIED SCIENCE

BROOKHAVEN NATIONAL LABORATORY UPTON, LONG ISLAND, NEW YORK 11973 


\section{DISCLAIMER}

This report was prepared as an account of work sponsored by an agency of the United States Government. Neither the United States Government nor any agency thereof, nor any of their employees, nor any of their contractors, subcontractors, or their employees makes any warranty, express or implied, or assumes any legal liability or responsibility for the accuracy, completeness, or usefulness of any information, apparatus, product or process disclosed, or represents that its use would not infringe privately owned rights. Reference herein to any specific commercial product, process, or service by trade name, trademark manufacturer, or otherwise, does not necessarily constitute or imply its endorsement, recommendation, or favoring by the United States Government or any agency thereof. The views and opinions of authors expressed herein do not necessarily state or reflect those of the United States Government or any agency, contractor, or subcontractor thereof. 


\section{DISCLAIMER}

Portions of this document may be illegible in electronic image products. Images are produced from the best available original document. 
BNL- 66150

INFORMAL REPORT

\title{
SENSITIVITY OF THE HOUSE PRESSURE TEST FOR DUCT LEAKAGE TO VARIATIONS IN THE DISTRIBUTION OF AIR LEAKAGE IN THE HOUSE ENVELOPE
}

\author{
BY: \\ JOHN W. ANDREWS \\ DECEMBER 1998
}

\begin{abstract}
Prepared for:
Office of Building Equipment

Office of Building Technology, State and Community Programs United States Department of Energy

Washington, DC 20585
\end{abstract}

Under Contract No. DE-AC02-98CH10886

Brookhaven National Laboratory

Upton, NY 11973-5000 


\begin{abstract}
The house pressure test for air leakage in ducts calculates the signed difference between the supply and return leakage from the response of the air pressure in the house to operation of the system fan. The currently accepted version of this calculation was based on particular assumptions about how the house envelope leakage is distributed between the walls, ceiling, and floor. This report generalizes the equation to account for an arbitrary distribution of envelope leakage. It concludes that the currently accepted equation is usually accurate to within $\pm 5 \%$, but in a small proportion of cases the results may diverge by $50 \%$ or more.
\end{abstract}




\section{TABLE OF CONTENTS}

Abstract

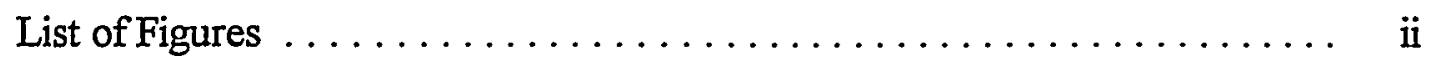

Introduction $\ldots \ldots \ldots \ldots \ldots \ldots \ldots \ldots \ldots \ldots \ldots \ldots \ldots, 1$

Pressure Distribution Within the Envelope $\ldots \ldots \ldots \ldots \ldots \ldots \ldots \ldots .2$

Integral of a Special Function $\ldots \ldots \ldots \ldots \ldots \ldots \ldots \ldots \ldots \ldots, \quad 3$

Envelope Leakage Flow with System Fan Off $\ldots \ldots \ldots \ldots \ldots \ldots \ldots$

Envelope Leakage Flow with System Fan On $\ldots \ldots \ldots \ldots \ldots \ldots$

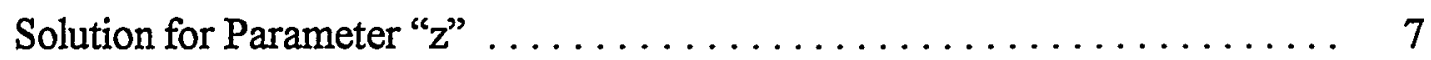

Is the Standard 152P Formula Accurate Enough? .............. 9

How Do Errors in the Signed Difference of Supply and

Return Leakage Translate into Errors in the Separate

Supply and Return Leakage Values? . . . . . . . . . . . . . . 11

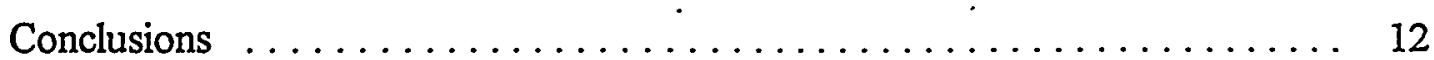

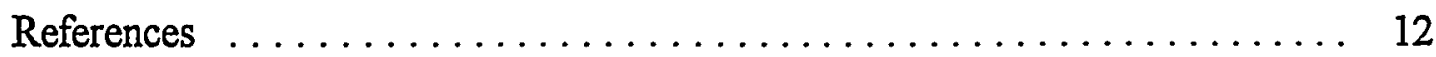

Appendix: Spreadsheets $\ldots \ldots \ldots \ldots \ldots \ldots \ldots \ldots \ldots \ldots \ldots \ldots \ldots$

\section{LIST OF FIGURES}

1. Dependence of Parameter " $z$ " on the Distribution of Air Leakage Within the Envelope $\ldots \ldots \ldots \ldots \ldots \ldots \ldots \ldots \ldots$

2. Iterative Solution for Parameter " $z " \ldots \ldots \ldots \ldots \ldots \ldots \ldots \ldots \ldots$

3. Frequency Histogram of Discrepancy in $\mathrm{Q}_{\text {sleaktrieak }}$ Between This Study and ASHRAE Standard 152P, for Slab-on-Grade Homes (Floor Leakage Assumed Equal to Zero)

4. Frequency Histogram of Discrepancy in $\mathrm{Q}_{\text {sleaktreak }}$ Between This Study and ASHRAE Standard 152P, for Homes with Open Foundations (Floor Leakage $\geq 25 \%$ of the Total) .................. 14 


\section{INTRODUCTION}

The purpose of this report is to derive a version of the equations that are used in the house pressure test for duct leakage to determine the signed difference between the supply and return leakage rates to/from outside. The house pressure test, which is one of two tests for duct leakage given as options in ASHRAE Standard 152P (ASHRAE 1998), indirectly measures the air leakage rates in duct systems. The leakage rates from the supply ducts to the outside and to the return ducts from the outside are determined as solutions to equations that have as inputs measured values of the pressure difference between the house and the attic under conditions of system fan off, system fan on, and system fan on with the return register(s) partially blocked. Pressure measurements within the supply and return ducts are also required.

A critical step in deriving the house pressure test protocol involves a formula for the air leakage rate to the outside from the supply ducts minus the air leakage rate from the outside to the return ducts. This equation was first derived by Mark Modera of the Lawrence Berkeley National Laboratory. (His derivation is as yet unpublished, but a descriptive treatment is given in Modera and Byrne 1997.) Modera's equation has since been incorporated in the draft version of Standard 152P (Method of Test for Determining the Design and Seasonal Efficiencies of Residential Thermal Distribution Systems), which is being developed by the American Society of Heating, Refrigerating, and Air Conditioning Engineers (ASHRAE).

The physical basis for the equation is that any unbalance in duct leakage will manifest itself as a change in the air pressure in the house when the system fan is turned on. For example, if leakage from outside to the return ducts exceeds that from the supply ducts to the outside, then the duct system is taking in a net amount of air from the outside, which it delivers to the building. This will cause the house pressure to go up when the fan comes on. Conversely, if supply leakage dominates, the house pressure will go down on fan startup. This phenomenon has been used for some time (under the name "dominant duct leakage test") to determine which side of the duct system leaks more than the other. Modera's addition was to show how the leakage flow coefficient of the building envelope could be used as a standard against which the duct leakage could be quantified, so that not only the sign but also the magnitude of the net leakage (supply minus return) could be estimated.

Modera's formula was derived under the assumption that the leakage flow coefficient of the envelope is divided into two equal parts, one relating to the ceiling and the other to the floor. No leakage through the wall was assumed. Although this might seem grossly unrealistic, since much air leakage usually occurs through cracks around windows and doors, it can be argued that what really was done was to apportion the leakage into roughly equal high and low components.

Recently, the degree to which these simplifying assumptions are immune to error in the results has come to be questioned. This report is an attempt to shed light on this issue by deriving an equation that allows for more generality in what is assumed about the envelope leakage distribution. 


\section{PRESSURE DISTRIBUTION WITHIN THE ENVELOPE}

Our first task is to describe the difference between the assumptions used by Modera in deriving the house-pressure-test formula in ASHRAE 1998 and those employed here. As stated above, Modera's formula was derived under the simplifying assumption that the envelope leakage flow coefficient was divided equally between floor and ceiling leakage, with no leakage attributed to the wall. Although this is likely to be quite unrealistic in many if not most single-family dwellings, it was felt that the results would not be highly dependent on these assumptions.

In an effort to determine how sensitive the house pressure test might be to the details of the envelope leakage distribution, this report modifies these assumptions in the following way:

1. The floor, ceiling, and walls are allowed to embody arbitrary fractions of the total envelope flow coefficient.

2. The pressure in the house is a function of vertical height only. That is, the pressure at any given height above the floor is the same regardless of the location within the house.

3. The pressure difference between the inside and outside varies linearly with height.

4. The flow coefficient for the wall is uniformly distributed over its vertical extent.

The first of these points represents the broadest possible generalization. This is then restricted somewhat by points 2,3 , and 4 , which are intended to make the calculation tractable. Although the real pressure and flow distributions may sometimes differ significantly from those implied by these latter points, particularly in windy conditions, the situation outlined above does represent a significant relaxation of the assumptions embodied in Modera's formula, and it should prove valuable to determine what impact variations of the leakage coefficients of the floor, ceiling, and walls will have on the results. If the impact is minimal, then we can with greater confidence use the Modera formula. If the impact is significant, then the modified formula may have to be substituted even if it is more complex.

Using the above assumptions, let us now represent the pressure difference between the inside and the outside of the house as a function of the vertical height $y$, with $y=0$ at the floor and $y=h$ at the ceiling. (For multistory housing, floor means the floor of the lowest conditioned story, and ceiling means the ceiling of the highest conditioned story. A flat floor and a flat ceiling are assumed.)

With the system fan off, the house pressure test requires a measurement of the pressure difference of the house with respect to the attic and calls this $\Delta \mathrm{P}_{\text {off. }}$. This pressure difference across the ceiling is representative of the pressure difference across the envelope at $y=h$. With the assumption of a linear relationship of the inside-to-outside pressure difference as a function of $y$, we may write: 


$$
P(y)=\Delta P_{\text {off }}+k(y-h)
$$

with $\mathrm{k}$ constant. The following relationships must hold:

- If $\Delta \mathrm{P}_{\text {off }}>0$, then $\mathrm{kh}>\Delta \mathrm{P}_{\text {off }}>0$

- If $\Delta \mathrm{P}_{\text {off }}<0$, then $\mathrm{kh}<\Delta \mathrm{P}_{\text {off }}<0$.

These are necessary so that $P(y)$ will have a zero somewhere in the range $0<y<h$. This zero, called the neutral level, means that air infiltrates below this level and exfiltrates above it (or vice versa) allowing a zero net infiltration of air.

\section{INTEGRAL OF A SPECIAL FUNCTION}

Functions of the form $\operatorname{sign}(x)|x|^{n}$ will appear quite often in what follows, because this is the form that the air flow across the envelope will take as a function of pressure difference. It will sometimes be necessary to integrate this function over a range that includes zero. This could be done by splitting the interval into two parts and treating each separately, but it will be more convenient to have a general formula, particularly because sometimes in the general case it will not be known whether or not the interval includes zero. By treating the cases $x_{0}<x_{1}<0$, $\mathrm{x}_{0}<0<\mathrm{x}_{1}$, and $0<\mathrm{x}_{0}<\mathrm{x}_{1}$ separately, it is easy to show that

$$
\int_{x_{0}}^{x_{1}} \operatorname{sign}(x)|x|^{n} d x=\frac{\left|x_{1}\right|^{n+1}-\left|x_{0}\right|^{n+1}}{n+1}
$$

regardless of whether $x_{0}$ and $x_{1}$ are of the same or opposite sign.

\section{ENVELOPE LEAKAGE FLOW WITH SYSTEM FAN OFF}

The first step in the derivation is to consider the case when the system fan is off. The procedure here is to write an equation for the net envelope leakage in terms of the leakage through the floor, ceiling, and walls, and then to note that with the fan off, this net leakage must equal zero. In writing this equation, we will use the pressure notation introduced above, together with the following terminology for the flow coefficients: 
$\mathrm{C}_{\text {tot }}=$ total envelope flow coefficient

$\mathrm{C}_{\mathrm{f}}=$ envelope flow coefficient for the floor

$\mathrm{C}_{\mathrm{c}}=$ envelope flow coefficient for the ceiling

$\mathrm{C}_{\mathrm{w}}=$ envelope flow coefficient for the walls

$\mathrm{n}_{\text {env }}=$ exponent in the pressure-flow relation $\mathrm{Q}=\mathrm{C} \Delta \mathrm{P}^{\mathrm{n}}$, assumed to be the same for all three envelope surfaces. (Typically $\mathrm{n}_{\mathrm{env}}$ is in the range $0.55-0.75$.)

(Note that $\mathrm{C}_{\text {tot }}=\mathrm{C}_{\mathrm{f}}+\mathrm{C}_{\mathrm{c}}+\mathrm{C}_{\mathrm{w}}$.)

We then may write:

$$
\begin{aligned}
0 & =C_{f} \operatorname{sign}\left(\Delta P_{\text {off }}-k h\right)\left|\Delta P_{o f f}-k h\right|^{n_{e n v}}+C_{c} \operatorname{sign}\left(\Delta P_{\text {off }}\right)\left|\Delta P_{\text {off }}\right|^{n_{e n v}} \\
& +\frac{C_{w}}{h} \int_{0}^{h} \operatorname{sign}\left(\Delta P_{o f f}-k h+k y\right)\left|\Delta P_{o f f}-k h+k y\right|^{n_{e n v}} d y
\end{aligned}
$$

Letting $\mathrm{u}=\Delta \mathrm{P}_{\text {off }}-\mathrm{kh}+\mathrm{ky}$ and noting that $\mathrm{dy}=(1 / \mathrm{k}) \mathrm{du}$ :

$$
\begin{aligned}
0= & C_{f} \operatorname{sign}\left(\Delta P_{o f f}-k h\right)\left|\Delta P_{o f f}-k h\right|^{n_{e n v}}+C_{c} \operatorname{sign}\left(\Delta P_{o f f}\right)\left|\Delta P_{o f f}\right|^{n_{e n v}} \\
& +\frac{C_{w}}{k h} \int_{\Delta P_{o f f}-k h}^{\Delta P_{o f f}} \operatorname{sign}(u)|u|^{n_{e n v}} d u
\end{aligned}
$$

which, upon performing the integral, becomes:

$$
\begin{aligned}
0= & C_{f} \operatorname{sign}\left(\Delta P_{\text {off }}-k h\right)\left|\Delta P_{o f f}-k h\right|^{n_{e n v}}+C_{c} \operatorname{sigh}\left(\Delta P_{o f f}\right)\left|\Delta P_{o f f}\right|^{n_{e n v}} \\
& +\frac{C_{w}}{k h\left(n_{e n v}+1\right)}\left(-\left|\Delta P_{o f f}-k h\right|^{n_{e n v}+1}+\mid \Delta P_{o f f} f^{n_{e n v}+1}\right)
\end{aligned}
$$

It will now be convenient to simplify the form of Equation 5 without adding any additional restrictive assumptions. We note that the signs of $\Delta \mathrm{P}_{\text {off }}-\mathrm{kh}$ and of $\Delta \mathrm{P}_{\text {off }}$ must be opposite in order for there to be zero net air inflow, i.e., zero must be between these two values. For the same reason, the sign of $\mathrm{k}$ must be the same as that of $\Delta \mathrm{P}_{\text {off }}$. It is therefore possible to get rid of the references to "sign" in Equation 5 by letting the signs of the first two terms on the right-hand side be opposite and noting that $|\mathrm{kh}|=\operatorname{sign}\left(\Delta \mathrm{P}_{\text {off }}\right) \mathrm{kh}$ : 


$$
\begin{aligned}
0= & -C_{f}\left|\Delta P_{o f f}-k h\right|^{n_{e n v}}+C_{c}\left|\Delta P_{o f f}\right|_{e n v}^{n} \\
& +\frac{C_{w}}{|k h|\left(n_{e n v}+1\right)}\left(-\left|\Delta P_{o f f}-k h\right|^{n_{e n v}+1}+\left|\Delta P_{o f f}\right|^{n_{e n v}+1}\right)
\end{aligned}
$$

We continue to simplify the form of the equation by defining $\mathrm{z}=\Delta \mathrm{P}_{\text {off }} /(\mathrm{kh})$ [with $0<\mathrm{z}<1$ because of $|\mathrm{kh}|>\left|\Delta \mathrm{P}_{\text {off }}\right|$ and $\left.\operatorname{sign}(\mathrm{kh})=\operatorname{sign}\left(\Delta \mathrm{P}_{\text {off }}\right)\right]$ and then (noting that $|\mathrm{a} / \mathrm{b}|=|\mathrm{a} / / \mathrm{b}|$ ) dividing each term by $|\mathrm{kh}|^{\text {nenv }}$ :

$$
0=-C_{f}(1-z)^{n_{e n v}}+C_{c} z^{n_{e n v}}+\frac{C_{w}}{\left(n_{e n v}+1\right)}\left[-(1-z)^{n_{e n v}+1}+z^{n_{e n v}+1}\right]
$$

The physical interpretation of $z$ is the distance from the ceiling to the neutral level as a fraction of the distance from the ceiling to the floor.

Because $n_{\text {env }}$ is not an integer, Equation 7 is without a closed-form solution (at least in terms of common functions). The value of $z$ is, however, a necessary input to the solution. We have devised an iterative solution that converges adequately in one step (in all cases tested) so that it is . amenable to use with a spreadsheet. It is worth noting, however, that for the Modera assumption $\mathrm{C}_{\mathrm{f}}=\mathrm{C}_{\mathrm{c}}$ and $\mathrm{C}_{\mathrm{w}}=0$, Equation. 7 is easily solved and $\mathrm{z}=1 / 2$.

So as not to interrupt the flow of the argument, consideration of the solution method will be deferred until later, with the reader being asked at this point to accept that a solution for $\mathrm{z}$ has been found.

\section{ENVELOPE LEAKAGE FLOW WITH SYSTEM FAN ON}

When the system fan is turned on, any imbalance in duct leakage is expected to have an effect on the pressure distribution in the house. If the return leakage (from outside) exceeds supply leakage (to outside), a net amount of air is taken up from the outside by the duct system and delivered to the house. This increases the pressures in the house. If supply leakage dominates, the house pressures are expected to decrease. In the house pressure test, the pressure difference across the ceiling (house with respect to attic) is measured with the system fan on and denoted $\Delta \mathrm{P}_{\text {on }}$. Assuming that turning the system fan on does not change the indoor-outdoor temperature difference significantly, i.e., assuming the equipment cycles frequently enough to maintain small indoor-air temperature swings, the relative distribution of pressures should not change. In particular, the value of $\mathrm{k}$--which is equal to $\Delta \mathrm{P}_{\text {off }} /(\mathrm{zh})$--should be the same. The pressure distribution in the house as a function of vertical height $y$ with the system fan on is then given by: 


$$
P^{\prime}(y)=\Delta P_{o n}+k(y-h)
$$

So we can write an equation for the net inflow of air from the duct system, and knowing $z$ (and hence $\mathrm{k}$ ) we can use it to solve for $\mathrm{Q}_{\text {steaktrleak }}$, which is the ASHRAE Standard 152P nomenclature for the signed difference between supply and return leakage rates. It must equal in magnitude the net inflow of air to the living space from the duct system. If we write an equation for the net outflow, in line with others' practice, then we have to make sure we include the proper minus sign:

$$
\begin{gathered}
Q_{\text {sleak }+ \text { rleak }}=-C_{f} \operatorname{sign}\left(\Delta P_{\text {on }}-k h\right)\left|\Delta P_{\text {on }}-k h\right|^{n_{\text {env }}}-C_{c} \operatorname{sigh}\left(\Delta P_{\text {on }}\right)\left|\Delta P_{\text {on }}\right|^{n_{\text {env }}} \\
-\frac{C_{w}}{h} \int_{0}^{h} \operatorname{sign}\left(\Delta P_{\text {on }}-k h+k y\right)\left|\Delta P_{o n}-k h+k y\right|^{n_{e n v}} d y
\end{gathered}
$$

In a similar manner to what was done in the fan-off case, one lets $\mathrm{u}=\Delta \mathrm{P}_{\text {on }}-\mathrm{kh}+\mathrm{ky}$ and notes that $d y=(1 / k) d u$ :

$$
\begin{aligned}
Q_{\text {sleak+rleak }} & =-C_{f} \operatorname{sign}\left(\Delta P_{\text {on }}-k h\right)\left|\Delta P_{\text {on }}-k h\right|^{n_{e n v}}-C_{c} \operatorname{sign}\left(\Delta P_{\text {on }}\right)\left|\Delta P_{\text {on }}\right|^{n_{e n v}} \\
& -\frac{C_{w}}{k h} \int_{\Delta P_{o n}-k h}^{\Delta P_{o n}} \operatorname{sign}(u)|u|^{n_{e n v}} d u
\end{aligned}
$$

which, upon performing the integral, becomes:

$$
\begin{aligned}
Q_{\text {sleakt }+r l e a k} & =-C_{f} \operatorname{sigh}\left(\Delta P_{o n}-k h\right)\left|\Delta P_{o n}-k h\right|^{n_{e n v}}-C_{c} \operatorname{sigh}\left(\Delta P_{o n}\right)\left|\Delta P_{o n}\right|^{n_{e n v}} \\
& -\frac{C_{w}}{k h\left(n_{e n v}+1\right)}\left(\left|\Delta P_{o n}\right|^{n_{e n v}+1}-\left|\Delta P_{o n}-k h\right|^{n_{e n v}+1}\right)
\end{aligned}
$$

We now express $\mathrm{k}$ in terms of measured values by inserting $\mathrm{kh}=\Delta \mathrm{P}_{\text {off }} / \mathrm{z}$ :

$$
\begin{aligned}
Q_{\text {sleak }+ \text { rleak }} & =-C_{f} \operatorname{sign}\left(\Delta P_{\text {on }}-\Delta P_{\text {off }} / z\right)\left|\Delta P_{o n}-\Delta P_{o f f} / z\right|^{n_{e n v}}-C_{c} \operatorname{sign}\left(\Delta P_{o n}\right)\left|\Delta P_{o n}\right|^{n_{e n v}} \\
& -\frac{C_{w} z}{\Delta P_{o f f}\left(n_{e n v}+1\right)}\left(\left|\Delta P_{o n}\right|^{n_{e n v}+1}-\left|\Delta P_{o n}-\Delta P_{o f f} / z\right|^{n_{e n v}+1}\right)
\end{aligned}
$$


We first note that if $\mathrm{C}_{\mathrm{f}}=\mathrm{C}_{\mathrm{c}}=\mathrm{C}_{\mathrm{tot}} / 2$ (implying $\mathrm{C}_{\mathrm{w}}=0$ ) and $\mathrm{z}=0.5$, which are the Modera assumptions, Equation 12 reduces to:

$$
Q_{\text {sleak }+ \text { rleak }}=\frac{1}{2} C_{\text {tot }}\left[-\operatorname{sign}\left(\Delta P_{\text {on }}-2 \Delta P_{\text {off }}\right)\left|\Delta P_{\text {on }}-2 \Delta P_{\text {off }}\right|^{n_{e n v}}-\operatorname{sign}\left(\Delta P_{\text {on }}\right)\left|\Delta P_{\text {on }}\right|^{n_{\text {env }}}\right]
$$

which is equivalent to:

$$
Q_{\text {sleaktrleak }}=\frac{1}{2} C_{\text {tot }}\left[\operatorname{sign}\left(2 \Delta P_{\text {off }}-\Delta P_{\text {on }}\right)\left|2 \Delta P_{\text {off }}-\Delta P_{\text {on }}\right|^{n_{\text {env }}}-\operatorname{sign}\left(\Delta P_{\text {on }}\right)\left|\Delta P_{\text {on }}\right|^{n_{\text {env }}}\right]
$$

This is the formula (due to Modera) that is in ASHRAE Standard 152P.

The careful reader will also note the $\Delta \mathrm{P}_{\text {off }}$ in the denominator of the third term of Equation 12 . This would appear troublesome, since it is quite possible for $\Delta \mathrm{P}_{\text {off }}$ to equal zero. Won't this cause the expression to "blow up"? The answer is no, because in the limit as $\Delta \mathrm{P}_{\text {off }} \rightarrow 0$, the numerator also approaches zero in such a way that the whole term has a finite limit.

\section{SOLUTION FOR PARAMETER "Z"}

We are now ready to pursue the project of comparing the values of $\mathrm{Q}_{\text {sleaktrleak }}$ obtained from Equation 12 with those from ASHRAE Standard 152 (Equation 14). The only roadblock yet to be cleared is that we have to determine how to solve Equation 7 for the parameter " $\mathrm{z}$ ", which appears in Equation 12. Ideally, the method of solution should be one that can be readily incorporated into a spreadsheet. This would facilitate the use of Equation 12 in practical applications, should the results show that Equation 14 is, in some circumstances at least, inadequate.

We begin by noting that for the special case $\mathrm{C}_{\mathrm{w}}=0$, Equation 7 can be readily solved, not just for Modera's $\mathrm{C}_{\mathrm{f}}=\mathrm{C}_{\mathrm{c}}=\mathrm{C}_{\mathrm{tor}} / 2$, but for any $\mathrm{C}_{\mathrm{f}}$ and $\mathrm{C}_{\mathrm{c}}$ :

$$
z=\frac{1}{1+\left(\frac{C_{c}}{C_{f}}\right)^{\frac{1}{n_{e n v}}}}
$$

The first step in generalizing to $C_{w} \neq 0$ is to note that for any value of $z$ (and remembering that $\mathrm{C}_{\mathrm{w}}=\mathrm{C}_{\mathrm{tot}}-\mathrm{C}_{\mathrm{c}}-\mathrm{C}_{\mathrm{f}}$, Equation 7 is linear in $\mathrm{C}_{\mathrm{c}}$ and $\mathrm{C}_{\mathrm{f}}$. We should therefore be able to graph lines of constant $z$ in the $C_{c}-C_{f}$ plane to get an idea of how this parameter behaves. Indeed, if we define $c_{c}=C_{c} / C_{t o t}, c_{f}=C_{f} / C_{t o t}$, and $c_{w}=C_{w} / C_{\text {tot }}$, so that $c_{c}+c_{f}+c_{w}=1$, a universal plot can be constructed that is valid for any $\mathrm{C}_{\text {tot }}$. Additionally, when three quantities always add to unity, 
they can be plotted in a very illuminating way as respective distances from the sides of an equilateral triangle each of whose sides has length $\sqrt{5} / 2$. Somewhat more conveniently, they can be represented on a right triangle with legs of unit length. In this case, $c_{f}$ and $c_{c}$ are the perpendicular distances from their respective legs, while $c_{w}$ is $\sqrt{2}$ times the distance from the hypotenuse.

Figure 1 shows such a plot. The horizontal and vertical axes represent $c_{c}$ and $c_{f}$, respectively, while $c_{\mathrm{w}}$. is proportional to the perpendicular distance from the hypotenuse. The diagonal dotted lines on the plot represent constant $c_{w}$, in 0.2 increments.

Loci of constant $\mathrm{z}$ are shown as solid lines. It can be seen that these are almost, but not quite, perpendicular to the side of the triangle representing $c_{\mathrm{w}}=0$ (except for the line $z=0.5$, which is exactly perpendicular). This fact then serves as the starting point for an iterative process. For each line of constant $z$, draw a dashed line that is exactly perpendicular to the hypotenuse and that intersects the solid line at the hypotenuse. Such a line will define a constant parameter $z_{0}$ that is equal to $\mathrm{z}$ where the dashed and solid lines intersect at the hypotenuse. Then $z_{0}$ will be equal to:

$$
z_{0}=\frac{1}{1+\left(\frac{c_{c}+c_{w} / 2}{c_{f}+c_{w} / 2}\right)^{\frac{1}{n_{e n v}}}}
$$

Here the small c's are shown, although Equation 16 is valid with either the C's or the c's.

The approach to iteration is shown in Figure 2. Equation 7 is rewritten in the form $f(z)=g(z)$, where

$$
\begin{aligned}
& f(z)=c_{c} z^{n_{e n v}}+\left(\frac{c_{w}}{n_{e n v}+1}\right) z^{n_{e n v}+1} \\
& g(z)=c_{f}(1-z)^{n_{e n v}}+\left(\frac{c_{w}}{n_{e n v}+1}\right)(1-z)^{n_{e n v}+1}
\end{aligned}
$$

The functions $f(z)$ and $g(z)$ are plotted separately. The point where they cross defines the desired value of $z$. The initial value $z_{0}$, calculated according to Equation 16 , is shown as a vertical line defining $f\left(z_{0}\right)$ and $g\left(z_{0}\right)$. Straight lines tangent to $f(z)$ and $g(z)$ at $z=z_{0}$ are next drawn, and their intersection is taken as an approximation to the intersection of $f$ and $g$. The value of $z$ at which this intersection occurs is the next approximation to the solution, which we call $z_{1}$.

The equations of these lines are given, respectively, by: 


$$
\begin{aligned}
& y=f\left(z_{0}\right)+f^{\prime}\left(z_{0}\right)\left(z-z_{0}\right) \\
& y=g\left(z_{0}\right)+g^{\prime}\left(z_{0}\right)\left(z-z_{0}\right)
\end{aligned}
$$

Solving for $z_{1}$, the intersection point, yields the equation:

$$
z_{1}=z_{0}+\frac{f\left(z_{0}\right)-g\left(z_{0}\right)}{g^{\prime}\left(z_{0}\right)-f^{\prime}\left(z_{0}\right)}
$$

Using $f$ and $g$ from Equation 17, one obtains

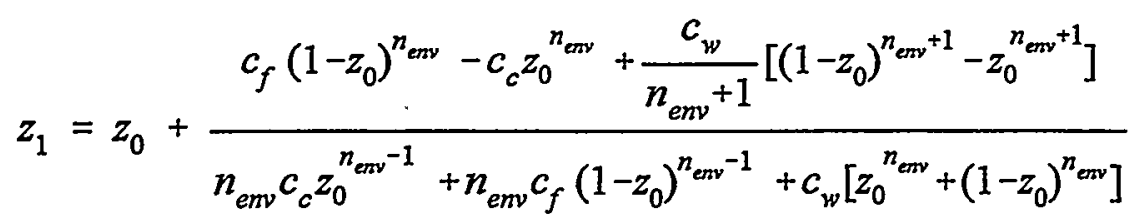

Needless to say, this process can be repeated if necessary to calculate a second iterative value of $z$, to be called $z_{2}$, with $z_{1}$ taking the role of $z_{0}$ in Equation 20 . However, one iteration is generally sufficient.

\section{IS THE STANDARD 152P EQUATION ACCURATE ENOUGH?}

The appendix to this report contains spreadsheets in which Equation 12, which was developed here, is compared with Equation 14, which is in ASHRAE Standard 152P. A value of $\mathrm{C}_{\text {to }}$ $157.29 \mathrm{cfm} / \mathrm{Pa}^{.65}$, was chosen to correspond to an envelope leakage in cfm at $50 \mathrm{~Pa}$ (CFM50) of 2000 with an exponent of 0.65 in the pressure-flow equation, representative of reasonably tight, but not supertight, average-size single-family housing. Each page represents values of the fractions of the envelope leakage flow coefficient in the floor, wall, and ceiling at 0.25 increments.

The entries on each page show values of $\Delta \mathrm{P}_{\text {off }}$ in $0.5 \mathrm{~Pa}$ increments from -3 to +3 (with 0.01 instead of 0.00 to avoid division of zero by zero), and $\Delta \mathrm{P}_{\text {on }}$ values in $1 \mathrm{~Pa}$ increments from 0 to 5 . (Negative values of $\Delta \mathrm{P}_{\text {on }}$ are included if one realizes that changing the sign of both $\Delta \mathrm{P}_{\text {off }}$ and $\Delta \mathrm{P}_{\text {on }}$ produces a $Q_{\text {sleaktrileak }}$ that is the same in magnitude and opposite in sign from the one in the table. (This has been checked using the spreadsheet, but since the values are redundant they are not reproduced here.)

The columns of the spreadsheet are described as follows: 
Column 1: The current value of $\Delta \mathrm{P}_{\text {off }}$

Column 2: The current value of $\Delta \mathrm{P}_{\text {on }}$.

Column 3: The value of $z_{0}$ calculated according to Equation 16.

Column 4: The value of $z_{1}$, resulting from the first iteration using Equation 20.

Column 5: The value of $z_{2}$, the second iteration of Equation 20.

Column 6: The value of $\Delta \mathrm{P}_{\text {off }} / \mathrm{z}_{1}-\Delta \mathrm{P}_{\text {or }}$.

Column 7: The value of $\Delta \mathrm{P}_{\text {off }} / \mathrm{z}_{2}-\Delta \mathrm{P}_{\text {on }}$.

Column 8: $Q_{\text {sleaktriteak }}$ using $z_{1}$ in Equation 12.

Column 9: $\mathrm{Q}_{\text {seaktrleak }}$ using $z_{2}$ in Equation 12.

Column 10: $\mathrm{Q}_{\text {sleaktrieak }}$ using Equation 14, the ASHRAE Standard 152P formula.

Column 11: The difference between the absolute values of Column 9 and Column 10.

Column 12: The percent difference between the above.

The first thing to notice is that Equation 12 and Equation 14 always give the same sign for $\mathrm{Q}_{\text {steaktrieak. }}$ That is, both equations always agree on which side of the duct system, supply or return, has more leakage.

Nevertheless, a quick perusal of these spreadsheets can be disquieting. It is not hard to find cases where the percent difference exceeds $50 \%$. A closer look, however, provides quite a bit of reassurance. Most of the time, the percentage deviation between the two values is quite small. Part of the reason for this is that there are certain cases for which the results are "pinned" to be equal. One obvious such case is when the actual leakage distribution is the same as that assumed in developing Equation 14 (the one in ASHRAE Standard 152P). Another occurs when the house pressure with the fan off is near zero. In real-world testing, this condition is often approximated, especially during calm weather in the spring and fall, when wind and stack effect are small.

Moreover, it is possible to identify "danger flags" whose absence makes it all but certain that the two values are within $5 \%$ of each other. These are discussed further below.

In analyzing the results further, we distinguished between slab-on-grade housing and houses with an open foundation (basement or crawl space). In slab housing one would expect that the fraction of leakage through the floor will be very close to zero, whereas with an open foundation one would generally expect significant leakage at the floor level. We therefore grouped the spreadsheets into three categories:

- Slab Cases: $\quad c_{\mathrm{f}}=0$ and $c_{c}=0,0.25$, or 0.50 (three cases).

- Open-Foundation Cases: $\quad c_{f}=0.25$ and $c_{c}=0,0.25$, or 0.50

$\mathrm{c}_{\mathrm{f}}=0.50$ and $\mathrm{c}_{\mathrm{c}}=0$ or 0.25

$c_{\mathrm{f}}=0.75$ and $\mathrm{c}_{\mathrm{c}}=0$

(six cases)

- "Unlikely" Cases: these are cases with no leakage through the walls or with ceiling leakage of $75 \%$ or more of the total. 
Figure 3 is a histogram for the slab cases showing the relative frequencies of various ranges of percentage deviations between $Q_{\text {sleaktricak }}$ as calculated according to Equation 14 (Standard 152P) and Equation 12 (this report). The deviations are between absolute values, so the bias toward positive numbers indicates that Equation 12 tends to show somewhat greater leakage imbalance than does Equation 14. The data points are divided into two categories, those for which $\left|\Delta \mathrm{P}_{\text {off }}\right|$ is relatively small $(\leq 1 \mathrm{~Pa})$ and those for which $\left|\Delta \mathrm{P}_{\text {off }}\right|$ exceeds $1 \mathrm{~Pa}$. For the latter set, the number of outliers (cases where the difference is greater than $5 \%$ ) is more than $40 \%$ of the total, and a small but significant number of these are extreme, i.e., greater than $35 \%$ deviation. When $\left|\Delta \mathrm{P}_{\text {off }}\right| \leq 1 \mathrm{~Pa}$, however, the picture brightens considerably. Now almost $80 \%$ of the cases agree within $5 \%$ and there are no extreme disagreements. Additionally, inspection of the spreadsheets reveals that nearly all of the moderate-disagreement cases, i.e., $6 \%$ to $25 \%$ deviation, occur when $\Delta \mathrm{P}_{\text {on }} \approx 0$ or when $\Delta \mathrm{P}_{\text {off }}$ is roughly half of $\Delta \mathrm{P}_{\text {on }}$. These conditions correspond to cases where the pressure difference across the ceiling or the floor is close to zero with the system fan on. The possibility exists, therefore, of developing a correction factor to be used when the house pressures lie within certain designated ranges.

The open-foundation cases, shown in Figure 4, are very similar. This was something of a surprise to the author, who expected the slab cases to deviate from Equation 14 more than the open-foundation cases, because the constraint of zero floor leakage is so clearly at variance with the assumptions behind that equation.

It should be mentioned that the cases where the ceiling has most of the leakage are somewhat more problematic, with greater and more frequent deviations from Equation 14. It should also be noted that the case where floor and ceiling leakage each account for half of the total, with none through the walls, that the deviation is always exactly zero. If that weren't so it would be cause for worry, since this is precisely the assumption on which Equation 14 is based.

\section{HOW DO ERRORS IN Qsleak+rleak TRANSLATE INTO ERRORS IN THE SEPARATE SUPPLY AND RETURN LEAKAGE VALUES?}

An important next step is to investigate how errors in $\mathrm{Q}_{\text {sleaktrieak }}$ stemming from leakage distribution in the envelope translate into errors in the separate values of supply and return leakage $\left(\mathrm{Q}_{\text {sleak }}\right.$ and $\left.\mathrm{Q}_{\text {rteak }}\right)$ as calculated according to the house pressure test algorithm. That step is beyond the scope of this report, but two observations bearing on its resolution should be made.

1. In addition to $Q_{\text {sleak+reak }}$ as defined above, the house pressure test also makes use of a signed difference in leakage rates when the return register is blocked, which is called $\mathrm{Q}_{\text {steaktrieakRB }}$. The same mathematics used to analyze the unblocked-register case can be used when the register is blocked. The percentage deviations for the two Q's, in any given case, will generally differ, however, because the house pressure with the system fan on is different. Thus, the general analysis is expected to be somewhat complicated. 
2. If the percent deviations for $\mathrm{Q}_{\text {sleakt+leak }}$ and $\mathrm{Q}_{\text {sleaktrieakRB }}$ are both small, as will often be the case, then the error in the individual leakage rates due to such errors will also be small.

3. Conditions where significant deviations are to be expected can be identified on the basis of the values of $\Delta \mathrm{P}_{\text {on }}$ and $\Delta \mathrm{P}_{\text {off }}$ and sufficiently accurate correction factors might be developed for use even in the cases where deviation is expected.

\section{CONCLUSIONS}

This report shows how an equation for the signed difference (algebraic sum) $Q_{\text {sleaktrleak }}$ of the duct leakage rates from the supply side to outside (taken as + ) and to the return side from outside (taken as -) is expected to depend on the detailed distribution of the leakage in the building envelope. ASHRAE Standard 152P uses an equation that is based on a specific assumption about this distribution, namely half the leakage flow coefficient due to the floor, half to the ceiling, and none to the walls. In most cases, the more-detailed equation yields results that are within $5 \%$ of the Standard $152 \mathrm{P}$ equation, but cases of $>5.0 \%$ deviation are not hard to find. The following conclusions are drawn from the work reported:

- For "realistic" cases, the Standard $152 \mathrm{P}$ value of $\mathrm{Q}_{\text {sleaktricak }}$ will differ from that produced by the more general formula by $5 \%$ or less about $80 \%$ of the time, when the absolute value of the house pressure with the system fan off is less than $1 \mathrm{~Pa}$.

- Conditions where greater deviation is found are largely restricted to those where the house pressure across the ceiling or the floor, with the system fan on, is close to zero. It would be useful to develop a correction factor applying to those cases that would improve agreement without requiring detailed knowledge of the leakage distribution in the envelope.

- $\quad$ Cases to beware of include those with very leaky ceilings (which might be identifiable by inspection) and those with large stack and wind effect, leading to values of the fan-off house pressure $\Delta \mathrm{P}_{\text {off }}$ in excess of $1 \mathrm{~Pa}$.

\section{REFERENCES}

1. ASHRAE 1998. Method of Test for Determining the Design and Seasonal Efficiencies of Residential Thermal Distribution Systems. Draft. American Society of Heating, Refrigerating, and Air-Conditioning Engineers, Inc., Atlanta, GA.

2. Modera, M. and J. Byrne. Can a New Duct Test Take the Pressure? Home Energy, January/February 1997, p. 29. 


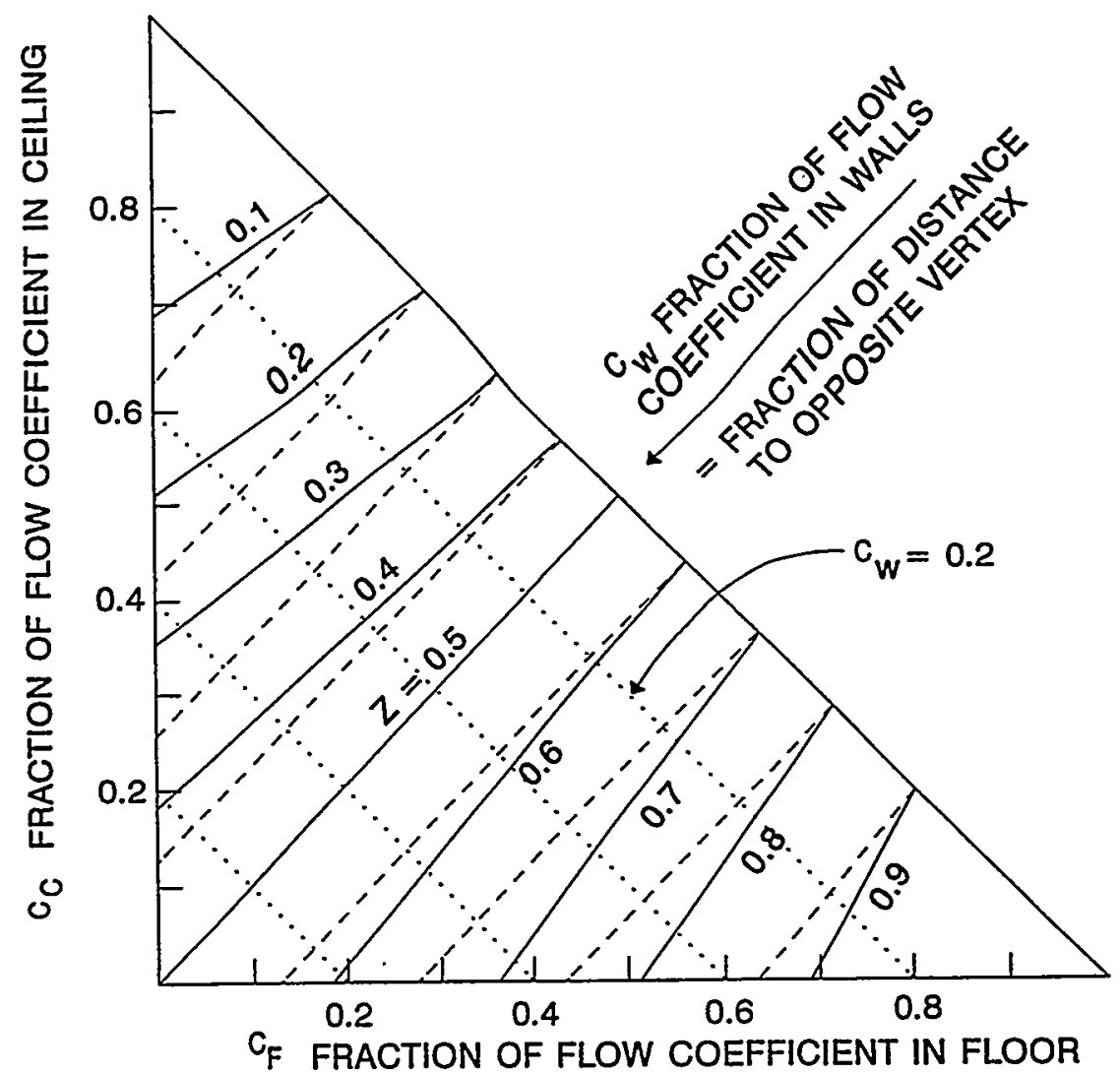

Figure 1. Dependence of Parameter " $z$ " on the Distribution of Air Leakage Within the Envelope

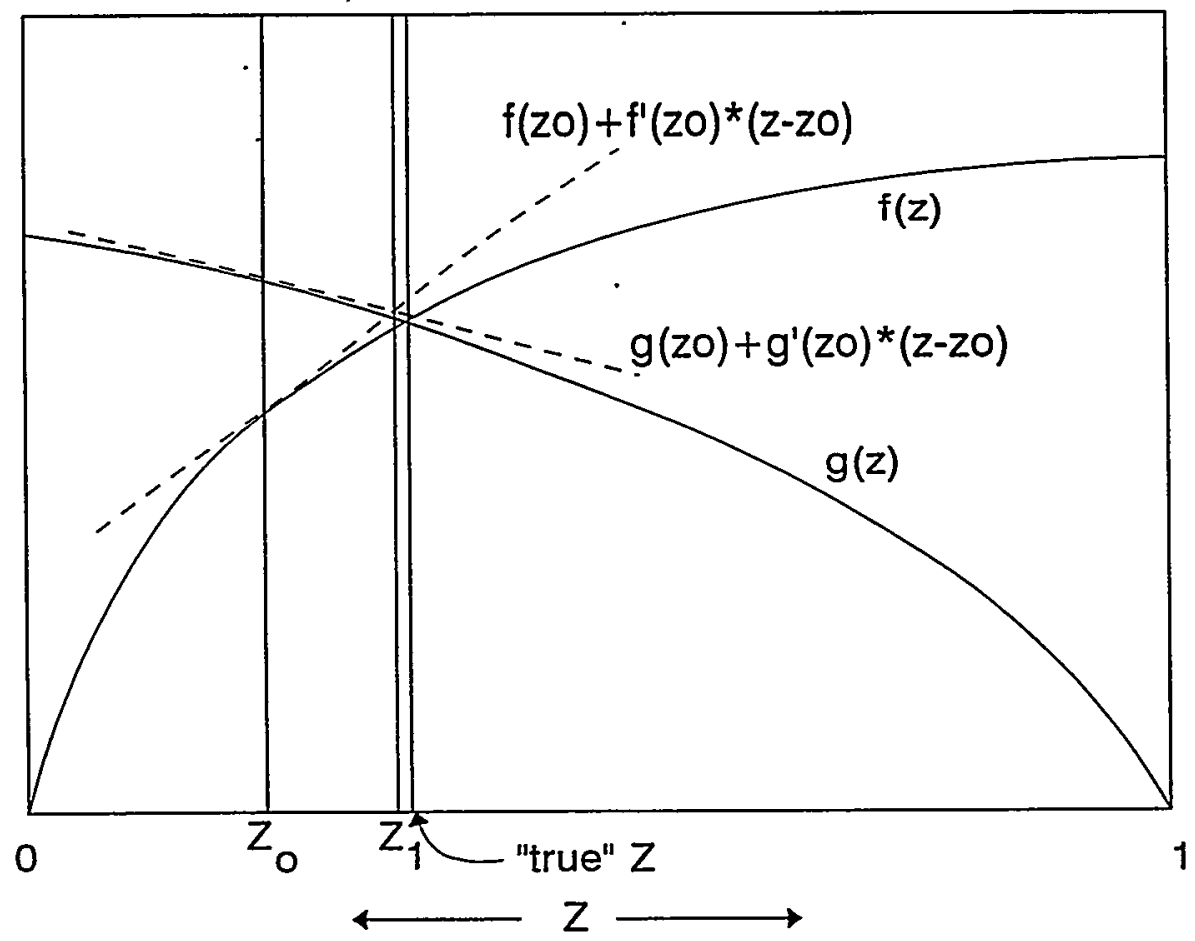

Figure 2. Iterative Solution for Parameter " $z$ " 


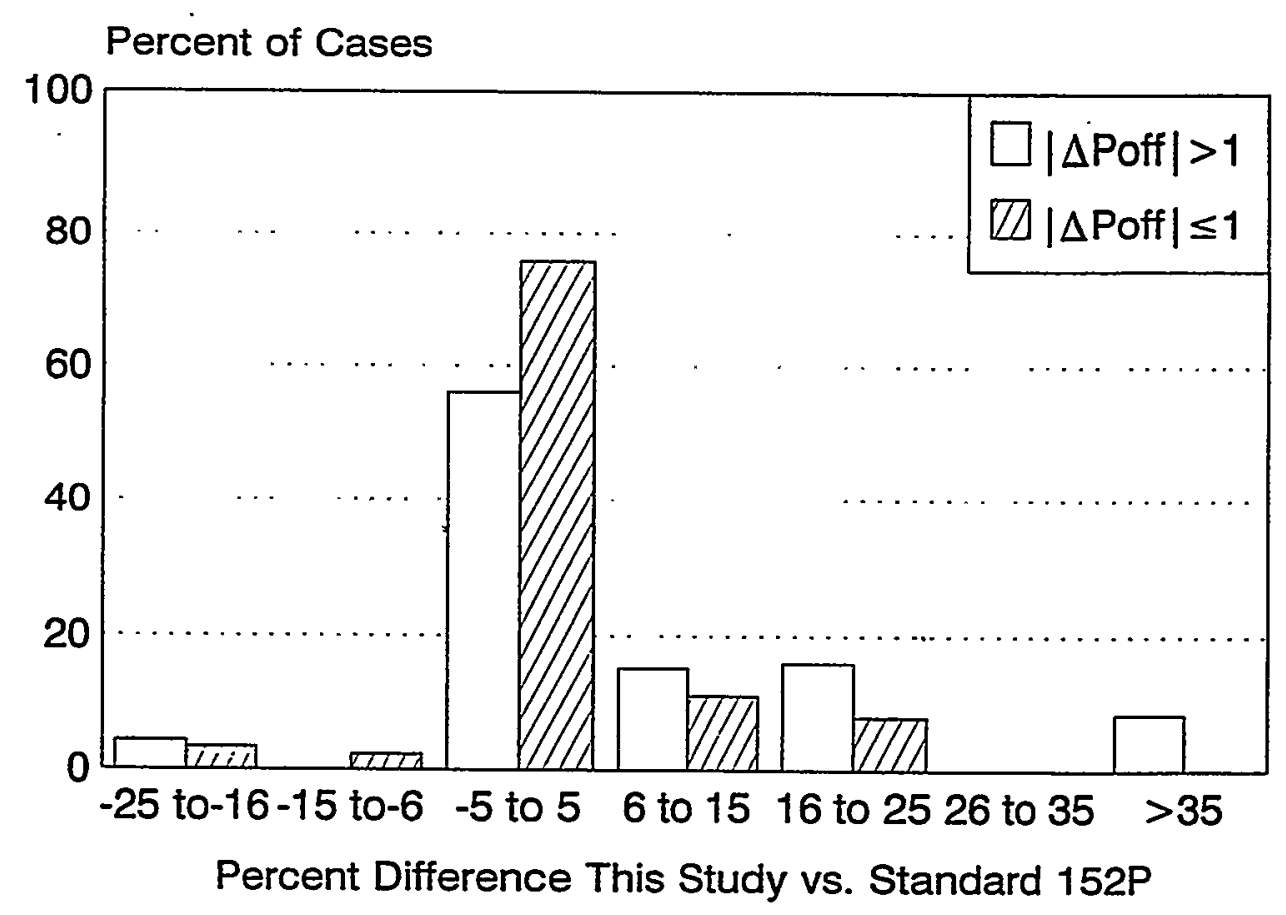

Figure 3. Frequency Histogram of Discrepancy in $\mathrm{Q}_{\text {sleaktrieak }}$ Between This Study and Standard 152P, for Slab-on-Grade Homes (Floor Leakage Assumed Equal to Zero)

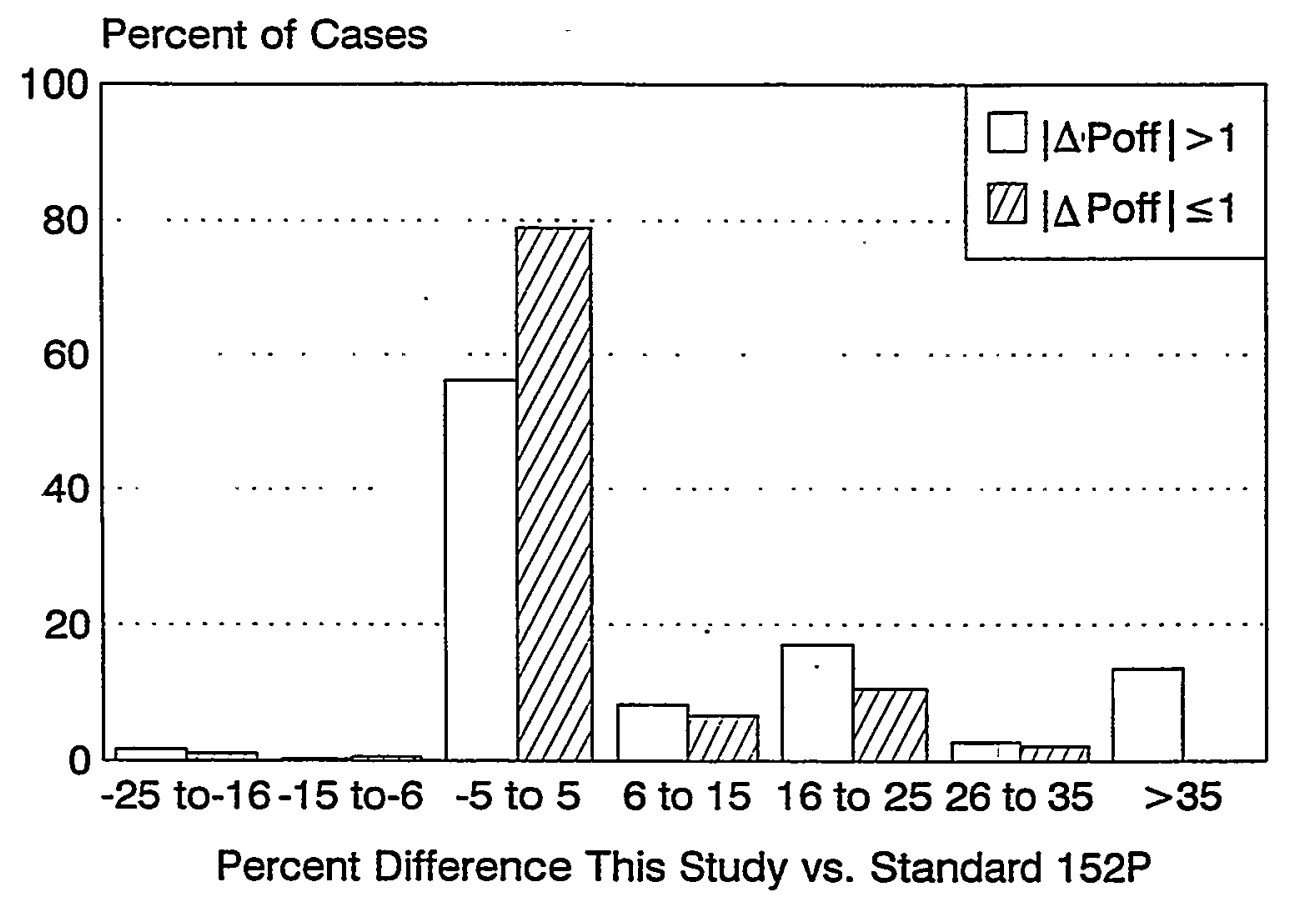

Figure 4. Frequency Histogram of Discrepancy in $\mathrm{Q}_{\text {sleaktrieak }}$ Between This Study and Standard $152 \mathrm{P}$, for Homes with Open Foundations (Floor Leakage $\geq 25 \%$ of the Total) 


\section{APPENDIX: SPREADSHEET CALCULATIONS OF Qsleak+rleak}

The following spreadsheets show the calculated values of Qsleak+rleak for various input values.

The columns are described as follows:

Column 1: The current value of $\Delta \mathrm{P}_{\text {off. }}$

Column 2: The current value of $\Delta \mathrm{P}_{\text {on }}$.

Column 3: The value of $z_{0}$ calculated according to Equation 16.

Column 4: The value of $z_{1}$, resulting from the first iteration using Equation 20.

Column 5: The value of $z_{2}$, the second iteration of Equation 20.

Column 6: The value of $\Delta \mathrm{P}_{\text {off }} / z_{1}-\Delta \mathrm{P}_{\text {on }}$ -

Column 7: The value of $\Delta \mathrm{P}_{\text {off }} / z_{2}-\Delta \mathrm{P}_{\text {on }}$.

Column 8: $Q_{\text {sleak }+ \text { ileak }}$ using $z_{1}$ in Equation 12.

Column 9: $Q_{\text {sleastricak }}$ using $z_{2}$ in Equation 12.

Column 10: $\mathrm{Q}_{\text {steaktrieak }}$ using Equation 14, the ASHRAE Standard 152P formula.

Column 11: The difference between Standard 152 (Eq. 14) and this report (Eq. 12) (absolute value of Column 9 minus absolute value of Column 10).

Column 12: The percent difference between the above. 
COMPARISON OF QST FORMULAS: ASHRAE STANDARD 152P vS. GENERALLED FORMULA

\begin{tabular}{|c|c|c|c|c|c|c|c|c|c|c|c|}
\hline $\begin{array}{l}\text { Ctot= } \\
\text { OPoff }\end{array}$ & $\frac{157.29}{\text { DPon }}$ & $\begin{array}{l}\text { nenve } \\
\text { Zo }\end{array}$ & $\frac{0.65}{21}$ & $22^{\mathrm{cf}=}$ & DPoff $\overline{0}$ & on ${ }^{c c=}$ & Osrgener & CW= & Qsr $152^{1}$ & $\begin{array}{l}\text { 1/nenv= } \\
\text { diff }\end{array}$ & $\begin{array}{l}1.538462 \\
\text { \%DIF }\end{array}$ \\
\hline$-3,00$ & 0.00 & 0.5000 & 0.5000 & 0.5000 & -6.0000 & -6.0000 & -306 & -306 & -252 & 53 & 19 \\
\hline-2.50 & 0.00 & 0.5000 & 0.5000 & 0.5000 & -5.0000 & -5.0000 & -271 & -271 & -224 & 47 & 19 \\
\hline$-2,00$ & 0.00 & 0.5000 & 0.5000 & 0.5000 & -4.0000 & -4.0000 & -235 & -235 & -194 & 41 & 19 \\
\hline-1.50 & 0.00 & 0.5000 & 0.5000 & 0.5000 & -3.0000 & -3.0000 & -195 & -195 & -161 & 34 & 19 \\
\hline-1.00 & 0.00 & 0.5000 & 0.5000 & 0.5000 & -2.0000 & -2.0000 & -150 & -150 & -123 & 26 & 19 \\
\hline-0.50 & 0.00 & 0.5000 & 0.5000 & 0.5000 & -1.0000 & -1.0000 & -95 & -95 & -79 & 17 & 19 \\
\hline 0.01 & 0.00 & 0.5000 & 0.5000 & 0.5000 & 0.0200 & 0.0200 & 7 & 7 & 6 & 1 & 19 \\
\hline 0.50 & 0.00 & 0.5000 & 0.5000 & 0,5000 & 1.0000 & 1.0000 & 95 & 95 & 79 & 17 & 19 \\
\hline 1,00 & 0,00 & 0.5000 & 0.5000 & 0.5000 & 2.0000 & 2.0000 & 150 & 150 & 123 & 26 & 19 \\
\hline 1,50 & 0,00 & 0.5000 & 0.5000 & 0.5000 & 3.0000 & 3.0000 & 195 & 195 & 161 & 34 & 19 \\
\hline 2.00 & 0.00 & 0.5000 & 0.5000 & 0.5000 & 4.0000 & 4.0000 & 235 & 235 & 194 & 41 & 19 \\
\hline 2.50 & 0.00 & 0.5000 & 0.5000 & 0.5000 & 5.0000 & 5.0000 & 271 & 271 & 224 & 47 & 19 \\
\hline 3.00 & 0.00 & 0.5000 & 0.5000 & 0.5000 & 6.0000 & 6.0000 & 306 & 305 & 252 & 53 & 19 \\
\hline-3.00 & 1.00 & 0.5000 & 0.5000 & 0.5000 & -7.0000 & -7.0000 & -378 & -378 & -357 & 21 & 6 \\
\hline-2.50 & 1.00 & 0.5000 & 0.5000 & 0.5000 & -6.0000 & -6.0000 & -348 & -348 & 331 & 17 & 5 \\
\hline-2.00 & 1.00 & 0.5000 & 0.5000 & 0.5000 & -5.0000 & -5.0000 & -315 & -315 & -303 & 13 & 4 \\
\hline-1.50 & 1.00 & 0.5000 & 0.5000 & 0.5000 & -4.0000 & -4.0000 & -281 & -281 & -272 & 9 & 3 \\
\hline-1.00 & 1.00 & 0.5000 & 0.5000 & 0.5000 & -3.0000 & -3.0000 & -244 & -244 & -239 & 5[ & $\overline{2}$ \\
\hline$-0,50$ & 1.00 & 0.5000 & 0.5000 & 0.5000 & -2.0000 & -2.0000 & -204 & -204 & -202 & 2 & 1 \\
\hline 0.01 & 1.00 & 0.5000 & 0.5000 & 0.5000 & -0.9800 & -0.9800 & -156 & -156 & -156 & 0 & 0 \\
\hline 0,50 & 1.00 & 0.5000 & 0.5000 & 0.5000 & 0.0000 & 0.0000 & -95 & -95 & -79 & 17 & 19 \\
\hline 1.00 & 1.00 & 0.5000 & 0.5000 & 0.5000 & 1.0000 & 1.0000 & 0 & 0 & 0 & ol & 0 \\
\hline 1.50 & 1.00 & 0.5000 & 0.5000 & 0.5000 & 2.0000 & 2.0000 & 68 & 68 & 45 & 23 & 41 \\
\hline 2.00 & 1.00 & 0.5000 & 0.5000 & 0.5000 & 3.0000 & 3.0000 & 122 & 122 & 82 & 40 & 39 \\
\hline 2.50 & 1.00 & 0.5000 & 0.5000 & 0.5000 & 4.0000 & 4.0000 & 169 & 169 & 115 & 54 & 38 \\
\hline 3.00 & 1.00 & 0.5000 & 0.5000 & 0.5000 & 5.0000 & 5.0000 & 210 & 210 & 145 & 65 & 37 \\
\hline$-3,00$ & 2.00 & 0.5000 & 0.5000 & 0.5000 & -8.0000 & -8.0000 & -441 & -441 & -427 & 14 & 3 \\
\hline-2.50 & 2.00 & 0.5000 & 0.5000 & 0.5000 & -7.0000 & -7.0000 & -413 & -413 & -402 & 11 & 3 \\
\hline$-2,00$ & 2.00 & 0.5000 & 0.5000 & 0.5000 & -6.0000 & -6.0000 & -383 & -383 & -375 & 8 & 2 \\
\hline-1.50 & 2.00 & 0.5000 & 0.5000 & 0.5000 & -5.0000 & -5.0000 & -353 & -353 & -347 & 5 & 2 \\
\hline-1.00 & 2.00 & 0.5000 & 0.5000 & 0.5000 & -4.0000 & -4.0000 & -320 & -320 & -317 & 3[ & 1 \\
\hline-0.50 & 2.00 & 0.5000 & 0.5000 & 0.5000 & -3.0000 & -3.0000 & -285 & -285 & -284 & 1 & 0 \\
\hline 0.01 & 2.00 & 0.5000 & 0.5000 & 0.5000 & -1.9800 & -1.9800 & -246 & -246 & -246 & 0 & 0 \\
\hline 0.50 & 2.00 & 0.5000 & 0.5000 & 0.5000 & -1.0000 & -1.0000 & -204 & -204 & -202 & 2 & 1 \\
\hline 1.00 & 2.00 & 0.5000 & 0.5000 & 0.5000 & 0.0000 & 0.0000 & -150 & -150 & -123 & 26 & 19 \\
\hline 1.50 & 2.00 & 0.5000 & 0.5000 & 0.5000 & 1.0000 & 1.0000 & -68 & -68 & -45 & 23 & 41 \\
\hline 2.00 & 2.00 & 0.5000 & 0.5000 & 0.5000 & 2.0000 & 2.0000 & 0 & 0 & 0 & 0 & 0 \\
\hline 2.50 & 2.00 & 0.5000 & 0.5000 & 0.5000 & 3.0000 & 3.0000 & 57 & 57 & 37 & 20 & 42 \\
\hline 3.00 & 2.00 & 0.5000 & 0.5000 & 0.5000 & 4.0000 & 4.0000 & 107 & 107 & 70 & 36 & 41 \\
\hline$-3,00$ & 3.00 & 0.5000 & 0.5000 & 0.5000 & -9.0000 & -9.0000 & -499 & -499 & -489 & 10 & 2 \\
\hline$-2,50$ & 3.00 & 0.5000 & 0.5000 & 0.5000 & -8.0000 & -8.0000 & -472 & -472 & -464 & 8 & 2 \\
\hline-2.00 & 3.00 & 0.5000 & 0.5000 & 0.5000 & -7.0000 & -7.0000 & -445 & -445 & -439 & 6 & 1 \\
\hline-1.50 & 3.00 & 0.5000 & 0.5000 & 0.5000 & -6.0000 & -6.0000 & -416 & -416 & -413 & 4 & 1 \\
\hline-1.00 & 3.00 & 0.5000 & 0.5000 & 0.5000 & -5.0000 & -5.0000 & -386 & -386 & -384 & 2 & 0 \\
\hline-0.50 & 3.00 & 0.5000 & 0.5000 & 0.5000 & -4.0000 & -4.0000 & -355 & -355 & -354 & 1 & 0 \\
\hline 0.01 & 3.00 & 0.5000 & 0.5000 & 0.5000 & -2.9800 & -2.9800 & -321 & -321 & -321 & 0 & 0 \\
\hline 0.50 & 3.00 & 0.5000 & 0.5000 & 0.5000 & -2.0000 & -2.0000 & -285 & -285 & -284 & 1 & 0 \\
\hline 1.00 & 3.00 & 0.5000 & 0.5000 & 0.5000 & -1.0000 & -1.0000 & -244 & -244 & -239 & 5 & 2 \\
\hline 1.50 & 3.00 & 0.5000 & 0.5000 & 0.5000 & 0.0000 & 0.0000 & -195 & -195 & -161 & 34 & 19 \\
\hline 2.00 & 3.00 & 0.5000 & 0.5000 & 0.5000 & 1.0000 & 1.0000 & -122 & -122 & -82 & 40 & 39 \\
\hline 2.50 & 3.00 & 0.5000 & 0.5000 & 0.5000 & 2.0000 & 2.0000 & -57 & -57 & -37 & 20 & 42 \\
\hline 3.00 & 3.00 & 0.5000 & 0.5000 & 0.5000 & 3.0000 & 3.0000 & 0 & 0 & 0 & 0 & 0 \\
\hline-3.00 & 4.00 & 0.5000 & 0.5000 & 0.5000 & -10.0000 & -10.0000 & -553 & -553 & -545 & 8 & 2 \\
\hline-2.50 & 4.00 & 0.5000 & 0.5000 & 0.5000 & -9.0000 & -9.0000 & -528 & -528 & -522 & 6 & 1 \\
\hline-2.00 & 4.00 & 0.5000 & 0.5000 & 0.5000 & -8.0000 & -8.0000 & -502 & -502 & -498 & 4 & 1 \\
\hline-1.50 & 4.00 & 0.5000 & 0.5000 & 0.5000 & -7.0000 & -7.0000 & -475 & -475 & -472 & 3 & 1 \\
\hline-1.00 & 4.00 & 0.5000 & 0.5000 & 0.5000 & -6.0000 & -6.0000 & -447 & -447 & -446 & 1[ & 0 \\
\hline-0.50 & 4.00 & 0.5000 & 0.5000 & 0.5000 & -5.0000 & -5.0000 & -418 & -418 & -418 & o) & 0 \\
\hline 0.01 & 4.00 & 0.5000 & 0.5000 & 0.5000 & -3.9800 & -3.9800 & .387 & -387 & -387 & 0 & 0 \\
\hline 0.50 & 4.00 & 0.5000 & 0.5000 & 0.5000 & -3.0000 & -3.0000 & -355 & -355 & -354 & 1 & 0 \\
\hline 1.00 & 4.00 & 0.5000 & 0.5000 & 0.5000 & -2.0000 & -2.0000 & -320 & -320 & -317 & 3 & 1 \\
\hline 1.50 & 4.00 & 0.5000 & 0.5000 & 0.5000 & -1.0000 & -1.0000 & -281 & -281 & -272 & 9 & 3 \\
\hline 2.00 & 4.00 & 0.5000 & 0.5000 & 0.5000 & 0.0000 & 0.0000 & -235 & -235 & -194 & 41 & 19 \\
\hline 2.50 & 4.00 & 0.5000 & 0.5000 & 0.5000 & 1.0000 & 1.0000 & -169 & -169 & -115 & 54 & 38 \\
\hline 3,00 & 4.00 & 0.5000 & 0.5000 & 0.5000 & 2.0000 & 2.0000 & -107 & -107 & -70 & 36 & 41 \\
\hline-3.00 & 5.00 & 0.5000 & 0.5000 & 0.5000 & -11.0000 & -11.0000 & -604 & -604 & -598 & 7 & 1 \\
\hline-2.50 & 5.00 & 0.5000 & 0.5000 & 0.5000 & -10.0000 & -10.0000 & -580 & -580 & -575 & 5 & 1 \\
\hline-2.00 & 5.00 & 0.5000 & 0.5000 & 0.5000 & -9.0000 & -9.0000 & -555 & -555 & -552 & 4 & 1 \\
\hline-1.50 & 5.00 & 0.5000 & 0.5000 & 0.5000 & -8.0000 & -8.0000 & -530 & -530 & -528 & 2 & $\underline{0}$ \\
\hline-1.00 & 5.00 & 0.5000 & 0.5000 & 0.5000 & -7.0000 & -7.0000 & -504 & -504 & -502 & 1[ & $\overline{0}$ \\
\hline-0.50 & 5.00 & 0.5000 & 0.5000 & 0.5000 & -6.0000 & -6.0000 & -476 & -476 & -476 & o & 0 \\
\hline 0.01 & 5.00 & 0.5000 & 0.5000 & 0.5000 & -4.9800 & -4.9800 & -447 & -447 & -447 & 0 & 0 \\
\hline 0,50 & 5.00 & 0.5000 & 0.5000 & 0.5000 & -4.0000 & -4.0000 & -418 & -418 & -418 & o & \\
\hline 1.00 & 5.00 & 0.5000 & 0.5000 & 0.5000 & -3.0000 & -3.0000 & -386 & -386 & -384 & 2 & 0 \\
\hline 1.50 & 5.00 & 0.5000 & 0.5000 & 0.5000 & -2.0000 & -2.0000 & -353 & -353 & -347 & 5 & 2 \\
\hline 2.00 & 5.00 & 0.5000 & 0.5000 & 0.5000 & -1.0000 & -1.0000 & -315 & -315 & -303 & 13 & 4 \\
\hline 2.5 & 5.00 & 0.5000 & 0.5000 & 0.5000 & 0.0000 & 0.0000 & -271 & -271 & -224 & 47 & 19 \\
\hline 3 & 5.00 & 0.5000 & 0.5000 & 0.5000 & 1.0000 & 1.0000 & -210 & -210 & -145 & 65 & 37 \\
\hline
\end{tabular}


COMPARISON OF QST FORMULAS: ASHRAE STANDARD 152P vS. GENERALZED FORMULA

\begin{tabular}{|c|c|c|c|c|c|c|c|c|c|c|c|}
\hline $\begin{array}{l}\text { Ctot= } \\
\text { DPoff }\end{array}$ & $\frac{157.29}{\text { DPon }}$ & $\begin{array}{c}\text { nenv= } \\
\text { Zo }\end{array}$ & $\frac{0.65}{\mathrm{Z1}}$ & $22^{c f=}$ & $\frac{0}{\mathrm{D}}$ & Pon ${ }^{c c=}$ & $\begin{array}{r}0.25 \\
\text { Qsr genera }\end{array}$ & ed & $\begin{array}{c}0.75 \\
\text { Qsr } 152\end{array}$ & $\begin{array}{l}1 / \text { nenv= } \\
\text { diff }\end{array}$ & $\begin{array}{l}1.538462 \\
\% \text { DIF }\end{array}$ \\
\hline-3.00 & 0.00 & 0.3131 & 0.3639 & 0.3640 & -8.2438 & -8.2414 & -282 & -282 & -252 & 30 & 11 \\
\hline-2.50 & 0.00 & 0.3131 & 0.3639 & 0.3640 & -6.8698 & -6.8678 & -250 & -250 & -224 & 26 & 11 \\
\hline-2.00 & 0.00 & 0.3131 & 0.3639 & 0.3640 & -5.4958 & -5.4942 & -216 & -216 & -194 & 23 & 11 \\
\hline-1.50 & 0.00 & 0.3131 & 0.3639 & 0.3640 & -4.1219 & -4.1207 & -180 & -179 & -161 & 19 & 11 \\
\hline-1.00 & 0.00 & 0.3131 & 0.3639 & 0.3640 & -2.7479 & -2.7471 & -138 & -138 & -123 & 14 & 11 \\
\hline-0.50 & 0.00 & 0.3131 & 0.3639 & 0.3640 & -1.3740 & -1.3736 & -88 & -88 & -79 & 9 & 11 \\
\hline 0.01 & 0.00 & 0.3131 & 0.3639 & 0.3640 & 0.0275 & 0.0275 & 7 & 7 & 6 & 1 & 11 \\
\hline 0.50 & 0.00 & 0.3131 & 0.3639 & 0.3640 & 1.3740 & 1.3736 & 88 & 88 & 79 & 9 & 11 \\
\hline 1.00 & 0.00 & 0.3131 & 0.3639 & 0.3640 & 2.7479 & 2.7471 & 138 & 138 & 123 & 14 & 11 \\
\hline 1.50 & 0.00 & 0.3131 & 0.3639 & 0.3640 & 4.1219 & 4.1207 & 180 & 179 & 161 & 19 & 11 \\
\hline 2.00 & 0.00 & 0.3131 & 0.3639 & 0.3640 & 5.4958 & 5.4942 & 216 & 216 & 194 & 23 & 11 \\
\hline 2.50 & 0.00 & 0.3131 & 0.3639 & 0.3640 & 6.8698 & 6.8678 & 250 & 250 & 224 & 26 & 11 \\
\hline 3.00 & 0.00 & 0.3131 & 0.3639 & 0.3640 & 8.2438 & 8.2414 & 282 & 282 & 252 & 30 & 11 \\
\hline-3.00 & 1.00 & 0.3131 & 0.3639 & 0.3640 & -9.2438 & -9.2414 & -371 & -371 & -357 & 14 & 4 \\
\hline-2.50 & 1.00 & 0.3131 & 0.3639 & 0.3640 & -7.8698 & -7.8678 & -342 & -342 & -331 & 11 & 3 \\
\hline-2.00 & 1.00 & 0.3131 & 0.3639 & 0.3640 & -6.4958 & -6.4942 & -311 & -311 & -303 & 9 & 3 \\
\hline-1.50 & 1.00 & 0.3131 & 0.3639 & 0.3640 & -5.1219 & -5.1207 & -279 & -279 & -272 & 7 & 2 \\
\hline-1.00 & 1.00 & 0.3131 & 0.3639 & 0.3640 & -3.7479 & -3.7471 & -243 & -243 & -239 & 4) & 2 \\
\hline-0.50 & 1.00 & 0.3131 & 0.3639 & 0.3640 & -2.3740 & -2.3736 & -204 & -204 & -202 & 2 & 1 \\
\hline 0.01 & 1.00 & 0.3131 & 0.3539 & 0.3640 & -0.9725 & -0.9725 & -156 & -156 & -156 & -0 & -0 \\
\hline 0.50 & 1.00 & 0.3131 & 0.3639 & 0.3640 & 0.3740 & 0.3736 & -81 & -81 & -79 & 2 & 3 \\
\hline 1.00 & 1.00 & 0.3131 & 0.3639 & 0.3640 & 1.7479 & 1.7471 & 0 & 0 & 0 & 0 & 0 \\
\hline 1.50 & 1.00 & 0.3131 & 0.3639 & 0.3640 & 3.1219 & 3.1207 & 57 & 57 & 45 & 12 & 24 \\
\hline 2.00 & 1.00 & 0.3131 & 0.3639 & 0.3640 & 4.4958 & 4.4942 & 103 & 103 & 82 & 21 & 23 \\
\hline 2.50 & 1.00 & 0.3131 & 0.3639 & 0.3640 & 5.8698 & 5.8678 & 143 & 143 & 115 & 28 & 22 \\
\hline 3.00 & 1.00 & 0.3131 & 0.3639 & 0.3640 & 7.2438 & 7.2414 & 180 & 180 & 145 & 34 & 21 \\
\hline-3.00 & 2.00 & 0.3131 & 0.3639 & 0.3640 & -10.2438 & -10.2414 & -438 & -438 & -427 & 10 & 2 \\
\hline-2.50 & 2.00 & 0.3131 & 0.3639 & 0.3640 & -8.8698 & -8.8678 & -410 & -410 & -402 & 8 & 2 \\
\hline-2.00 & 2.00 & 0.3131 & 0.3639 & 0.3640 & -7.4958 & -7.4942 & -382 & -382 & -375 & 7 & 2 \\
\hline-1.50 & 2.00 & 0.3131 & 0.3639 & 0.3640 & -6.1219 & -6.1207 & -352 & -352 & -347 & 5 & 1 \\
\hline-1.00 & 2.00 & 0.3131 & 0.3639 & 0.3640 & -4.7479 & -4.7471 & -320 & -320 & -317 & 3 & 1 \\
\hline-0.50 & 2.00 & 0.3131 & 0.3639 & 0.3640 & -3.3740 & -3.3736 & -285 & -285 & -284 & 1 & 0 \\
\hline 0.01 & 2.00 & 0.3131 & 0.3639 & 0.3640 & -1.9725 & -1.9725 & -246 & -246 & -246 & -0 & -0 \\
\hline 0.50 & 2.00 & 0.3131 & 0.3639 & 0.3640 & -0.6260 & -0.6264 & -201 & -201 & -202 & -1 & -1 \\
\hline 1.00 & 2.00 & 0.3131 & 0.3639 & 0.3640 & 0.7479 & 0.7471 & -127 & -127 & -123 & 4 & 3 \\
\hline 1.50 & 2.00 & 0.3131 & 0.3639 & 0.3640 & 2.1219 & 2.1207 & -56 & -56 & -45 & 11 & 23 \\
\hline 2.00 & 2.00 & 0.3131 & 0.3639 & 0.3640 & 3.4958 & 3.4942 & 0 & 0 & 0 & 0 & 0 \\
\hline $\begin{array}{l}2.50 \\
3.00\end{array}$ & $\begin{array}{l}2.00 \\
2.00\end{array}$ & $\begin{array}{l}0.3131 \\
0.3131\end{array}$ & $\begin{array}{l}0.3639 \\
0.3639\end{array}$ & $\begin{array}{l}0.3640 \\
0.3640\end{array}$ & $\begin{array}{l}4.8698 \\
6.2438\end{array}$ & $\begin{array}{l}4.8678 \\
6.2414\end{array}$ & $\begin{array}{l}47 \\
89\end{array}$ & $\begin{array}{l}47 \\
89\end{array}$ & $\begin{array}{l}37 \\
70\end{array}$ & $\begin{array}{l}10 \\
19\end{array}$ & $\begin{array}{l}24 \\
24\end{array}$ \\
\hline-3.00 & 3.00 & 0.3131 & 0.3639 & 0.3640 & -11.2438 & -11.2414 & -497 & -497 & -489 & 9 & 2 \\
\hline-2.50 & 3.00 & 0.3131 & 0.3639 & 0.3640 & -9.8698 & -9.8678 & -471 & -471 & -464 & 7 & 1 \\
\hline-2.00 & 3.00 & 0.3131 & 0.3639 & 0.3640 & -8.4958 & -8.4942 & -445 & -445 & -439 & 5 & 1 \\
\hline-1.50 & 3.00 & 0.3131 & 0.3639 & 0.3640 & -7.1219 & -7.1207 & -417 & -417 & -413 & 4 & 1 \\
\hline-1.00 & 3.00 & 0.3131 & 0.3639 & 0.3640 & -5.7479 & -5.7471 & -387 & -387 & -384 & 2 & 1 \\
\hline-0.50 & 3.00 & 0.3131 & 0.3639 & 0.3640 & -4.3740 & -4.3736 & -355 & -355 & -354 & 1 & 0 \\
\hline 0.01 & 3.00 & 0.3131 & 0.3639 & 0.3640 & -2.9725 & -2.9725 & -321 & -321 & -321 & -0 & -0 \\
\hline 0.50 & 3.00 & 0.3131 & 0.3639 & 0.3640 & -1.6260 & -1.6264 & -283 & -283 & -284 & -1 & -0 \\
\hline 1.00 & 3.00 & 0.3131 & 0.3639 & 0.3640 & -0.2521 & -0.2529 & -237 & -237 & -239 & -2 & -1 \\
\hline 1.50 & 3.00 & 0.3131 & 0.3639 & 0.3640 & 1.1219 & 1.1207 & -166 & -166 & -161 & 5 & 3 \\
\hline 2.00 & 3.00 & 0.3131 & 0.3639 & $0.3640^{\circ}$ & 2.4958 & 2.4942 & -101 & -101 & -82 & 19 & 21 \\
\hline 2.50 & 3.00 & 0.3131 & 0.3639 & 0.3640 & 3.8698 & 3.8678 & -47 & -47 & -37 & 10 & 23 \\
\hline 3.00 & $\mathbf{3 . 0 0}$ & 0.3131 & 0.3639 & 0.3640 & 5.2438 & 5.2414 & 0 & 0 & 0 & 0 & 0 \\
\hline-3.00 & 4.00 & 0.3131 & 0.3639 & 0.3640 & -12.2438 & -12.2414 & -552 & -552 & -545 & 7 & 1 \\
\hline-2.50 & 4.00 & 0.3131 & 0.3639 & 0.3640 & -10.8698 & -10.8678 & -528 & -528 & -522 & 6 & 1 \\
\hline-2.00 & 4.00 & 0.3131 & 0.3639 & 0.3640 & -9.4958 & -9.4942 & -502 & -502 & -498 & 5 & 1 \\
\hline-1.50 & 4.00 & 0.3131 & 0.3639 & 0.3640 & -8.1219 & -8.1207 & -476 & -476 & -472 & 3 & 1 \\
\hline-1.00 & 4.00 & 0.3131 & 0.3639 & 0.3640 & -6.7479 & -6.7471 & -448 & -448 & -446 & 2 & 0 \\
\hline-0.50 & 4.00 & 0.3131 & 0.3639 & 0.3640 & -5.3740 & -5.3736 & -419 & -419 & -418 & 1 & 0 \\
\hline 0.01 & 4.00 & 0.3131 & 0.3639 & 0.3640 & -3.9725 & -3.9725 & -387 & -387 & -387 & -0 & -0 \\
\hline 0.50 & 4.00 & 0.3131 & 0.3639 & 0.3640 & -2.6260 & -2.6264 & -353 & -353 & -354 & -1 & -0 \\
\hline 1.00 & 4.00 & 0.3131 & 0.3639 & 0.3640 & -1.2521 & -1.2529 & -315 & -315 & -317 & -2 & -1 \\
\hline 1.50 & 4.00 & 0.3131 & 0.3639 & 0.3640 & 0.1219 & 0.1207 & -267 & -267 & -272 & -5 & -2 \\
\hline 2.00 & 4.00 & 0.3131 & 0.3639 & 0.3640 & 1.4958 & 1.4942 & -200 & -200 & -194 & 6 & 3 \\
\hline 2.50 & 4.00 & 0.3131 & 0.3639 & 0.3640 & 2.8698 & 2.8678 & -140 & -140 & -115 & 25 & 20 \\
\hline 3.00 & 4.00 & 0.3131 & 0.3639 & 0.3640 & 4.2438 & 4.2414 & -88 & -88 & -70 & 18 & 23 \\
\hline-3.00 & 5.00 & 0.3131 & 0.3639 & 0.3640 & -13.2438 & -13.2414 & -604 & -604 & -598 & 7 & 1 \\
\hline-2.50 & 5.00 & 0.3131 & 0.3639 & 0.3640 & -11.8698 & -11.8678 & -581 & -581 & -575 & 5 & 1 \\
\hline-2.00 & 5.00 & 0.3131 & 0.3639 & 0.3640 & -10.4958 & -10.4942 & -556 & -556 & -552 & 4 & 1 \\
\hline-1.50 & 5.00 & 0.3131 & 0.3639 & 0.3640 & -9.1219 & -9.1207 & -531 & -531 & -528 & 3 & 1 \\
\hline-1.00 & 5.00 & 0.3131 & 0.3639 & 0.3640 & -7.7479 & -7.7471 & -504 & -504 & -502 & 2 & 0 \\
\hline-0.50 & 5.00 & 0.3131 & 0.3639 & 0.3640 & -6.3740 & -6.3736 & -477 & -477 & -476 & 1 & 0 \\
\hline 0.01 & 5.00 & 0.3131 & 0.3639 & 0.3640 & -4.9725 & -4.9725 & -447 & -447 & -447 & -0 & -0 \\
\hline 0.50 & 5.00 & 0.3131 & 0.3639 & 0.3640 & -3.6260 & $-\mathbf{3 . 6 2 6 4}$ & -417 & -417 & -418 & -1 & -0 \\
\hline 1.00 & 5.00 & 0.3131 & 0.3639 & 0.3640 & -2.2521 & -2.2529 & -383 & -383 & -384 & -2 & -0 \\
\hline 1.50 & 5.00 & 0.3131 & 0.3539 & 0.3640 & -0.8781 & -0.8793 & -345 & -345 & -347 & -2 & -1 \\
\hline 2.00 & 5.00 & 0.3131 & 0.3639 & 0.3640 & 0.4958 & 0.4942 & -293 & -293 & -303 & -9 & -3 \\
\hline 2.50 & 5.00 & 0.3131 & 0.3639 & 0.3640 & 1.8698 & 1.8678 & -231 & -231 & -224 & 7 & 3 \\
\hline 3.00 & 5.00 & 0.3131 & 0.3639 & 0.3640 & 3.2438 & 3.2414 & -175 & -175 & -145 & 30 & 19 \\
\hline
\end{tabular}


COMPARISON OF QST FORMULAS: ASHRAE STANDARD 152P vS. GENERALIZED FORMULA

\begin{tabular}{|c|c|c|c|c|c|c|c|c|c|c|c|}
\hline $\begin{array}{l}\text { Clot= } \\
\text { DPoff }\end{array}$ & $\frac{157.29}{\text { DPon }}$ & $\begin{array}{c}\text { nenve } \\
\text { Zo }\end{array}$ & $\frac{0.65}{21}$ & $22^{c f=}$ & $\frac{0}{\mathrm{DPoff} / Z-\mathrm{D}}$ & on $c c=$ & $\begin{array}{r}0.5 \\
\text { Qsrgenere }\end{array}$ & $\mathrm{eW}=$ & Qsr 152 & $\begin{array}{l}1 / \text { nenve } \\
\text { diff }\end{array}$ & $\begin{array}{l}1.538462 \\
\% \text { DIF }\end{array}$ \\
\hline-3.00 & 0.00 & 0.1558 & 0.2097 & 0.2109 & -14.3089 & -14.2276 & -269 & -268 & -252 & 16 & 6 \\
\hline$-2,50$ & 0.00 & 0.1558 & 0.2097 & 0.2109 & -11.9240 & -11.8564 & -239 & -238 & -224 & 14 & 6 \\
\hline$-2,00$ & 0.00 & 0.1558 & 0.2097 & 0.2109 & -9.5392 & -9.4851 & -206 & -206 & -194 & 12 & 6 \\
\hline$-1,50$ & 0,00 & 0.1558 & 0.2097 & 0.2109 & -7.1544 & -7.1138 & -171 & -171 & -161 & 10 & 6 \\
\hline-1.00 & 0.00 & 0.1558 & 0.2097 & 0.2109 & -4.7696 & -4.7425 & -132 & -131 & -123 & 8 & 6 \\
\hline-0.50 & 0.00 & 0.1558 & 0.2097 & 0.2109 & -2.3848 & -2.3713 & -84 & -84 & -79 & 5 & 6 \\
\hline 0.01 & 0.00 & 0.1558 & 0.2097 & 0.2109 & 0.0477 & 0.0474 & 7 & 7 & 6 & 요 & 6 \\
\hline 0.50 & 0.00 & 0.1558 & 0.2097 & 0.2109 & 2.3848 & 2.3713 & 84 & 84 & 79 & 5 & 6 \\
\hline 1.00 & 0.00 & 0.1558 & 0.2097 & 0.2109 & 4.7696 & 4.7425 & 132 & 131 & 123 & 8. & 6 \\
\hline 1.50 & 0.00 & 0.1558 & 0.2097 & 0.2109 & 7.1544 & 7.1138 & 171 & 171 & 161 & 10 & 6 \\
\hline 2.00 & 0.00 & 0.1558 & 0.2097 & 0.2109 & 9.5392 & 9.4851 & 206 & 206 & 194 & 12 & 6 \\
\hline 2.50 & 0.00 & 0.1558 & 0.2097 & 0.2109 & 11.9240 & 11.8564 & 239 & 238 & 224 & 14 & 6 \\
\hline 3,00 & 0.00 & 0.1558 & 0.2097 & 0.2109 & 14.3089 & 14.2276 & 269 & 268 & 252 & 16 & 6 \\
\hline$-3,00$ & 1.00 & 0.1558 & 0.2097 & 0.2109 & -15.3089 & -15.2276 & -376 & -375 & -357 & 18 & 5 \\
\hline-2.50 & 1.00 & 0.1558 & 0.2097 & 0.2109 & -12.9240 & -12.8564 & -347 & -346 & -331 & 16 & 5 \\
\hline-2.00 & 1.00 & 0.1558 & 0.2097 & 0.2109 & -10.5392 & -10.4851 & -317 & -316 & -303 & 14 & 4 \\
\hline-1.50 & 1.00 & 0.1558 & 0.2097 & 0.2109 & -8.1544 & -8.1138 & -285 & -284 & -272 & 12 & 4 \\
\hline-1.00 & 1.00 & 0.1558 & 0.2097 & 0.2109 & -5.7696 & -5.7425 & -249 & -248 & -239 & 9 & 4 \\
\hline-0.50 & 1.00 & 0.1558 & 0.2097 & 0.2109 & -3.3848 & -3.3713 & -208 & -208 & -202 & 6 & 3 \\
\hline 0.01 & 1.00 & 0.1558 & 0.2097 & 0.2109 & -0.9523 & -0.9526 & -156 & -156 & -156 & -0 & -0 \\
\hline 0.50 & 1.00 & 0.1558 & 0.2097 & 0.2109 & 1.3848 & 1.3713 & -64 & -65 & -79 & -14 & -19 \\
\hline 1.00 & 1.00 & 0.1558 & 0.2097 & 0.2109 & 3.7696 & 3.7425 & 1 & 0 & 0 & 0 & 0 \\
\hline 1.50 & 1.00 & 0.1558 & 0.2097 & 0.2109 & 6.1544 & 6.1138 & 48 & 48 & 45 & 3 & 6 \\
\hline 2.00 & 1.00 & 0.1558 & 0.2097 & 0.2109 & 8.5392 & 8.4851 & 88 & 88 & 82 & 6 & 7 \\
\hline 2.50 & 1.00 & 0.1558 & 0.2097 & 0.2109 & 10.9240 & 10.8564 & 124 & 123 & 115 & 8 & 7 \\
\hline 3.00 & 1.00 & 0.1558 & 0.2097 & 0.2109 & 13.3089 & 13.2276 & 156 & 155 & 145 & 10 & 7 \\
\hline-3.00 & 2.00 & 0.1558 & 0.2097 & 0.2109 & -16.3089 & -16.2276 & -446 & -446 & -427 & 18 & 4 \\
\hline-2.50 & 2.00 & 0.1558 & 0.2097 & 0.2109 & -13.9240 & -13.8564 & -419 & -418 & -402 & 16 & 4 \\
\hline-2.00 & 2.00 & 0.1558 & 0.2097 & 0.2109 & -11.5392 & -11.4851 & -390 & -390 & -375 & 14 & 4 \\
\hline-1.50 & 2.00 & 0.1558 & 0.2097 & 0.2109 & -9.1544 & -9.1138 & -360 & -359 & -347 & 12 & 3 \\
\hline-1.00 & 2.00 & 0.1558 & 0.2097 & 0.2109 & -6.7696 & -6.7425 & -327 & -326 & -317 & 9 & 3 \\
\hline$-0,50$ & 2.00 & 0.1558 & 0.2097 & 0.2109 & -4.3848 & -4.3713 & -290 & -290 & -284 & 5 & 2 \\
\hline 0.01 & 2.00 & 0.1558 & 0.2097 & 0.2109 & -1.9523 & -1.9526 & -246 & -246 & -246 & -0 & -0 \\
\hline 0.50 & 2.00 & 0.1558 & 0.2097 & 0.2109 & 0.3848 & 0.3713 & -182 & -183 & -202 & -19 & -10 \\
\hline 1.00 & 2.00 & 0.1558 & 0.2097 & 0.2109 & 2.7696 & 2.7425 & -101 & -102 & -123 & -22 & -19 \\
\hline 1.50 & 2.00 & 0.1558 & 0.2097 & 0.2109 & 5.1544 & 5.1138 & -45 & -45 & -45 & 1 & 2 \\
\hline 2.00 & 2.00 & 0.1558 & 0.2097 & 0.2109 & 7.5392 & 7.4851 & 1 & 0 & 0 & 0 & 1 \\
\hline 2.50 & 2.00 & 0.1558 & 0.2097 & 0.2109 & 9.9240 & 9.8564 & 40 & 39 & 37 & 2 & 5 \\
\hline 3.00 & 2.00 & 0.1558 & 0.2097 & 0.2109 & 12.3089 & 12.2276 & 76 & 75 & 70 & 4 & 6 \\
\hline$-3,00$ & 3.00 & 0.1558 & 0.2097 & 0.2109 & -17.3089 & -17.2276 & -508 & -507 & -489 & 19 & 4 \\
\hline-2.50 & 3.00 & 0.1558 & 0.2097 & 0.2109 & -14.9240 & -14.8564 & -482 & -481 & -464 & 17 & 4 \\
\hline-2.00 & 3.00 & 0.1558 & 0.2097 & 0.2109 & -12.5392 & -12.4851 & -454 & -454 & -439 & 14 & 3 \\
\hline-1.50 & 3.00 & 0.1558 & 0.2097 & 0.2109 & -10.1544 & -10.1138 & -425 & -424 & -413 & 12 & 3 \\
\hline-1.00 & 3.00 & 0.1558 & 0.2097 & 0.2109 & -7.7696 & -7.7425 & -394 & -393 & -384 & 9 & 2 \\
\hline-0.50 & 3.00 & 0.1558 & 0.2097 & 0.2109 & -5.3848 & -5.3713 & -360 & -359 & -354 & 5 & 1 \\
\hline 0.01 & 3.00 & 0.1558 & 0.2097 & 0.2109 & -2.9523 & -2.9526 & -320 & -320 & -321 & -0 & -0 \\
\hline 0.50 & 3.00 & 0.1558 & 0.2097 & 0.2109 & -0.6152 & -0.6287 & -274 & -274 & -284 & -10 & -3 \\
\hline 1.00 & 3.00 & 0.1558 & 0.2097 & 0.2109 & 1.7696 & 1.7425 & -196 & -197 & -239 & -42 & -19 \\
\hline 1.50 & 3.00 & 0.1558 & 0.2097 & 0.2109 & 4.1544 & 4.1138 & -132 & -133 & -161 & -28 & -19 \\
\hline 2.00 & 3.00 & 0.1558 & 0.2097 & 0.2109 & 6.5392 & 6.4851 & -80 & -82 & -82 & -0 & -1 \\
\hline 2.50 & 3.00 & 0.1558 & 0.2097 & 0.2109 & 8.9240 & 8.8564 & -37 & -38 & -37 & 1 & 3 \\
\hline 3.00 & 3.00 & 0.1558 & 0.2097 & 0.2109 & 11.3089 & 11.2276 & 1 & 0 & 0 & 0 & 1 \\
\hline-3.00 & 4.00 & 0.1558 & 0.2097 & 0.2109 & -18.3089 & -18.2276 & -564 & .564 & -545 & 19 & 3 \\
\hline-2.50 & 4.00 & 0.1558 & 0.2097 & 0.2109 & -15.9240 & -15.8564 & -539 & -538 & -522 & 17 & 3 \\
\hline-2.00 & 4.00 & 0.15 & 0.2097 & 0.2109 & -13.5392 & -13.4851 & -512 & -512 & -498 & 14 & 3 \\
\hline-1.50 & 4.00 & 0.1558 & 0.2097 & 0.2109 & -11.1544 & -11.1138 & -484 & -484 & -472 & 12 & 2 \\
\hline-1.00 & 4.00 & 0.1558 & 0.2097 & 0.2109 & -8.7696 & -8.7425 & -455 & -454 & -446 & 9 & 2 \\
\hline-0.50 & 4.00 & 0.1558 & 0.2097 & 0.2109 & -6.3848 & -6.3713 & -423 & -422 & -418 & 5 & 1 \\
\hline 0.01 & 4.00 & 0.1558 & 0.2097 & 0.2109 & -3.9523 & -3.9526 & -387 & -387 & -387 & -0 & -0 \\
\hline 0.50 & 4.00 & 0.1558 & 0.2097 & 0.2109 & -1.6152 & -1.6287 & -346 & -347 & -354 & -8 & -2 \\
\hline 1.00 & 4.00 & 0.1558 & 0.2097 & 0.2109 & 0.7696 & 0.7425 & -286 & -286 & -317 & $-31 \mid$ & -10 \\
\hline 1.50 & 4.00 & 0.1558 & 0.2097 & 0.2109 & 3.1544 & 3.1138 & -215 & -216 & -272 & -56 & -23 \\
\hline 2.00 & 4.00 & 0.1558 & 0.2097 & 0.2109 & 5.5392 & 5.4851 & -159 & -160 & -194 & -34 & -19 \\
\hline 2.50 & 4.00 & 0.1558 & 0.2097 & 0.2109 & 7.9240 & 7.8564 & -111 & -113 & -115 & -2 & -2 \\
\hline 3.00 & 4.00 & 0.1558 & 0.2097 & 0.2109 & 10.3089 & 10.2276 & -70 & -71 & -70 & 1 & 2 \\
\hline-3.00 & 5.00 & 0.1558 & 0.2097 & 0.2109 & -19.3089 & -19.2276 & -617 & -616 & -598 & 19 & 3 \\
\hline-2.50 & 5.00 & 0.1558 & 0.2097 & 0.2109 & -16.9240 & -16.8564 & -592 & -592 & -575 & 16 & 3 \\
\hline-2.00 & 5.00 & 0.1558 & 0.2097 & 0.2109 & -14.5392 & -14.4851 & -567 & -566 & -552 & 14 & 3 \\
\hline-1.50 & 5.00 & 0.1558 & 0.2097 & 0.2109 & -12.1544 & -12.1138 & -540 & -539 & -528 & 11 & 2 \\
\hline-1.00 & 5.00 & 0.1558 & 0.2097 & 0.2109 & -9.7696 & -9.7425 & -511 & -511 & -502 & 8 & 2 \\
\hline-0.50 & 5.00 & 0.1558 & 0.2097 & 0.2109 & -7.3848 & -7.3713 & -481 & -481 & -476 & 5 & 1 \\
\hline 0.01 & 5.00 & 0.1558 & 0.2097 & 0.2109 & -4.9523 & -4.9526 & -447 & -447 & -447 & -0 & -0 \\
\hline 0.50 & 5.00 & 0.1558 & 0.2097 & 0.2109 & -2.6152 & -2.6287 & -411 & -411 & -418 & -7 & -2 \\
\hline 1.00 & 5.00 & 0.1558 & 0.2097 & 0.2109 & -0.2304 & -0.2575 & -365 & -366 & -384 & -19 & -5 \\
\hline 1.50 & 5.00 & 0.1558 & 0.2097 & 0.2109 & 2.1544 & 2.1138 & -295 & -296 & -347 & -51 & -16 \\
\hline 2.00 & 5.00 & 0.1558 & 0.2097 & 0.2109 & 4.5392 & 4.4851 & -234 & -236 & -303 & -67 & -25 \\
\hline 2.50 & 5.00 & 0.1558 & 0.2097 & 0.2109 & 6.9240 & 6.8564 & -183 & -185 & -224 & -39 & -19 \\
\hline 3.00 & 5.00 & 0.1558 & 0.2097 & 0.2109 & 9.3089 & 9.2276 & -139 & -140 & -145 & -5 & 3 \\
\hline
\end{tabular}




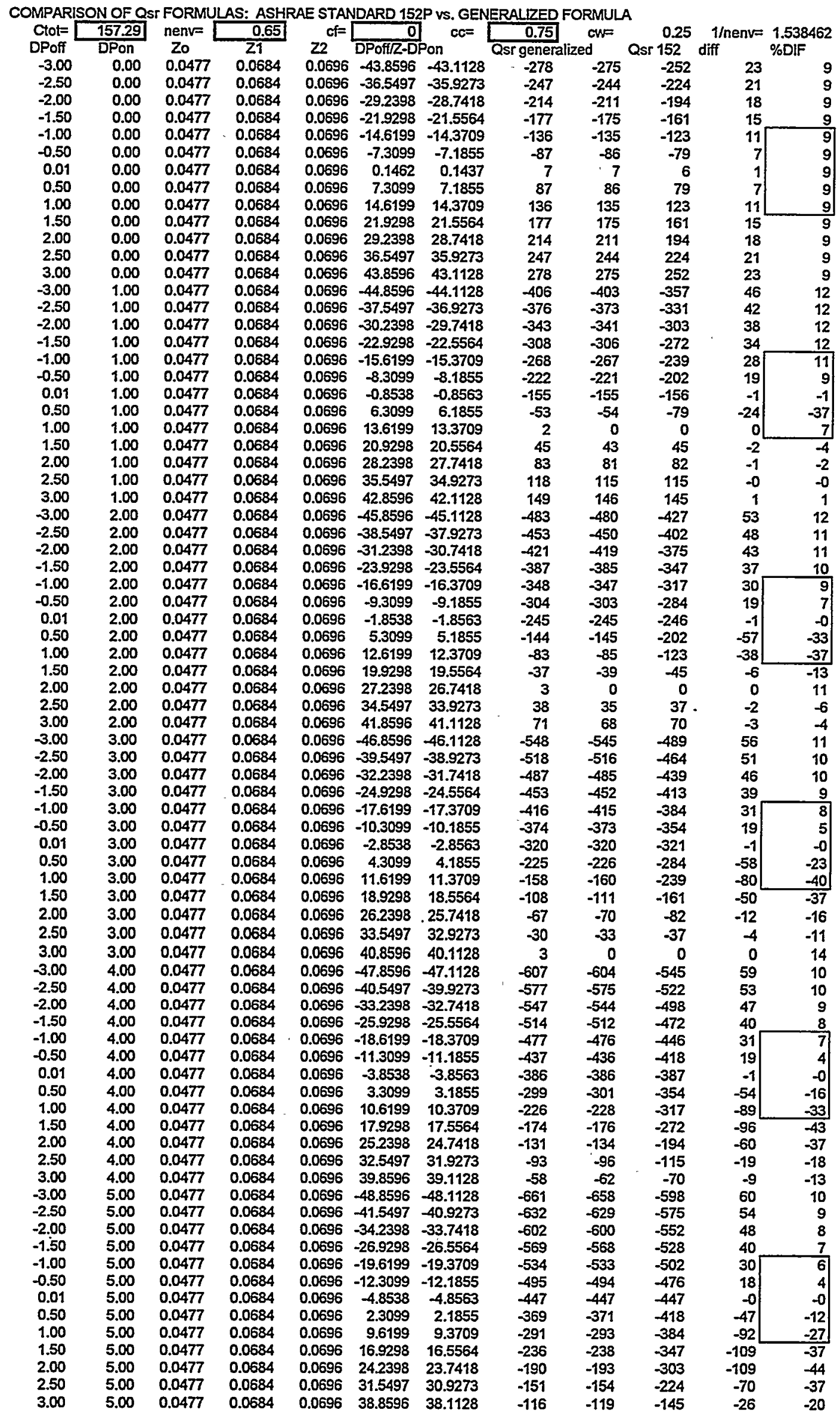


COMPARISON OF QST FORMULAS: ASHRAE STANDARD 152P vS. GENERALIZED FORMULA

\begin{tabular}{|c|c|c|c|c|c|c|c|c|c|c|c|}
\hline $\begin{array}{l}\text { Clot= } \\
\text { DPoff }\end{array}$ & $\frac{157.29}{\text { DPon }}$ & $\begin{array}{c}\text { nenve } \\
\text { Zo }\end{array}$ & $\frac{0.65}{21}$ & $22^{\mathrm{cf}=[}$ & \begin{tabular}{|r|}
0 \\
DPoff/Z-DF
\end{tabular} & $\left.\right|_{\text {Pon }} c c=$ & \begin{tabular}{|r|}
0.95 \\
Qsr genera
\end{tabular} & $\mathrm{CW}=$ & Qsr $\begin{array}{c}0.05 \\
152\end{array}$ & $\begin{array}{l}\text { 1/nenv= } \\
\text { diff }\end{array}$ & $\begin{array}{l}1.538462 \\
\% \text { DIF }\end{array}$ \\
\hline-3.00 & 0.00 & 0.0036 & 0.0048 & 0.0049 & 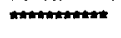 & 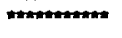 & -311 & -308 & -252 & 56 & 20 \\
\hline-2.50 & 0.00 & 0.0036 & 0.0048 & 0.0049 & 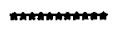 & (1) & -276 & -273 & -224 & 49 & 20 \\
\hline-2.00 & 0.00 & 0.0036 & 0.0048 & 0.0049 & 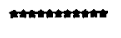 & 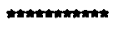 & -239 & -236 & -194 & 43 & 20 \\
\hline-1.50 & 0.00 & 0.0036 & 0.0048 & 0.0049 & 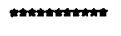 & TH & -198 & -196 & -161 & 35 & 20 \\
\hline-1.00 & 0.00 & 0.0036 & 0.0048 & 0.0049 & 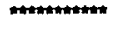 & 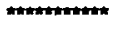 & -152 & -151 & -123 & 27 & 20 \\
\hline-0.50 & 0.00 & 0.0036 & 0.0048 & 0.0049 & (1) & " & -97 & -96 & -79 & 17 & 20 \\
\hline 0.01 & 0.00 & 0.0036 & 0.0048 & 0.0049 & 2.0627 & 2.0299 & 8 & 8 & 6 & 1 & 20 \\
\hline 0.50 & 0.00 & 0.0036 & 0.0048 & 0.0049 & 103.1371 & 101.4946 & 97 & 96 & 79 & 17 & 20 \\
\hline 1.00 & 0.00 & 0.0036 & 0.0048 & 0.0049 & 206.2742 & 202.9892 & 152 & 151 & 123 & 27 & 20 \\
\hline 1.50 & 0.00 & 0.0036 & 0.0048 & 0.0049 & 309.4113 & 304.4838 & 198 & 196 & 161 & 35 & 20 \\
\hline 2.00 & 0.00 & 0.0036 & 0.0048 & 0.0049 & 412.5484 & 405.9784 & 239 & 236 & 194 & 43 & 20 \\
\hline 2.50 & 0.00 & 0.0036 & 0.0048 & 0.0049 & 515.6855 & 507.4730 & 276 & 273 & 224 & 49 & 20 \\
\hline 3.00 & 0,00 & 0.0036 & 0.0048 & 0.0049 & 618.8226 & 608.9675 & 311 & 308 & 252 & 56 & 20 \\
\hline$-3,00$ & 1.00 & 0.0036 & 0.0048 & 0.0049 & matomethe & 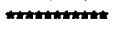 & -461 & -458 & -357 & 101 & 25 \\
\hline-2.50 & 1.00 & 0.0036 & 0.0048 & 0.0049 & 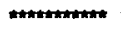 & 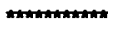 & -427 & -424 & -331 & 93 & 25 \\
\hline-2.00 & 1.00 & 0.0036 & 0.0048 & 0.0049 & 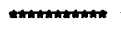 & 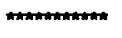 & -389 & -387 & -303 & 84 & 24 \\
\hline-1.50 & 1.00 & 0.0036 & 0.0048 & 0.0049 & tom & (1) & -349 & -347 & -272 & 74 & 24 \\
\hline-1.00 & 1.00 & 0.0036 & 0.0048 & 0.0049 & 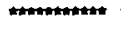 & 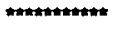 & -303 & 301 & -239 & 62 & 23 \\
\hline-0.50 & 1.00 & 0.0036 & 0.0048 & 0.0049 & 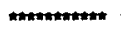 & 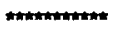 & -248 & -247 & -202 & 45 & 20 \\
\hline 0.01 & 1,00 & 0.0036 & 0.0048 & 0.0049 & 1.0527 & 1.0299 & -149 & -149 & -156 & -7 & -5 \\
\hline 0.50 & 1.00 & 0.0036 & 0.0048 & 0.0049 & 102.1371 & 100.4946 & .54 & .55 & -79 & -24 & -35 \\
\hline 1.00 & 1.00 & 0.0036 & 0.0048 & 0.0049 & 205.2742 & 201.9892 & 2 & 0 & 0 & ol & 8 \\
\hline 1.50 & 1.00 & 0.0036 & 0.0048 & 0.0049 & 308.4113 & 303.4838 & 48 & 46 & 45 & 1 & 2 \\
\hline 2,00 & 1.00 & 0.0036 & 0.0048 & 0.0049 & 411.5484 & 404.9784 & 89 & 86 & 82 & 4 & 5 \\
\hline 2.50 & 1.00 & 0.0036 & 0.0048 & 0.0049 & 514.6855 & 506.4730 & 126 & 123 & 115 & 8 & 7 \\
\hline 3,00 & 1.00 & 0.0036 & 0.0048 & 0.0049 & 617.8226 & 607.9675 & 161 & 157 & 145 & 12 & 8 \\
\hline-3.00 & 2.00 & 0.0036 & 0.0048 & 0.0049 & 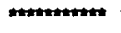 & 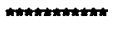 & -547 & -544 & -427 & 117 & 24 \\
\hline-2.50 & 2.00 & 0.0036 & 0.0048 & 0.0049 & 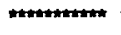 & 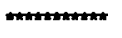 & -512 & -510 & -402 & 108 & 24 \\
\hline-2.00 & 2.00 & 0.0036 & 0.0048 & 0.0049 & 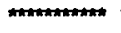 & 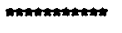 & -475 & -473 & -375 & 97 & 23 \\
\hline-1.50 & 2.00 & 0.0036 & 0.0048 & 0.0049 & 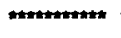 & " & -435 & -433 & -347 & 85 & 22 \\
\hline-1.00 & 2.00 & 0.0036 & 0.0048 & 0.0049 & 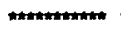 & 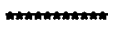 & -389 & -388 & -317 & 70 & 20 \\
\hline-0.50 & 2.00 & 0.0036 & 0.0048 & 0.0049 & 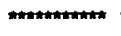 & 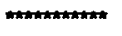 & -334 & -333 & -284 & 49 & 16 \\
\hline 0.01 & 2.00 & 0.0036 & 0.0048 & 0.0049 & 0.0627 & 0.0299 & -242 & -242 & -246 & -4 & -2 \\
\hline 0.50 & 2.00 & 0.0036 & 0.0048 & 0.0049 & 101.1371 & 99.4946 & -141 & -142 & -202 & -60 & -35 \\
\hline 1.00 & 2.00 & 0,0036 & 0.0048 & 0.0049 & 204.2742 & 200.9892 & -85 & -86 & -123 & -37 & -35 \\
\hline 1.50 & 2.00 & 0.0036 & 0.0048 & 0.0049 & 307.4113 & 302.4838 & -38 & -41 & -45 & -4 & -10 \\
\hline 2.00 & 2.00 & 0.0036 & 0.0048 & 0.0049 & 410.5484 & 403.9784 & 2 & 0 & 0 & 0 & 13 \\
\hline 2.50 & 2.00 & 0.0036 & 0.0048 & 0.0049 & 513.6855 & 505.4730 & 40 & 37 & 37 & -0 & -0 \\
\hline 3,00 & 2.00 & 0.0036 & 0.0048 & 0.0049 & 616.8226 & 606.9675 & 75 & 72 & 70 & 1 & 2 \\
\hline-3.00 & 3.00 & 0.0036 & 0.0048 & 0.0049 & 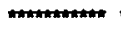 & 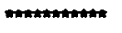 & -619 & -615 & -489 & 127 & 23 \\
\hline-2.50 & 3.00 & 0.0036 & 0.0048 & 0.0049 & 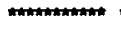 & 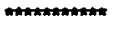 & -584 & -581 & -464 & 117 & 22 \\
\hline-2.00 & 3.00 & 0.0036 & 0.0048 & 0.0049 & (1) & A & -547 & -544 & -439 & 105 & 21 \\
\hline-1.50 & 3.00 & 0.0036 & 0.0048 & 0.0049 & - & 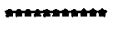 & -506 & -504 & -413 & 92 & 20 \\
\hline-1.00 & 3.00 & 0.0036 & 0.0048 & 0.0049 & 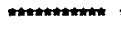 & (1) & -461 & -459 & -384 & 75 & 18 \\
\hline-0.50 & 3,00 & 0.0036 & 0.0048 & 0.0049 & 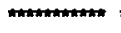 & 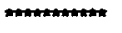 & -407 & -406 & -354 & 51 & 14. \\
\hline 0.01 & 3,00 & 0.0036 & 0.0048 & 0.0049 & -0.9373 & -0.9701 & -317 & -317 & -321 & -3 & -1 \\
\hline 0.50 & 3.00 & 0.0036 & 0.0048 & 0.0049 & 100.1371 & 98.4946 & -213 & -214 & -284 & -70 & -28 \\
\hline 1.00 & 3.00 & 0.0036 & 0.0048 & 0.0049 & 203.2742 & 199.9892 & -157 & -158 & -239 & -81 & -41 \\
\hline 1.50 & 3.00 & 0.0036 & 0.0048 & 0.0049 & 306.4113 & 301.4838 & -110 & -112 & -161 & -48 & -35 \\
\hline 2.00 & 3.00 & 0.0036 & 0.0048 & 0.0049 & 409.5484 & 402.9784 & -69 & -72 & -82 & -10 & -13 \\
\hline 2.50 & 3.00 & 0.0036 & 0.0048 & 0.0049 & 512.6855 & 504.4730 & -32 & -35 & -37 & -3 & -7 \\
\hline 3.00 & 3,00 & 0.0036 & 0.0048 & 0.0049 & 615.8226 & 605.9675 & 3 & 0 & 0 & 0 & 16 \\
\hline$-3,00$ & 4.00 & 0.0036 & 0.0048 & 0.0049 & 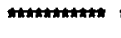 & 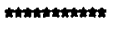 & -682 & -679 & -545 & 134 & 22 \\
\hline-2.50 & 4.00 & 0.0036 & 0.0048 & 0.0049 & 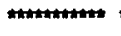 & 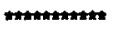 & .648 & -645 & -522 & 123 & 21 \\
\hline-2.00 & 4.00 & 0.0036 & 0.0048 & 0.0049 & 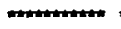 & 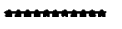 & -611 & -608 & -498 & 111 & 20 \\
\hline-1.50 & 4.00 & 0.0036 & 0.0048 & 0.0049 & 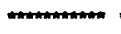 & 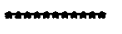 & -570 & -568 & -472 & 96 & 18 \\
\hline-1.00 & 4.00 & 0.0036 & 0.0048 & 0.0049 & 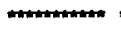 & 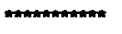 & -525 & -523 & -446 & 78 & 16 \\
\hline-0.50 & 4.00 & 0.0036 & 0.0048 & 0.0049 & 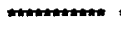 & " & -471 & -470 & -418 & 52 & 12 \\
\hline 0.01 & 4.00 & 0.0036 & 0.0048 & 0.0049 & -1.9373 & -1.9701 & -384 & -384 & -387 & -3 & -1 \\
\hline 0.50 & 4.00 & 0.0036 & 0.0048 & 0.0049 & 99.1371 & 97.4946 & -277 & -279 & -354 & -76 & -24 \\
\hline 1.00 & 4.00 & 0.0036 & 0.0048 & 0.0049 & 202.2742 & 198.9892 & -221 & -222 & -317 & -95 & -35 \\
\hline 1.50 & 4.00 & 0.0036 & 0.0048 & 0.0049 & 305.4113 & 300.4838 & -174 & -176 & -272 & -96 & -43 \\
\hline 2.00 & 4.00 & 0.0036 & 0.0048 & 0.0049 & 408.5484 & 401.9784 & -133 & -135 & -194 & -58 & -35 \\
\hline 2.50 & 4.00 & 0.0036 & 0.0048 & 0.0049 & 511.6855 & 503.4730 & -95 & -98 & -115 & -17 & -16 \\
\hline 3.00 & 4.00 & 0.0036 & 0.0048 & 0.0049 & 614.8226 & 604.9675 & -60 & -64 & -70 & -7 & -10 \\
\hline-3.00 & 5.00 & 0.0036 & 0.0048 & 0.0049 & 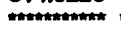 & (1) & -740 & -737 & -598 & 140 & 21 \\
\hline-2.50 & 5.00 & 0.0036 & 0.0048 & 0.0049 & 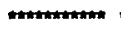 & 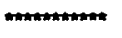 & -706 & -703 & -575 & 128 & 20 \\
\hline-2.00 & 5.00 & 0.0036 & 0.0048 & 0.0049 & 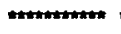 & 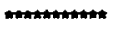 & -669 & -666 & -552 & 115 & 19 \\
\hline-1.50 & 5.00 & 0.0036 & 0.0048 & 0.0049 & 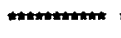 & 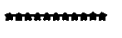 & -629 & -627 & -528 & 99 & 17 \\
\hline-1.00 & 5.00 & 0.0036 & 0.0048 & 0.0049 & 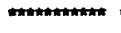 & 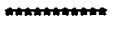 & -583 & -582 & -502 & 79 & 15 \\
\hline-0.50 & 5.00 & 0.0036 & 0.0048 & 0.0049 & (1) & 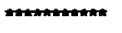 & -530 & -529 & -476 & 53 & 10 \\
\hline 0.01 & 5.00 & 0.0036 & 0.0048 & 0.0049 & -2.9373 & -2.9701 & -445 & -445 & -447 & -3 & -1 \\
\hline 0.50 & 5.00 & 0.0036 & 0.0048 & 0.0049 & 98.1371 & 96.4946 & -337 & -338 & -418 & -80 & -21 \\
\hline 1.00 & 5.00 & 0.0036 & 0.0048 & 0.0049 & 201.2742 & 197.9892 & -279 & -281 & -384 & -103 & -31 \\
\hline 1.50 & 5.00 & 0.0036 & 0.0048 & 0.0049 & 304.4113 & 299.4838 & -233 & -235 & -347 & -113 & 39 \\
\hline 2.00 & 5.00 & 0.0036 & 0.0048 & 0.0049 & 407.5484 & 400.9784 & -191 & -194 & -303 & -109 & -44 \\
\hline 2.50 & 5.00 & 0.0036 & 0.0048 & 0.0049 & 510.6855 & 502.4730 & -154 & -157 & -224 & -67 & -35 \\
\hline 3.00 & 5.00 & 0.0036 & 0.0048 & 0.0049 & 613.8226 & 603.9675 & -119 & -122 & -145 & -23 & -17 \\
\hline
\end{tabular}




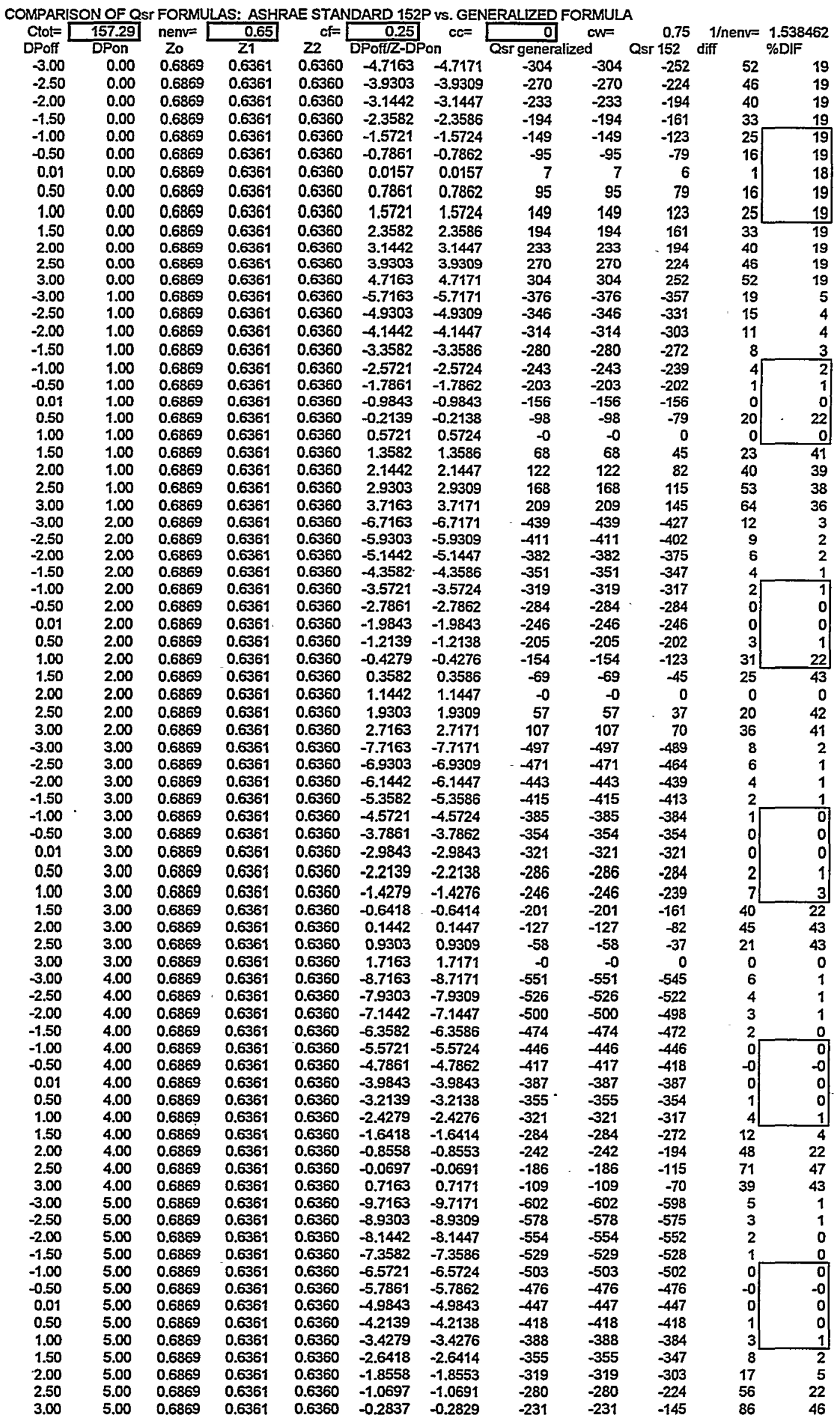




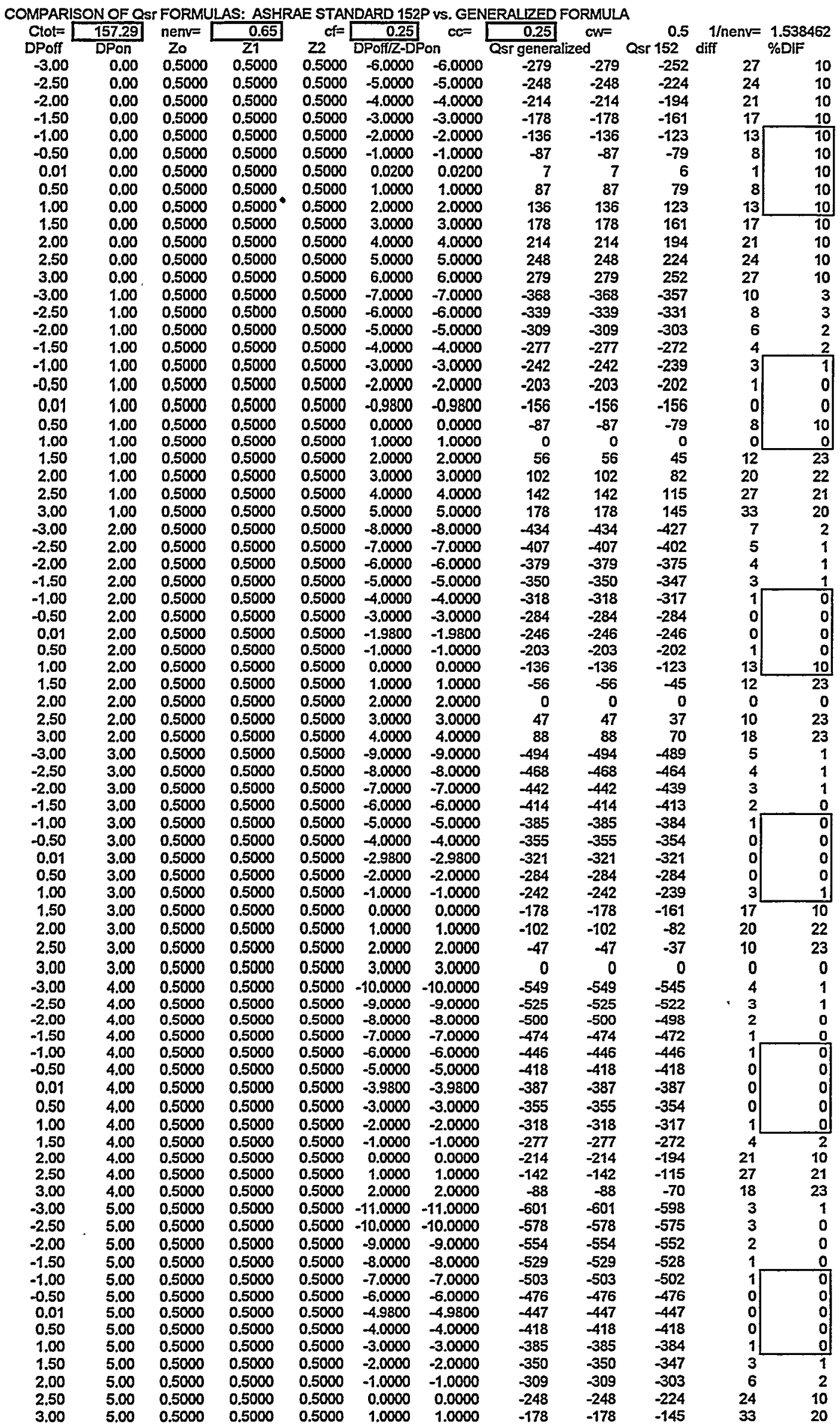




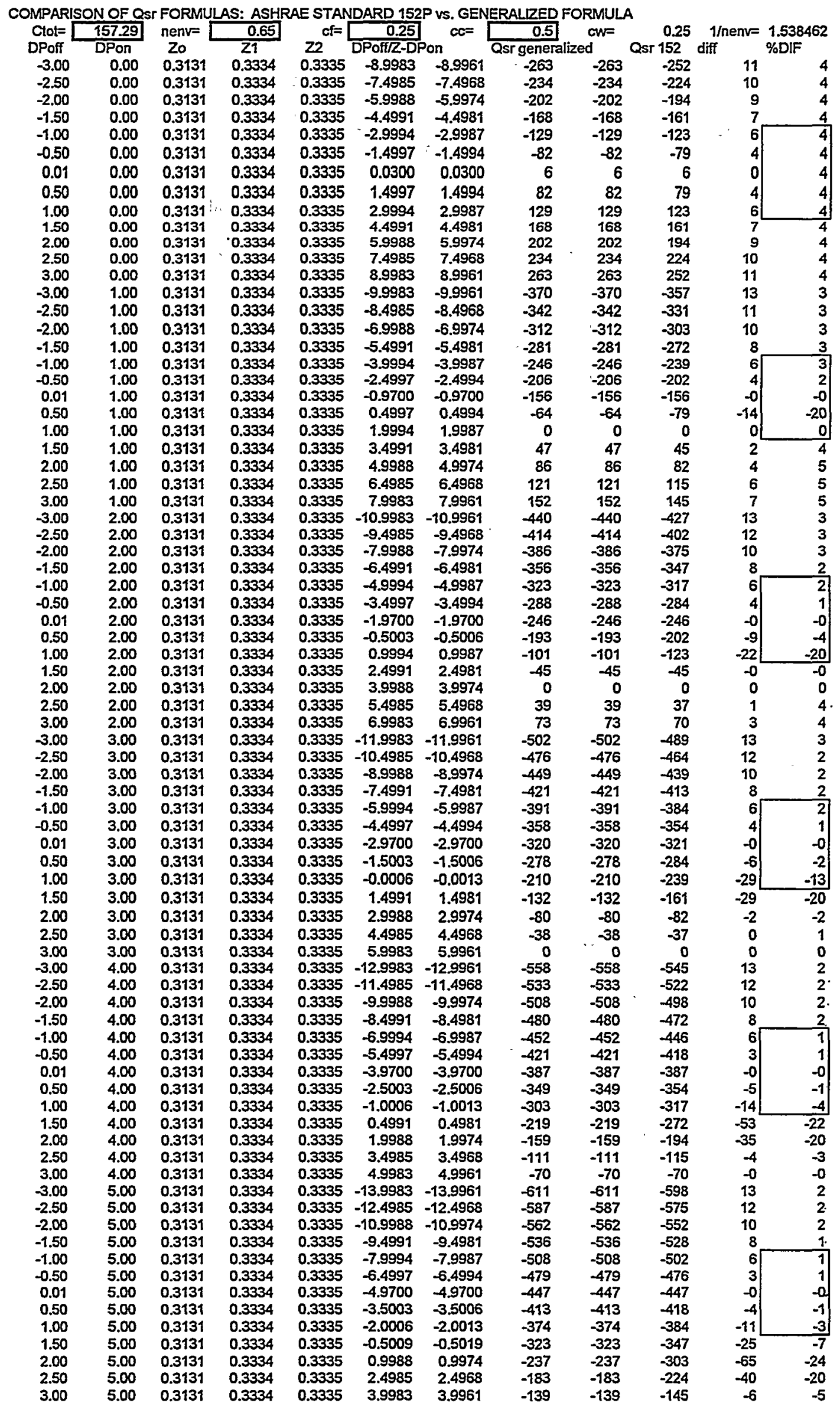


COMPARISON OF QST FORMULAS: ASHRAE STANDARD 152P VS. GENERALIZED FORMULA

\begin{tabular}{|c|c|c|c|c|c|c|c|c|c|c|c|}
\hline $\begin{array}{l}\text { Ctot= } \\
\text { DPoff }\end{array}$ & $\frac{157.29}{\text { DPon }}$ & $\begin{array}{c}\text { nenve } \\
\text { Zo }\end{array}$ & $\frac{0.65}{21}$ & $22^{c f=}$ & \begin{tabular}{r|}
0.25 \\
$D P o f f / Z-D F$
\end{tabular} & on & \begin{tabular}{|r|}
0.75 \\
Qsr genera
\end{tabular} & cw= & Qsr $152^{0}$ & $\begin{array}{l}\text { 1/nenv= } \\
\text { diff }\end{array}$ & $\begin{array}{l}1.538462 \\
\% \text { DIF }\end{array}$ \\
\hline-3.00 & 0.00 & 0.1558 & 0.1558 & 0.1558 & -19.2613 & -19.2613 & -269 & -269 & -252 & 17 & 6 \\
\hline$-2,50$ & 0.00 & 0.1558 & 0.1558 & 0.1558 & -16.0510 & -16.0510 & -239 & -239 & -224 & 15 & 6 \\
\hline-2.00 & 0.00 & 0.1558 & 0.1558 & 0.1558 & -12.8408 & -12.8408 & -207 & -207 & -194 & 13 & 6 \\
\hline-1.50 & 0.00 & 0.1558 & 0.1558 & 0.1558 & -9.6306 & -9.6306 & -171 & -171 & -161 & 11 & 6 \\
\hline-1.00 & 0.00 & 0.1558 & 0.1558 & 0.1558 & -6.4204 & -6.4204 & -132 & -132 & -123 & 8 & 6 \\
\hline-0.50 & 0.00 & 0.1558 & 0.1558 & 0.1558 & -3.2102 & -3.2102 & -84 & -84 & -79 & 5 & 6 \\
\hline 0.01 & 0.00 & 0.1558 & 0.1558 & 0.1558 & 0.0642 & 0.0642 & 7 & 7 & 6 & o) & 6 \\
\hline 0.50 & 0.00 & 0.1558 & 0.1558 & 0.1558 & 3.2102 & 3.2102 & 84 & 84 & 79 & 5 & 6 \\
\hline 1,00 & 0.00 & 0.1558 & 0.1558 & 0.1558 & 6.4204 & 6.4204 & 132 & 132 & 123 & 8 & 6 \\
\hline 1.50 & 0.00 & 0.1558 & 0.1558 & 0.1558 & 9.6306 & 9.6306 & 171 & 171 & 161 & 11 & 6 \\
\hline 2,00 & 0.00 & 0.1558 & 0.1558 & 0.1558 & 12.8408 & 12.8408 & 207 & 207 & 194 & 13 & 6 \\
\hline 2.50 & 0.00 & 0.1558 & 0.1558 & 0.1558 & 16.0510 & 16.0510 & 239 & 239 & 224 & 15 & 6 \\
\hline 3,00 & 0.00 & 0.1558 & 0.1558 & 0.1558 & 19.2613 & 19.2613 & 269 & 269 & 252 & 17 & 6 \\
\hline-3.00 & 1.00 & 0.1558 & 0.1558 & 0.1558 & -20.2613 & -20.2613 & -396 & -396 & -357 & 39 & 10 \\
\hline-2.50 & 1.00 & 0.1558 & 0.1558 & 0.1558 & -17.0510 & -17.0510 & -366 & -366 & -331 & 36 & 10 \\
\hline-2.00 & 1.00 & 0.1558 & 0.1558 & 0.1558 & -13.8408 & -13.8408 & -335 & -335 & -303 & 32 & 10 \\
\hline-1.50 & 1.00 & 0.1558 & 0.1558 & 0.1558 & -10.6306 & -10.6306 & -301 & -301 & -272 & 28 & 10 \\
\hline$-1,00$ & 1.00 & 0.1558 & 0.1558 & 0.1558 & -7.4204 & -7.4204 & -263 & -263 & -239 & 23 & 9 \\
\hline$-0,50$ & $1, \infty$ & 0.1558 & 0.1558 & 0.1558 & -4.2102 & -4.2102 & -218 & -218 & -202 & 16 & 8 \\
\hline 0.01 & 1.00 & 0.1558 & 0.1558 & 0.1558 & -0.9358 & -0.9358 & -156 & -156 & -156 & -1 & -0 \\
\hline 0.50 & 1.00 & 0.1558 & 0.1558 & 0.1558 & 2.2102 & 2.2102 & -52 & -52 & -79 & -27 & -41 \\
\hline 1.00 & 1.00 & 0.1558 & 0.1558 & 0.1558 & 5.4204 & 5.4204 & 0 & 0 & 0 & 0 & 0 \\
\hline 1.50 & 1.00 & 0.1558 & 0.1558 & 0.1558 & 8.6306 & 8.6306 & 42 & 42 & 45 & -3 & -7 \\
\hline 2.00 & 1.00 & 0.1558 & 0.1558 & 0.1558 & 11.8408 & 11.8408 & 78 & 78 & 82 & -4 & -5 \\
\hline 2.50 & 1.00 & 0.1558 & 0.1558 & 0.1558 & 15.0510 & 15.0510 & 111 & 111 & 115 & -4 & -3 \\
\hline 3.00 & 1.00 & 0.1558 & 0.1558 & 0.1558 & 18.2613 & 18.2613 & 142 & 142 & 145 & -3 & -2 . \\
\hline-3.00 & 2.00 & 0.1558 & 0.1558 & 0.1558 & -21.2613 & -21.2613 & -472 & -472 & -427 & 45 & 10 \\
\hline-2.50 & 2.00 & 0.1558 & 0.1558 & 0.1558 & -18.0510 & -18.0510 & -443 & -443 & -402 & 41 & 10 \\
\hline-2.00 & 2.00 & 0.1558 & 0.1558 & 0.1558 & -14.8408 & -14.8408 & -412 & -412 & -375 & 37 & 9 \\
\hline-1.50 & 2.00 & 0.1558 & 0.1558 & 0.1558 & -11.6306 & -11.6306 & -379 & -379 & -347 & 32 & 9 \\
\hline-1.00 & 2.00 & 0.1558 & 0.1558 & 0.1558 & -8.4204 & -8.4204 & -342 & -342 & -317 & 25 & 8 \\
\hline-0.50 & 2.00 & 0.1558 & 0.1558 & 0.1558 & -5.2102 & -5.2102 & -300 & -300 & -284 & 16 & 5 \\
\hline 0.01 & 2.00 & 0.1558 & 0.1558 & 0.1558 & -1.9358 & -1.9358 & -246 & -246 & -246 & -0 & -0 \\
\hline 0.50 & 2.00 & 0.1558 & 0.1558 & 0.1558 & 1.2102 & 1.2102 & -141 & -141 & -202 & -61 & 36 \\
\hline 1.00 & 2.00 & 0.1558 & 0.1558 & 0.1558 & 4.4204 & 4.4204 & -82 & -82 & -123 & -42 & -41 \\
\hline 1.50 & 2.00 & 0.1558 & 0.1558 & 0.1558 & 7.6306 & 7.6306 & -38 & -38 & -45 & -7 & -17 \\
\hline 2.00 & 2.00 & 0.1558 & 0.1558 & 0.1558 & 10.8408 & 10.8408 & 0 & 0 & 0 & 0 & 0 \\
\hline 2.50 & 2.00 & 0.1558 & 0.1558 & 0.1558 & 14.0510 & 14.0510 & 34 & 34 & 37 & -3 & -9 \\
\hline 3,00 & 2.00 & 0.1558 & 0.1558 & 0.1558 & 17.2613 & 17.2613 & 65 & 65 & 70 & -5 & -7 \\
\hline-3.00 & 3.00 & 0.1558 & 0.1558 & 0.1558 & -22.2613 & -22.2613 & -536 & -536 & -489 & 48 & 9 \\
\hline-2.50 & 3.00 & 0.1558 & 0.1558 & 0.1558 & -19.0510 & -19.0510 & -508 & -508 & -464 & 43 & 9 \\
\hline-2.00 & 3.00 & 0.1558 & 0.1558 & 0.1558 & -15.8408 & -15.8408 & -478 & -478 & -439 & 39 & 8 \\
\hline-1.50 & 3.00 & 0.1558 & 0.1558 & 0.1558 & -12.6306 & -12.6306 & -445 & -445 & -413 & 33 & 8 \\
\hline-1.00 & 3.00 & 0.1558 & 0.1558 & 0.1558 & -9.4204 & -9.4204 & -410 & -410 & -384 & 25 & 6 \\
\hline-0.50 & 3.00 & 0.1558 & 0.1558 & 0.1558 & -6.2102 & -6.2102 & -370 & -370 & -354 & 16 & 4 \\
\hline 0.01 & 3.00 & 0.1558 & 0.1558 & 0.1558 & -2.9358 & -2.9358 & -320 & -320 & -321 & -0 & -0 \\
\hline 0.50 & 3.00 & 0.1558 & 0.1558 & 0.1558 & 0.2102 & 0.2102 & -227 & -227 & -284 & -57 & -22 \\
\hline 1.00 & 3.00 & 0.1558 & 0.1558 & 0.1558 & 3.4204 & 3.4204 & -153 & -153 & -239 & -86 & -44 \\
\hline 1.50 & 3.00 & 0.1558 & 0.1558 & 0.1558 & 6.6306 & 6.6306 & -106 & -106 & -161 & -54 & -41 \\
\hline 2.00 & 3.00 & 0.1558 & 0.1558 & 0.1558 & 9.8408 & 9.8408 & -67 & -67 & -82 & -15 & -20 \\
\hline 2.50 & 3.00 & 0.1558 & 0.1558 & 0.1558 & 13.0510 & 13.0510 & -32 & -32 & -37 & -5 & -15 \\
\hline 3.00 & 3.00 & 0.1558 & 0.1558 & 0.1558 & 16.2613 & 16.2613 & 0 & 0 & 0 & 0 & 0 \\
\hline$-3,00$ & 4,00 & 0.1558 & 0.1558 & 0.1558 & -23.2613 & -23.2613 & -595 & -595 & -545 & 50 & 9 \\
\hline-2.50 & 4.00 & 0.1558 & 0.1558 & 0.1558 & -20.0510 & -20.0510 & -567 & -567 & -522 & 45 & 8 \\
\hline-2.00 & 4.00 & 0.1558 & 0.1558 & 0.1558 & -16.8408 & -16.8408 & -537 & -537 & -498 & 39 & 8 \\
\hline-1.50 & 4.00 & 0.1558 & 0.1558 & 0.1558 & -13.6306 & -13.6306 & -505 & -505 & -472 & 33 & 7 \\
\hline-1.00 & 4.00 & 0.1558 & 0.1558 & 0.1558 & -10.4204 & -10.4204 & -471 & -471 & -446 & 25 & 5 \\
\hline-0.50 & 4.00 & 0.1558 & 0.1558 & 0.1558 & -7.2102 & -7.2102 & -432 & -432 & -418 & 15 & 4 \\
\hline 0.01 & 4.00 & 0.1558 & 0.1558 & 0.1558 & -3.9358 & -3.9358 & -386 & -386 & -387 & -0 & -0 \\
\hline 0.50 & 4.00 & 0.1558 & 0.1558 & 0.1558 & -0.7898 & -0.7898 & -324 & -324 & -354 & -30 & -9 \\
\hline 1.00 & 4.00 & 0.1558 & 0.1558 & 0.1558 & 2.4204 & 2.4204 & -221 & -221 & -317 & -96 & -36 \\
\hline 1.50 & 4.00 & 0.1558 & 0.1558 & 0.1558 & 5.6306 & 5.6306 & -170 & -170 & -272 & -103 & -46 \\
\hline 2.00 & 4.00 & 0.1558 & 0.1558 & 0.1558 & 8.8408 & 8.8408 & -128 & -128 & -194 & -65 & -41 \\
\hline 2.50 & 4.00 & 0.1558 & 0.1558 & 0.1558 & 12.0510 & 12.0510 & -92 & -92 & -115 & -23 & -22 \\
\hline 3.00 & 4.00 & 0.1558 & 0.1558 & 0.1558 & 15.2613 & 15.2613 & -59 & -59 & -70 & -11 & -17 \\
\hline-3.00 & 5.00 & 0.1558 & 0.1558 & 0.1558 & -24.2613 & -24.2613 & -648 & -648 & -598 & 51 & 8 \\
\hline-2.50 & 5.00 & 0.1558 & 0.1558 & 0.1558 & -21.0510 & -21.0510 & -621 & -621 & -575 & 46 & 8 \\
\hline$-2,00$ & 5.00 & 0.1558 & 0.1558 & 0.1558 & -17.8408 & -17.8408 & -592 & -592 & -552 & 40 & 7 \\
\hline-1.50 & 5.00 & 0.1558 & 0.1558 & 0.1558 & -14.6306 & -14.6306 & -561 & -561 & -528 & 33 & 6 \\
\hline-1.00 & 5.00 & 0.1558 & 0.1558 & 0.1558 & -11.4204 & -11.4204 & -527 & -527 & -502 & 25 & 5 \\
\hline-0.50 & 5.00 & 0.1558 & 0.1558 & 0.1558 & -8.2102 & -8.2102 & -490 & -490 & -476 & 14 & 3 \\
\hline 0.01 & 5.00 & 0.1558 & 0.1558 & 0.1558 & -4.9358 & -4.9358 & -447 & -447 & -447 & -0 & -0. \\
\hline 0.50 & 5.00 & 0.1558 & 0.1558 & 0.1558 & -1.7898 & -1.7898 & -393 & -393 & -418 & -24 & -6 \\
\hline 1.00 & 5.00 & 0.1558 & 0.1558 & 0.1558 & 1.4204 & 1.4204 & -286 & -286 & 384 & -98 & -29 \\
\hline 1.50 & 5.00 & 0.1558 & 0.1558 & 0.1558 & 4.6306 & 4.6306 & -229 & -229 & -347 & -118 & -41 \\
\hline 2.00 & 5.00 & 0.1558 & 0.1558 & 0.1558 & 7.8408 & 7.8408 & -186 & -186 & -303 & -117 & -48 \\
\hline 2.50 & 5.00 & 0.1558 & 0.1558 & 0.1558 & 11.0510 & 11.0510 & -148 & -148 & -224 & -75 & -41 \\
\hline 3,00 & 5.00 & 0.1558 & 0.1558 & 0.1558 & 14.2613 & 14.2613 & -115 & -115 & -145 & -31 & -24 \\
\hline
\end{tabular}




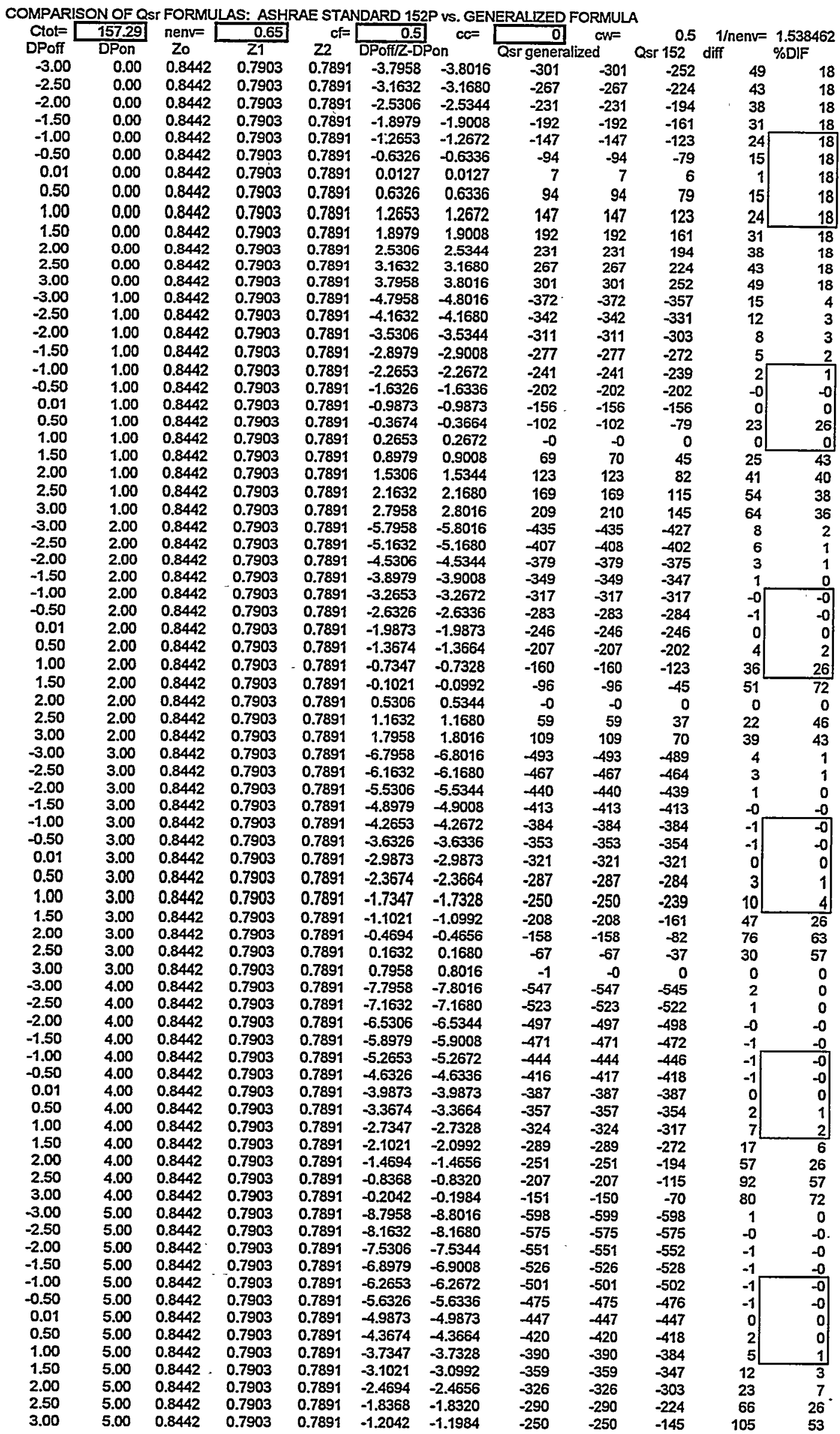


COMPARISON OF QST FORMULAS: ASHRAE STANDARD 152P vS. GENERALIZED FORMULA

\begin{tabular}{|c|c|c|c|c|c|c|c|c|c|c|c|}
\hline $\begin{array}{l}\text { Ctot= } \\
\text { DPoff }\end{array}$ & $\frac{157.29}{\text { DPon }}$ & $\begin{array}{c}\text { nenv= } \\
\text { Zo }\end{array}$ & $\frac{0.65}{21}$ & $22^{c f=1}$ & \begin{tabular}{|r|}
0.5 \\
DPoff $/ Z-D F$
\end{tabular} & on $c c=$ & \begin{tabular}{|r|}
0.25 \\
Qss genera
\end{tabular} & $\mathrm{cW}=$ & Qsr 152 & $\begin{array}{l}\text { 1/nenv= } \\
\text { diff }\end{array}$ & $\begin{array}{l}1.538462 \\
\% D I F\end{array}$ \\
\hline-3.00 & 0.00 & 0.6869 & 0.6666 & 0.6665 & -4.5004 & -4.5010 & -272 & -272 & -252 & 20 & 8 \\
\hline-2.50 & 0.00 & 0.6869 & 0.6666 & 0.6665 & -3.7504 & -3.7508 & -242 & -242 & -224 & 18 & 8 \\
\hline-2.00 & 0.00 & 0.6869 & 0.6666 & 0.6665 & -3.0003 & -3.0007 & -209 & -209 & -194 & 16 & 8 \\
\hline-1.50 & 0.00 & 0.6869 & 0.6666 & 0.6665 & -2.2502 & -2.2505 & -174 & -174 & -161 & 13 & 8 \\
\hline-1.00 & 0.00 & 0.6869 & 0.6666 & 0.6665 & -1.5001 & -1.5003 & -133 & -133 & -123 & 10 & 8 \\
\hline-0.50 & 0.00 & 0.6869 & 0.6666 & 0.6665 & -0.7501 & -0.7502 & -85 & -85 & -79 & 6 & 8 \\
\hline 0.01 & 0.00 & 0.6869 & 0.6666 & 0.6665 & 0.0150 & 0.0150 & 7 & 7 & 6 & 1 & 8 \\
\hline 0.50 & 0.00 & 0.6869 & 0.6666 & 0.6665 & 0.7501 & 0.7502 & 85 & 85 & 79 & 6 & 8 \\
\hline 1.00 & 0.00 & 0.6869 & 0.6666 & 0.6665 & 1.5001 & 1.5003 & 133 & 133 & 123 & 10 & 8 \\
\hline 1.50 & 0.00 & 0.6869 & 0.6666 & 0.6665 & 2.2502 & 2.2505 & 174 & 174 & 161 & 13 & 8 \\
\hline 2,00 & 0.00 & 0.6869 & 0.6666 & 0.6665 & 3.0003 & 3.0007 & 209 & 209 & 194 & 16 & 8 \\
\hline 2.50 & 0.00 & 0.6869 & 0.6666 & 0.6665 & 3.7504 & 3.7508 & 242 & 242 & 224 & 18 & 8 \\
\hline 3.00 & 0.00 & 0.6869 & 0.6666 & 0.6665 & 4.5004 & 4.5010 & 272 & 272 & 252 & 20 & 8 \\
\hline-3.00 & 1.00 & 0.6869 & 0.6666 & 0.6665 & -5.5004 & -5.5010 & -360 & -360 & -357 & 3 & 1 \\
\hline$-2,50$ & 1.00 & 0.6869 & 0.66666 & 0.6665 & -4.7504 & -4.7508 & -333 & -333 & -331 & 2 & 1 \\
\hline-2.00 & 1.00 & 0.6869 & 0.6666 & 0.6665 & -4.0003 & -4.0007 & -303 & -303 & -303 & 1 & 0 \\
\hline-1.50 & 1.00 & 0.6869 & 0.6666 & 0.6665 & -3.2502 & -3.2505 & -272 & -272 & -272 & -0 & -0 \\
\hline-1.00 & 1.00 & 0.6869 & 0.6666 & 0.6665 & -2.5001 & -2.5003 & -238 & -238 & -239 & -1 & -0 \\
\hline-0.50 & 1.00 & 0.6869 & 0.6666 & 0.6665 & -1.7501 & -1.7502 & -201 & -201 & -202 & -1 & -1 \\
\hline 0.01 & 1.00 & 0.6869 & 0.6666 & 0.6665 & -0.9850 & -0.9850 & -156 & -156 & -156 & 0 & 0 \\
\hline 0,50 & 1,00 & 0.6869 & 0.6666 & 0.6665 & -0.2499 & -0.2498 & -100 & -100 & -79 & 21 & 24 \\
\hline 1,00 & 1.00 & 0.6869 & 0.6666 & 0.6665 & 0.5001 & 0.5003 & -0 & 0 & 0 & 0 & 0 \\
\hline $\begin{array}{l}1.50 \\
2.00\end{array}$ & $\begin{array}{l}1.00 \\
1.00\end{array}$ & $\begin{array}{l}0.6869 \\
0.6869\end{array}$ & $\begin{array}{l}0.6666 \\
0.6666\end{array}$ & $\begin{array}{l}0.6665 \\
0.6665\end{array}$ & $\begin{array}{l}1.2502 \\
2.0003\end{array}$ & $\begin{array}{l}1.2505 \\
2.0007\end{array}$ & $\begin{array}{r}56 \\
101\end{array}$ & $\begin{array}{r}56 \\
101\end{array}$ & $\begin{array}{l}45 \\
82\end{array}$ & $\begin{array}{l}12 \\
19\end{array}$ & $\begin{array}{l}23 \\
21\end{array}$ \\
\hline 2.50 & 1.00 & 0.6869 & 0.6666 & 0.6665 & 2.7504 & 2.7508 & 140 & 140 & 115 & 25 & 20 \\
\hline 3.00 & 1.00 & 0.6869 & 0.6666 & 0.6665 & 3.5004 & 3.5010 & 175 & 175 & 145 & 30 & 18 \\
\hline-3.00 & 2.00 & 0.6869 & 0.6666 & 0.6665 & -6.5004 & -6.5010 & -427 & -427 & -427 & -0 & -0 \\
\hline-2.50 & 2.00 & 0.6869 & 0.6666 & 0.6665 & -5.7504 & -5.7508 & -401 & -401 & -402 & -1 & -0 \\
\hline$-2,00$ & 2.00 & 0.6869 & 0.6666 & 0.6665 & -5.0003 & -5.0007 & -374 & -374 & -375 & -2 & -0 \\
\hline-1.50 & 2.00 & 0.6869 & 0.6666 & 0.6665 & -4.2502 & -4.2505 & -345 & -345 & -347 & -2 & -1 \\
\hline$-1,00$ & 2.00 & 0.6869 & 0.6666 & 0.6665 & -3.5001 & -3.5003 & -315 & -315 & -317 & -2 & -1 \\
\hline-0.50 & 2.00 & 0.6869 & 0.6666 & 0.6665 & -2.7501 & -2.7502 & -282 & -282 & -284 & -2 & -1 \\
\hline 0.01 & 2.00 & 0.6869 & 0.6666 & 0.6665 & -1.9850 & -1.9850 & -246 & -246 & -246 & 0 & 0 \\
\hline 0,50 & 2.00 & 0.6869 & 0.6666 & 0.6665 & -1.2499 & -1.2498 & -206 & -206 & -202 & 4 & 2 \\
\hline 1.00 & 2.00 & 0.6869 & 0.6666 & 0.6665 & -0.4999 & -0.4997 & -157 & -157 & -123 & 33 & 24 \\
\hline 1.50 & 2.00 & 0.6869 & 0.6666 & 0.6665 & 0.2502 & 0.2505 & -62 & -62 & -45 & 17 & 32 \\
\hline 2.00 & 2.00 & 0.6869 & 0.6666 & 0.6665 & 1.0003 & 1.0007 & -0 & -0 & 0 & 0 & 0 \\
\hline 2.50 & 2.00 & 0.6869 & 0.6666 & 0.6665 & 1.7504 & 1.7508 & 48 & 48 & 37 & 10 & 24 \\
\hline 3,00 & 2.00 & 0.6869 & 0.6666 & 0.6665 & 2.5004 & 2.5010 & 88 & 88 & 70 & 18 & 23 \\
\hline-3.00 & 3.00 & 0.6869 & 0.6666 & 0.6665 & -7.5004 & -7.5010 & -486 & -486 & -489 & -2 & -0 \\
\hline-2.50 & 3.00 & 0.6869 & 0.6666 & 0.6665 & -6.7504 & -6.7508 & -462 & -462 & -464 & -3 & -1 \\
\hline-2.00 & 3.00 & 0.6869 & 0.6666 & 0.6665 & -6.0003 & -6.0007 & -436 & -436 & -439 & -3 & -1 \\
\hline-1.50 & 3.00 & 0.6869 & 0.6666 & 0.6665 & -5.2502 & -5.2505 & -410 & -410 & -413 & -3 & -1 \\
\hline-1.00 & 3.00 & 0.6869 & 0.6666 & 0.6665 & -4.5001 & -4.5003 & -382 & -382 & -384 & -2 & -1 \\
\hline$-0,50$ & 3.00 & 0.6869 & 0.6666 & 0.6665 & -3.7501 & -3.7502 & -353 & -353 & -354 & -2 & -0 \\
\hline 0.01 & 3.00 & 0.6869 & 0.6666 & 0.6665 & -2.9850 & -2.9850 & -321 & -321 & -321 & 0 & 이 \\
\hline 0.50 & 3.00 & 0.6869 & 0.6666 & 0.6665 & -2.2499 & -2.2498 & -287 & -287 & -284 & 3 & 1 \\
\hline 1,00 & 3,00 & 0.6869 & 0.6666 & 0.6665 & -1.4999 & -1.4997 & -249 & -249 & -239 & 10 & 4 \\
\hline 1.50 & 3.00 & 0.6869 & 0.6666 & 0.6665 & -0.7498 & -0.7495 & -204 & -204 & -161 & 43 & 24 \\
\hline 2.00 & 3.00 & 0.6869 & 0.6666 & 0.6665 & 0.0003 & 0.0007 & -129 & -128 & -82 & 46 & 44 \\
\hline 2,50 & 3.00 & 0.6869 & 0.6666 & 0.6665 & 0.7504 & 0.7508 & -50 & -50 & -37 & 13 & 29 \\
\hline 3,00 & 3,00 & 0.6869 & 0.6666 & 0.6665 & 1.5004 & 1.5010 & -0 & -0 & 0 & 0 & 0 \\
\hline-3.00 & 4.00 & 0.6869 & 0.6666 & 0.6665 & -8.5004 & -8.5010 & .542 & -542 & -545 & -3 & -1 \\
\hline$-2,50$ & 4.00 & 0.6869 & 0.6666 & 0.6665 & -7.7504 & -7.7508 & -518 & -518 & -522 & -3 & -1 \\
\hline$-2,00$ & 4.00 & 0.6869 & 0.6666 & 0.6665 & -7.0003 & -7.0007 & -494 & -494 & -498 & -3 & -1 \\
\hline-1.50 & 4.00 & 0.6869 & 0.6666 & 0.6665 & -6.2502 & -6.2505 & -469 & -469 & -472 & -3 & -1 \\
\hline-1.00 & 4.00 & 0.6869 & 0.6666 & 0.6665 & -5.5001 & -5.5003 & -443 & -443 & -446 & -3 & -1 \\
\hline$-0,50$ & 4.00 & 0.6869 & 0.6666 & 0.6665 & -4.7501 & -4.7502 & -416 & -416 & -418 & -2 & -0 \\
\hline 0.01 & 4.00 & 0.6869 & 0.6666 & 0.6665 & -3.9850 & -3.9850 & -387 & -387 & -387 & 0 & 0 \\
\hline 0.50 & 4.00 & 0.6869 & 0.6666 & 0.6665 & -3.2499 & -3.2498 & -357 & -357 & -354 & 3 & 1 \\
\hline 1.00 & 4.00 & 0.6869 & 0.6666 & 0.6665 & -2.4999 & -2.4997 & -324 & -324 & -317 & 7 & 2 \\
\hline 1.50 & 4.00 & 0.6869 & 0.6666 & 0.6665 & -1.7498 & -1.7495 & -288 & -288 & -272 & 15 & 5 \\
\hline 2.00 & 4.00 & 0.6869 & 0.6666 & 0.6665 & -0.9997 & -0.9993 & -246 & -246 & -194 & 52 & 24 \\
\hline 2.50 & 4.00 & 0.6869 & 0.6666 & 0.6665 & -0.2496 & -0.2492 & -191 & -191 & -115 & 76 & 49 \\
\hline 3.00 & 4.00 & 0.6869 & 0.6666 & 0.6665 & 0.5004 & 0.5010 & -97 & -97 & -70 & 27 & 32 \\
\hline-3.00 & 5.00 & 0.6869 & 0.6666 & 0.6665 & -9.5004 & -9.5010 & -594 & -594 & -598 & -4 & -1 \\
\hline-2.50 & 5.00 & 0.6869 & 0.6666 & 0.6665 & -8.7504 & -8.7508 & -571 & -571 & -575 & -4 & -1 \\
\hline$-2,00$ & 5.00 & 0.6869 & 0.6666 & 0.6665 & -8.0003 & -8.0007 & -548 & -548 & -552 & -4 & -1 \\
\hline-1.50 & 5.00 & 0.6869 & 0.6666 & 0.6665 & -7.2502 & -7.2505 & -525 & -525 & -528 & -3 & -1 \\
\hline-1.00 & 5.00 & 0.6869 & 0.6666 & 0.6665 & -6.5001 & -6.5003 & -500 & -500 & -502 & -3 & -1 \\
\hline-0.50 & 5.00 & 0.6869 & 0.6666 & 0.6665 & -5.7501 & -5.7502 & -474 & -474 & -476 & -2 & -0 \\
\hline 0.01 & 5.00 & 0.6869 & 0.6666 & 0.6665 & -4.9850 & -4.9850 & -447 & -447 & -447 & 0 & 0 \\
\hline 0.50 & 5.00 & 0.6869 & 0.6666 & 0.6665 & -4.2499 & -4.2498 & -420 & -420 & -418 & 2 & 1 \\
\hline 1.00 & 5.00 & 0.6869 & 0.6666 & 0.6665 & -3.4999 & -3.4997 & -390 & -390 & -384 & $\overline{6}$ & 1 \\
\hline 1.50 & 5.00 & 0.6869 & 0.6666 & 0.6665 & -2.7498 & -2.7495 & -358 & -358 & -347 & 11 & 3 \\
\hline 2.00 & 5.00 & 0.6869 & 0.6666 & 0.6665 & -1.9997 & -1.9993 & -323 & -323 & -303 & 21 & 7 \\
\hline 2.50 & 5.00 & 0.6869 & 0.6666 & 0.6665 & -1.2496 & -1.2492 & -284 & -284 & -224 & 60 & 24 \\
\hline 3.00 & 5,00 & 0.6869 & 0.6666 & 0.6665 & $-0,4996$ & -0.4990 & -236 & -236 & -145 & 90 & 47 \\
\hline
\end{tabular}


COMPARISON OF QST FORMULAS: ASHRAE STANDARD 152P VS. GENERALIZED FORMULA

\begin{tabular}{|c|c|c|c|c|c|c|c|c|c|c|c|}
\hline $\begin{array}{l}\text { Ctot= } \\
\text { DPoff }\end{array}$ & $\frac{157.29}{\text { DPon }}$ & $\begin{array}{c}\text { nenv= } \\
\text { Zo }\end{array}$ & $\frac{0.65}{\mathrm{Z1}}$ & $\mathrm{Z2}$ & \begin{tabular}{|r|}
0.5 \\
DPoff $/ 2-D$
\end{tabular} & $\int_{\text {Pon }} c c=$ & \begin{tabular}{|r|}
0.5 \\
Qsr genera
\end{tabular} & $\begin{array}{l}\text { cw= } \\
\text { ized }\end{array}$ & $\operatorname{Qsr} 152^{0}$ & $\begin{array}{l}1 / n e n v= \\
\text { diff }\end{array}$ & $\begin{aligned}= & 1.538462 \\
& \% \text { DIF }\end{aligned}$ \\
\hline-3.00 & 0.00 & 0.5000 & 0.5000 & 0.5000 & -6.0000 & -6.0000 & -252 & -252 & -252 & 0 & 0 \\
\hline-2.50 & 0.00 & 0.5000 & 0.5000 & 0.5000 & -5.0000 & -5.0000 & -224 & -224 & -224 & 0 & 0 \\
\hline-2.00 & 0.00 & 0.5000 & 0.5000 & 0.5000 & -4.0000 & -4.0000 & -194 & -194 & -194 & 0 & 0 \\
\hline-1.50 & 0.00 & 0.5000 & 0.5000 & 0.5000 & 3.0000 & -3.0000 & -161 & -161 & -161 & 0 & 0 \\
\hline-1.00 & 0.00 & 0.5000 & 0.5000 & 0.5000 & -2.0000 & -2.0000 & -123 & -123 & -123 & 0 & 0 \\
\hline-0.50 & 0.00 & 0.5000 & 0.5000 & 0.5000 & -1.0000 & -1.0000 & -79 & -79 & -79 & 0 & 0 \\
\hline 0.01 & 0.00 & 0.5000 & 0.5000 & 0.5000 & 0.0200 & 0.0200 & 6 & 6 & 6 & 0 & 0 \\
\hline 0.50 & 0.00 & 0.5000 & 0.5000 & 0.5000 & 1.0000 & 1.0000 & 79 & 79 & 79 & 0 & 0 \\
\hline 1.00 & 0.00 & 0.5000 & 0.5000 & 0.5000 & 2.0000 & 2.0000 & 123 & 123 & 123 & 0 & 0 \\
\hline 1.50 & 0.00 & 0.5000 & 0.5000 & 0.5000 & 3.0000 & 3.0000 & 161 & 161 & 161 & 0 & 0 \\
\hline 2.00 & 0.00 & 0.5000 & 0.5000 & 0.5000 & 4.0000 & 4.0000 & 194 & 194 & 194 & 0 & 0 \\
\hline 2.50 & 0.00 & 0.5000 & 0.5000 & 0.5000 & 5.0000 & 5.0000 & 224 & 224 & 224 & 0 & 0 \\
\hline 3.00 & 0.00 & 0.5000 & 0.5000 & 0.5000 & 6.0000 & 6.0000 & 252 & 252 & 252 & o & 0 \\
\hline-3.00 & 1.00 & 0.5000 & 0.5000 & 0.5000 & -7.0000 & -7.0000 & -357 & -357 & -357 & 0 & 0 \\
\hline-2.50 & 1.00 & 0.5000 & 0.5000 & 0.5000 & -6.0000 & -6.0000 & -331 & -331 & 331 & 0 & 0 \\
\hline-2.00 & 1.00 & 0.5000 & 0.5000 & 0.5000 & -5.0000 & -5.0000 & -303 & -303 & -303 & 0 & 0 \\
\hline-1.50 & 1.00 & 0.5000 & 0.5000 & 0.5000 & -4.0000 & -4.0000 & -272 & -272 & -272 & 0 & 0 \\
\hline-1.00 & 1.00 & 0.5000 & 0.5000 & 0.5000 & 3.0000 & -3.0000 & -239 & -239 & -239 & 0 & 0 \\
\hline-0.50 & 1.00 & 0.5000 & 0.5000 & 0.5000 & -2.0000 & -2.0000 & -202 & -202 & -202 & 0 & 0 \\
\hline 0.01 & 1.00 & 0.5000 & 0.5000 & 0.5000 & -0.9800 & -0.9800 & -156 & -156 & -156 & 0 & 0 \\
\hline 0.50 & 1.00 & 0.5000 & 0.5000 & 0.5000 & 0.0000 & 0.0000 & -79 & -79 & -79 & 0 & 0 \\
\hline 1.00 & 1.00 & 0.5000 & 0.5000 & 0.5000 & 1.0000 & 1.0000 & 0 & 0 & 0 & 0 & 0 \\
\hline 1.50 & 1.00 & 0.5000 & 0.5000 & 0.5000 & 2.0000 & 2.0000 & 45 & 45 & 45 & 0 & 0 \\
\hline 2.00 & 1.00 & 0.5000 & 0.5000 & 0.5000 & 3.0000 & 3.0000 & 82 & 82 & 82 & 0 & 0 \\
\hline 2.50 & 1.00 & 0.5000 & 0.5000 & 0.5000 & 4.0000 & 4.0000 & 115 & 115 & 115 & 0 & 0 \\
\hline 3.00 & 1.00 & 0.5000 & 0.5000 & 0.5000 & 5.0000 & 5.0000 & 145 & 145 & 145 & 0 & 0 \\
\hline-3.00 & 2.00 & 0.5000 & 0.5000 & 0.5000 & -8.0000 & -8.0000 & -427 & -427 & -427 & 0 & 0 \\
\hline-2.50 & 2.00 & 0.5000 & 0.5000 & 0.5000 & -7.0000 & -7.0000 & -402 & -402 & -402 & 0 & 0 \\
\hline-2.00 & 2.00 & 0.5000 & 0.5000 & 0.5000 & -6.0000 & -6.0000 & -375 & -375 & -375 & 0 & 0 \\
\hline-1.50 & 2.00 & 0.5000 & 0.5000 & 0.5000 & -5.0000 & -5.0000 & -347 & -347 & -347 & 0 & 0 \\
\hline-1.00 & 2.00 & 0.5000 & 0.5000 & 0.5000 & -4.0000 & -4.0000 & -317 & -317 & -317 & 0 & 0 \\
\hline-0.50 & 2.00 & 0.5000 & 0.5000 & 0.5000 & -3.0000 & -3.0000 & -284 & -284 & -284 & 0 & 0 \\
\hline 0.01 & 2.00 & 0.5000 & 0.5000 & 0.5000 & -1.9800 & -1.9800 & -246 & -246 & -246 & 0 & 0 \\
\hline 0.50 & 2.00 & 0.5000 & 0.5000 & 0.5000 & -1.0000 & -1.0000 & -202 & -202 & -202 & 0 & 0 \\
\hline 1.00 & 2.00 & 0.5000 & 0.5000 & 0.5000 & 0.0000 & .0 .0000 & -123 & -123 & -123 & 0 & 0 \\
\hline 1.50 & 2.00 & 0.5000 & 0.5000 & 0.5000 & 1.0000 & 1.0000 & -45 & -45 & -45 & 0 & 0 \\
\hline 2.00 & 2.00 & 0.5000 & 0.5000 & 0.5000 & 2.0000 & 2.0000 & 0 & D & 0 & D & D \\
\hline 2.50 & 2.00 & 0.5000 & 0.5000 & 0.5000 & 3.0000 & 3.0000 & 37 & 37 & 37 & 0 & 0 \\
\hline 3.00 & 2.00 & 0.5000 & 0.5000 & 0.5000 & 4.0000 & 4.0000 & 70 & 70 & 70 & 0 & 0 \\
\hline-3.00 & 3.00 & 0.5000 & 0.5000 & 0.5000 & -9.0000 & -9.0000 & -489 & -489 & -489 & 0 & 0 \\
\hline-2.50 & 3.00 & 0.5000 & 0.5000 & 0.5000 & $-8,0000$ & -8.0000 & -464 & -464 & -464 & 0 & 0 \\
\hline-2.00 & 3.00 & 0.5000 & 0.5000 & 0.5000 & -7.0000 & -7.0000 & -439 & -439 & -439 & 0 & 0 \\
\hline-1.50 & 3.00 & 0.5000 & 0.5000 & 0.5000 & -6.0000 & -6.0000 & -413 & -413 & -413 & 0 & 0 \\
\hline-1.00 & 3.00 & 0.5000 & 0.5000 & 0.5000 & -5.0000 & -5.0000 & -384 & -384 & -384 & 0 & 0 \\
\hline-0.50 & 3.00 & 0.5000 & 0.5000 & 0.5000 & -4.0000 & -4.0000 & -354 & -354 & -354 & 0 & 0 \\
\hline 0.01 & 3.00 & 0.5000 & 0.5000 & 0.5000 & -2.9800 & -2.9800 & -321 & -321 & -321 & 0 & 0 \\
\hline 0.50 & 3.00 & 0.5000 & 0.5000 & 0.5000 & -2.0000 & -2.0000 & -284 & -284 & -284 & 0 & 0 \\
\hline 1.00 & 3.00 & 0.5000 & 0.5000 & 0.5000 & -1.0000 & -1.0000 & -239 & -239 & -239 & 0 & 0 \\
\hline 1.50 & 3.00 & 0.5000 & 0.5000 & 0.5000 & 0.0000 & 0.0000 & -161 & -161 & -161 & 0 & 0 \\
\hline 2.00 & 3.00 & 0.5000 & 0.5000 & 0.5000 & 1.0000 & 1.0000 & -82 & -82 & -82 & 0 & 0 \\
\hline 2.50 & 3.00 & 0.5000 & 0.5000 & 0.5000 & 2.0000 & 2.0000 & -37 & -37 & 37 & 0 & 0 \\
\hline 3.00 & 3.00 & 0.5000 & 0.5000 & 0.5000 & 3.0000 & 3.0000 & 0 & 0 & 0 & 0 & 0 \\
\hline-3.00 & 4.00 & 0.5000 & 0.5000 & 0.5000 & -10.0000 & -10.0000 & -545 & -545 & -545 & 0 & 0 \\
\hline-2.50 & 4.00 & 0.5000 & 0.5000 & 0.5000 & -9.0000 & -9.0000 & -522 & -522 & -522 & 0 & 0 \\
\hline-2.00 & 4.00 & 0.5000 & 0.5000 & 0.5000 & -8.0000 & -8.0000 & -498 & -498 & -498 & 0 & 0 \\
\hline-1.50 & 4.00 & 0.5000 & 0.5000 & 0.5000 & -7.0000 & -7.0000 & -472 & -472 & -472 & 0 & 0 \\
\hline-1.00 & 4.00 & 0.5000 & 0.5000 & 0.5000 & -6.0000 & -6.0000 & -446 & -446 & -446 & 0 & 0 \\
\hline-0.50 & 4.00 & 0.5000 & 0.5000 & 0.5000 & -5.0000 & -5.0000 & -418 & -418 & -418 & 0 & 0 \\
\hline 0.01 & 4.00 & 0.5000 & 0.5000 & 0.5000 & -3.9800 & -3.9800 & -387 & -387 & -387 & 0 & 0 \\
\hline 0.50 & 4.00 & 0.5000 & 0.5000 & 0.5000 & -3.0000 & -3.0000 & -354 & -354 & -354 & 0 & 0 \\
\hline 1.00 & 4.00 & 0.5000 & 0.5000 & 0.5000 & -2.0000 & -2.0000 & -317 & -317 & -317 & 0 & 0 \\
\hline 1.50 & 4.00 & 0.5000 & 0.5000 & 0.5000 & -1.0000 & -1.0000 & -272 & -272 & -272 & 0 & 0 \\
\hline 2.00 & 4.00 & 0.5000 & 0.5000 & 0.5000 & 0.0000 & 0.0000 & -194 & -194 & -194 & 0 & 0 \\
\hline 2.50 & 4.00 & 0.5000 & 0.5000 & 0.5000 & 1.0000 & 1.0000 & -115 & -115 & -115 & 0 & 0 \\
\hline 3.00 & 4.00 & 0.5000 & 0.5000 & 0.5000 & 2.0000 & 2.0000 & -70 & -70 & -70 & 0 & 0 \\
\hline-3.00 & 5.00 & 0.5000 & 0.5000 & 0.5000 & -11.0000 & -11.0000 & -598 & -598 & -598 & 0 & 0 \\
\hline-2.50 & 5.00 & 0.5000 & 0.5000 & 0.5000 & -10.0000 & -10.0000 & -575 & -575 & -575 & 0 & 0 \\
\hline-2.00 & 5.00 & 0.5000 & 0.5000 & 0.5000 & -9.0000 & -9.0000 & -552 & -552 & -552 & 0 & 0 \\
\hline-1.50 & 5.00 & 0.5000 & 0.5000 & 0.5000 & -8.0000 & -8.0000 & -528 & -528 & -528 & 0 & 0 \\
\hline-1.00 & 5.00 & 0.5000 & 0.5000 & 0.5000 & -7.0000 & -7.0000 & -502 & -502 & -502 & 0 & 0 \\
\hline-0.50 & 5.00 & 0.5000 & 0.5000 & 0.5000 & -6.0000 & -6.0000 & -476 & -476 & -476 & 0 & 0 \\
\hline 0.01 & 5.00 & 0.5000 & 0.5000 & 0.5000 & -4.9800 & -4.9800 & -447 & -447 & -447 & 0 & 0 \\
\hline 0.50 & 5.00 & 0.5000 & 0.5000 & 0.5000 & -4.0000 & -4.0000 & -418 & -418 & -418 & 0 & 0 \\
\hline 1.00 & 5.00 & 0.5000 & 0.5000 & 0.5000 & -3.0000 & -3.0000 & -384 & -384 & -384 & 0 & 0 \\
\hline 1.50 & 5.00 & 0.5000 & 0.5000 & 0.5000 & -2.0000 & -2.0000 & -347 & -347 & -347 & 0 & 0 \\
\hline 2.00 & 5.00 & 0.5000 & 0.5000 & 0.5000 & -1.0000 & -1.0000 & -303 & -303 & -303 & 0 & 0 \\
\hline 2.50 & 5.00 & 0.5000 & 0.5000 & 0.5000 & 0.0000 & 0.0000 & -224 & -224 & -224 & 0 & 0 \\
\hline 3.00 & 5.00 & 0.5000 & 0.5000 & 0.5000 & 1.0000 & 1.0000 & -145 & -145 & -145 & 0 & 0 \\
\hline
\end{tabular}


COMPARISON OF QST FORMULAS: ASHRAE STANDARD 152P vS. GENERALIZED FORMULA

\begin{tabular}{|c|c|c|c|c|c|c|c|c|c|c|c|}
\hline $\begin{array}{l}\text { Ctot= } \\
\text { DPoff }\end{array}$ & $\frac{157.29}{\text { DPon }}$ & $\begin{array}{c}\text { nenv }= \\
\text { Zo }\end{array}$ & $\frac{0.65}{\mathrm{Z1}}$ & $22^{c f=}$ & \begin{tabular}{|r|}
0.75 \\
DPoff/Z-D
\end{tabular} & on $c c=$ & \begin{tabular}{|r|}
0 \\
Qsr genera
\end{tabular} & $c W=$ & $\begin{array}{c}0.25 \\
\text { Qsr } 152\end{array}$ & $\begin{array}{l}\text { 1/nenve } \\
\text { diff }\end{array}$ & $\begin{array}{l}1.538462 \\
\% \text { DIF }\end{array}$ \\
\hline-3.00 & 0.00 & 0.9523 & 0.9316 & 0.9304 & -3.2203 & -3.2244 & -303 & -304 & -252 & 51 & 19 \\
\hline-2.50 & 0.00 & 0.9523 & 0.9316 & 0.9304 & -2.6836 & -2.6870 & -269 & -270 & -224 & 46 & 19 \\
\hline-2.00 & 0.00 & 0.9523 & 0.9316 & 0.9304 & -2.1468 & -2.1496 & -233 & -233 & -194 & 40 & 19 \\
\hline-1.50 & 0.00 & 0.9523 & 0.9316 & 0.9304 & -1.6101 & -1.6122 & -193 & -193 & -161 & 33 & 19 \\
\hline-1.00 & 0.00 & 0.9523 & 0.9316 & 0.9304 & -1.0734 & -1.0748 & -148 & -149 & -123 & 25 & 19 \\
\hline-0.50 & 0.00 & 0.9523 & 0.9316 & 0.9304 & -0.5367 & -0.5374 & -95 & -95 & -79 & 16 & 19 \\
\hline 0.01 & 0.00 & 0.9523 & 0.9316 & 0.9304 & 0.0107 & 0.0107 & 7 & 7 & 6 & 1 & 18 \\
\hline 0.50 & 0.00 & 0.9523 & 0.9316 & 0.9304 & 0.5367 & 0.5374 & 95 & 95 & 79 & 16 & 19 \\
\hline 1.00 & 0.00 & 0.9523 & 0.9316 & 0.9304 & 1.0734 & 1.0748 & 148 & 149 & 123 & 25 & 19 \\
\hline 1.50 & 0.00 & 0.9523 & 0.9316 & 0.9304 & 1.6101 & 1.6122 & 193 & 193 & 161 & 33 & 19 \\
\hline 2,00 & 0.00 & 0.9523 & 0.9316 & 0.9304 & 2.1468 & 2.1496 & 233 & 233 & 194 & 40 & 19 \\
\hline 2.50 & 0.00 & 0.9523 & 0.9316 & 0.9304 & 2.6836 & 2.6870 & 269 & 270 & 224 & 46 & 19 \\
\hline 3.00 & 0.00 & 0.9523 & 0.9316 & 0.9304 & 3.2203 & 3.2244 & 303 & 304 & 252 & 51 & 19 \\
\hline-3.00 & 1.00 & 0.9523 & 0.9316 & 0.9304 & -4.2203 & -4.2244 & -373 & -373 & -357 & 16 & 4 \\
\hline-2.50 & 1.00 & 0.9523 & 0.9316 & 0.9304 & -3.6836 & -3.6870 & -343 & -343 & -331 & 12 & 4 \\
\hline-2.00 & 1.00 & 0.9523 & 0.9316 & 0.9304 & -3.1468 & -3.1496 & -311 & -311 & -303 & 9 & 3 \\
\hline-1.50 & 1.00 & 0.9523 & 0.9316 & 0.9304 & -2.6101 & -2.6122 & -277 & -277 & -272 & 5 & 2 \\
\hline-1.00 & 1.00 & 0.9523 & 0.9316 & 0.9304 & -2.0734 & -2.0748 & -241 & -241 & -239 & 2 & 1 \\
\hline-0.50 & 1.00 & 0.9523 & 0.9316 & 0.9304 & -1.5367 & -1.5374 & -202 & -202 & -202 & -0 & -0 \\
\hline 0.01 & 1.00 & 0.9523 & 0.9316 & 0.9304 & -0.9893 & -0.9893 & -156 & -156 & -156 & 0 & 0 \\
\hline 0.50 & 1.00 & 0.9523 & 0.9316 & 0.9304 & -0.4633 & -0.4626 & -103 & -103 & -79 & 25 & 27 \\
\hline 1.00 & 1.00 & 0.9523 & 0.9316 & 0.9304 & 0.0734 & 0.0748 & -0 & -0 & 0 & 0 & 1 \\
\hline 1.50 & 1.00 & 0.9523 & 0.9316 & 0.9304 & 0.6101 & 0.6122 & 77 & 78 & 45 & 33 & 54 \\
\hline 2.00 & 1.00 & 0.9523 & 0.9316 & 0.9304 & 1.1468 & 1.1496 & 132 & 132 & 82 & 50 & 47 \\
\hline 2,50 & 1.00 & 0.9523 & 0.9316 & 0.9304 & 1.6836 & 1.6870 & 178 & 178 & 115 & 63 & 43 \\
\hline 3.00 & 1.00 & 0.9523 & 0.9316 & 0.9304 & 2.2203 & 2.2244 & 218 & 219 & 145 & 73 & 40 \\
\hline-3.00 & 2.00 & 0.9523 & 0.9316 & 0.9304 & -5.2203 & -5.2244 & -435 & -435 & -427 & 8 & 2 \\
\hline-2.50 & 2.00 & 0.9523 & 0.9316 & 0.9304 & -4.6836 & -4.6870 & -407 & -408 & -402 & 6 & 1 \\
\hline-2.00 & 2.00 & 0.9523 & 0.9316 & 0.9304 & -4.1468 & -4.1495 & -379 & -379 & -375 & 3 & 1 \\
\hline-1.50 & 2.00 & 0.9523 & 0.9316 & 0.9304 & 3.6101 & -3.6122 & -348 & -348 & -347 & 1 & 0 \\
\hline-1.00 & 2.00 & 0.9523 & 0.9316 & 0.9304 & -3.0734 & -3.0748 & -317 & -317 & -317 & -0 & -0 \\
\hline$-0,50$ & 2.00 & 0.9523 & 0.9316 & 0.9304 & -2.5367 & -2.5374 & -283 & -283 & -284 & -1 & -0 \\
\hline 0,01 & 2.00 & 0.9523 & 0.9316 & 0.9304 & -1.9893 & -1.9893 & -246 & -246 & -246 & 0 & 0 \\
\hline 0.50 & 2.00 & 0.9523 & 0.9316 & 0.9304 & -1.4633 & -1.4626 & -207 & -207 & -202 & 5 & 3 \\
\hline 1.00 & 2.00 & 0.9523 & 0.9316 & 0.9304 & -0.9266 & -0.9252 & -162 & -162 & -123 & 39 & 27 \\
\hline 1.50 & 2.00 & 0.9523 & 0.9316 & 0.9304 & -0.3899 & -0.3878 & -107 & -107 & -45 & 62 & 82 \\
\hline 2.00 & 2.00 & 0.9523 & 0.9316 & 0.9304 & 0.1468 & 0.1496 & -0 & -0 & 0 & 0 & 2 \\
\hline 2.50 & 2.00 & 0.9523 & 0.9316 & 0.9304 & 0.6836 & 0.6870 & 69 & 69 & 37 & 32 & 60 \\
\hline 3.00 & 2.00 & 0.9523 & 0.9316 & 0.9304 & 1.2203 & 1.2244 & 121 & 122 & 70 & 51 & 54 \\
\hline-3.00 & 3.00 & 0.9523 & 0.9316 & 0.9304 & -6.2203 & -6.2244 & -493 & -493 & -489 & 4 & 1 \\
\hline-2.50 & 3.00 & 0.9523 & 0.9316 & 0.9304 & -5.6836 & -5.6870 & -467 & -467 & -464 & 2 & 1 \\
\hline-2.00 & 3.00 & 0.9523 & 0.9316 & 0.9304 & -5.1468 & -5.1496 & -440 & -440 & -439 & 1 & 0 \\
\hline$-1,50$ & 3.00 & 0.9523 & 0.9316 & 0.9304 & -4.6101 & -4.6122 & -412 & -412 & -413 & -0 & -0 \\
\hline-1.00 & 3.00 & 0.9523 & 0.9316 & 0.9304 & -4.0734 & -4.0748 & -383 & -383 & -384 & -1 & -0 \\
\hline-0.50 & 3.00 & 0.9523 & 0.9316 & 0.9304 & -3.5367 & -3.5374 & -353 & -353 & -354 & -1 & -0 \\
\hline 0.01 & 3.00 & 0.9523 & 0.9316 & 0.9304 & -2.9893 & -2.9893 & -321 & -321 & 321 & 0 & 0 \\
\hline 0,50 & 3.00 & 0.9523 & 0.9316 & 0.9304 & -2.4633 & -2.4626 & -287 & -287 & -284 & 3 & 1 \\
\hline 1.00 & 3.00 & 0.9523 & 0.9316 & 0.9304 & -1.9266 & -1.9252 & -251 & -251 & -239 & 12 & 5 \\
\hline 1.50 & 3.00 & 0.9523 & 0.9316 & 0.9304 & -1.3899 & -1.3878 & -211 & -211 & -161 & 51 & 27 \\
\hline 2.00 & 3.00 & 0.9523 & 0.9316 & 0.9304 & -0.8532 & -0.8504 & -166 & -166 & -82 & 84 & 68 \\
\hline 2.50 & 3.00 & 0.9523 & 0.9316 & 0.9304 & -0.3164 & -0.3130 & -109 & -108 & -37 & 71 & 98 \\
\hline 3.00 & 3.00 & 0.9523 & 0.9316 & 0.9304 & 0.2203 & 0.2244 & $\begin{array}{r}-1 \\
-1\end{array}$ & -0 & 0 & 0 & 3 \\
\hline-3.00 & 4.00 & 0.9523 & 0.9316 & 0.9304 & -7.2203 & -7.2244 & -547 & -547 & -545 & 2 & 0 \\
\hline-2.50 & 4.00 & 0.9523 & 0.9316 & 0.9304 & -6.6836 & -6.6870 & -522 & -522 & -522 & 1 & 0 \\
\hline$-2,00$ & 4.00 & 0.9523 & 0.9316 & 0.9304 & -6.1468 & -6.1496 & -497 & -497 & -498 & -1 & -0 \\
\hline-1.50 & 4.00 & 0.9523 & 0.9316 & 0.9304 & -5.6101 & -5.6122 & -471 & -471 & -472 & -1 & -0 \\
\hline$-1,00$ & 4.00 & 0.9523 & 0.9316 & 0.9304 & -5.0734 & -5.0748 & -444 & -444 & -446 & -2 & -0 \\
\hline-0.50 & 4.00 & 0.9523 & 0.9316 & 0.9304 & -4.5367 & -4.5374 & -416 & -416 & -418 & -1 & -0 \\
\hline 0.01 & 4.00 & 0.9523 & 0.9316 & 0.9304 & -3.9893 & -3.9893 & -387 & -387 & -387 & 0 & 0 \\
\hline 0,50 & 4.00 & 0.9523 & 0.9316 & 0.9304 & -3.4633 & -3.4626 & -357 & -357 & -354 & 3 & 1 \\
\hline 1.00 & 4.00 & 0.9523 & 0.9316 & 0.9304 & -2.9266 & -2.9252 & -325 & -325 & -317 & 8 & 3 \\
\hline 1.50 & 4.00 & 0.9523 & 0.9316 & 0.9304 & -2.3899 & -2.3878 & -291 & -291 & -272 & 19 & 7 \\
\hline 2.00 & 4.00 & 0.9523 & 0.9316 & 0.9304 & -1.8532 & -1.8504 & -255 & -255 & -194 & 61 & 27 \\
\hline 2.50 & 4.00 & 0.9523 & 0.9316 & 0.9304 & -1.3164 & -1.3130 & -215 & -214 & -115 & 99 & 60 \\
\hline 3,00 & 4.00 & 0.9523 & 0.9316 & 0.9304 & -0.7797 & -0.7756 & -168 & -168 & -70 & 98 & 82 \\
\hline-3.00 & 5.00 & 0.9523 & 0.9316 & 0.9304 & -8.2203 & -8.2244 & -598 & -598 & -598 & 0 & 0 \\
\hline-2.50 & 5.00 & 0.9523 & 0.9316 & 0.9304 & -7.6836 & -7.6870 & -574 & -575 & -575 & -1 & -0 \\
\hline-2.00 & 5.00 & 0.9523 & 0.9316 & 0.9304 & -7.1468 & -7.1496 & -550 & -551 & -552 & -1 & -0 \\
\hline-1.50 & 5.00 & 0.9523 & 0.9316 & 0.9304 & -6.6101 & -6.6122 & -526 & -526 & -528 & -2 & -0 \\
\hline-1.00 & 5.00 & 0.9523 & 0.9316 & 0.9304 & -6.0734 & -6.0748 & -501 & -501 & -502 & -2 & -0 \\
\hline-0.50 & 5.00 & 0.9523 & 0.9316 & 0.9304 & -5.5367 & -5.5374 & -475 & -475 & -476 & -1 & -0 \\
\hline 0.01 & 5.00 & 0.9523 & 0.9316 & 0.9304 & -4.9893 & -4.9893 & -447 & -447 & -447 & 0 & 0 \\
\hline 0.50 & 5.00 & 0.9523 & 0.9316 & 0.9304 & -4.4633 & -4.4626 & -420 & -420 & -418 & 2 & 1 \\
\hline 1.00 & 5.00 & 0.9523 & 0.9316 & 0.9304 & -3.9266 & -3.9252 & -391 & -391 & -384 & 6 & 2 \\
\hline 1.50 & 5.00 & 0.9523 & 0.9316 & 0.9304 & -3.3899 & -3.3878 & -361 & -360 & -347 & 13 & 4 \\
\hline 2,00 & 5,00 & 0.9523 & 0.9316 & 0.9304 & -2.8532 & -2.8504 & -329 & -328 & -303 & 26 & 8 \\
\hline 2.50 & 5.00 & 0.9523 & 0.9316 & 0.9304 & -2.3164 & -2.3130 & -295 & -294 & -224 & 70 & 27 \\
\hline 30 & 500 & 0.9523 & 09316 & 0.9304 & -1.7797 & -17756 & -258 & -257 & -145 & 112 & 56 \\
\hline
\end{tabular}


COMPARISON OF QST FORMULAS: ASHRAE STANDARD 152P vS. GENERALIZED FORMULA

\begin{tabular}{|c|c|c|c|c|c|c|c|c|c|c|c|}
\hline $\begin{array}{l}\text { Ctot= } \\
\text { DPoff }\end{array}$ & $\begin{array}{l}157.29 \\
\text { DPon }\end{array}$ & $\begin{array}{c}\text { nenve } \\
\text { Zo }\end{array}$ & $\frac{0.65}{\mathrm{Z1}}$ & $22^{c f=}$ & \begin{tabular}{|r|}
0.75 \\
DPoff $/ Z-D$
\end{tabular} & on $c c=$ & $\begin{array}{r}0.25 \\
\text { Qsr geners }\end{array}$ & ed & Qsr $152^{0}$ & $\begin{array}{l}\text { 1/nenve } \\
\text { diff }\end{array}$ & $\begin{array}{l}1.538462 \\
\% \text { DIF }\end{array}$ \\
\hline-3.00 & 0.00 & 0.8442 & 0.8442 & 0.8442 & -3.5535 & -3.5535 & -269 & -269 & -252 & 17 & 6 \\
\hline-2.50 & 0.00 & 0.8442 & 0.8442 & 0.8442 & -2.9612 & -2.9612 & -239 & -239 & -224 & 15 & 6 \\
\hline-2.00 & 0.00 & 0.8442 & 0.8442 & 0.8442 & -2.3690 & -2.3690 & -207 & -207 & -194 & 13 & 6 \\
\hline-1.50 & 0.00 & 0.8442 & 0.8442 & 0.8442 & -1.7767 & -1.7767 & -171 & -171 & -161 & 11 & 6 \\
\hline-1.00 & 0.00 & 0.8442 & 0.8442 & 0.8442 & -1.1845 & -1.1845 & -132 & -132 & -123 & 8 & $\overline{6}$ \\
\hline-0.50 & 0.00 & 0.8442 & 0.8442 & 0.8442 & -0.5922 & -0.5922 & -84 & -84 & -79 & 5 & 6 \\
\hline 0.01 & 0.00 & 0.8442 & 0.8442 & 0.8442 & 0.0118 & 0.0118 & 7 & 7 & 6 & 0 & 6 \\
\hline 0.50 & 0.00 & 0.8442 & 0.8442 & 0.8442 & 0.5922 & 0.5922 & 84 & 84 & 79 & 5 & 6 \\
\hline 1.00 & 0.00 & 0.8442 & 0.8442 & 0.8442 & 1.1845 & 1.1845 & 132 & 132 & 123 & 8 & 6 \\
\hline 1.50 & 0.00 & 0.8442 & 0.8442 & 0.8442 & 1.7767 & 1.7767 & 171 & 171 & 161 & 11 & 6 \\
\hline 2.00 & 0.00 & 0.8442 & 0.8442 & 0.8442 & 2.3690 & 2.3690 & 207 & 207 & 194 & 13 & 6 \\
\hline 2.50 & 0.00 & 0.8442 & 0.8442 & 0.8442 & 2.9612 & 2.9612 & 239 & 239 & 224 & 15 & 6 \\
\hline 3.00 & 0.00 & 0.8442 & 0.8442 & 0.8442 & 3.5535 & 3.5535 & 269 & 269 & 252 & 17 & 6 \\
\hline-3.00 & 1.00 & 0.8442 & 0.8442 & 0.8442 & -4.5535 & -4.5535 & -355 & -355 & -357 & -2 & -1 \\
\hline-2.50 & 1.00 & 0.8442 & 0.8442 & 0.8442 & -3.9612 & -3.9612 & -328 & -328 & -331 & -3 & -1 \\
\hline-2.00 & 1.00 & 0.8442 & 0.8442 & 0.8442 & -3.3690 & -3.3690 & -299 & -299 & -303 & -3 & -1 \\
\hline-1.50 & 1.00 & 0.8442 & 0.8442 & 0.8442 & -2.7767 & -2.7767 & -268 & -268 & -272 & -4 & -1 \\
\hline-1.00 & 1.00 & 0.8442 & 0.8442 & 0.8442 & -2.1845 & -2.1845 & -235 & -235 & -239 & -4 & -2 \\
\hline-0.50 & 1.00 & 0.8442 & 0.8442 & 0.8442 & -1.5922 & -1.5922 & -199 & -199 & -202 & -3 & -2 \\
\hline 0.01 & 1.00 & 0.8442 & 0.8442 & 0.8442 & -0.9882 & -0.9882 & -156 & -156 & -156 & 0 & 0 \\
\hline 0.50 & 1.00 & 0.8442 & 0.8442 & 0.8442 & -0.4078 & -0.4078 & -105 & -105 & -79 & 27 & 29 \\
\hline 1.00 & 1.00 & 0.8442 & 0.8442 & 0.8442 & 0.1845 & 0.1845 & -0 & -0 & 0 & 0 & 0 \\
\hline 1.50 & 1.00 & 0.8442 & 0.8442 & 0.8442 & 0.7767 & 0.7767 & 61 & 61 & 45 & 16 & 30 \\
\hline 2.00 & 1.00 & 0.8442 & 0.8442 & 0.8442 & 1.3690 & 1.3690 & 105 & 105 & 82 & 23 & 25 \\
\hline 2.50 & 1.00 & 0.8442 & 0.8442 & 0.8442 & 1.9612 & 1.9612 & 143 & 143 & 115 & 28 & 22 \\
\hline 3.00 & 1.00 & 0.8442 & 0.8442 & 0.8442 & 2.5535 & 2.5535 & 178 & 178 & 145 & 32 & 20 \\
\hline-3.00 & 2.00 & 0.8442 & 0.8442 & 0.8442 & -5.5535 & -5.5535 & -421 & -421 & -427 & -6 & -1 \\
\hline-2.50 & 2.00 & 0.8442 & 0.8442 & 0.8442 & -4.9612 & -4.9612 & -396 & -396 & -402 & -6 & -2 \\
\hline-2.00 & 2.00 & 0.8442 & 0.8442 & 0.8442 & -4.3690 & -4.3690 & -369 & -369 & -375 & -6 & -2 \\
\hline-1.50 & 2.00 & 0.8442 & 0.8442 & 0.8442 & $\mathbf{3 . 7 7 6 7}$ & -3.7767 & -342 & -342 & -347 & -6 & -2 \\
\hline-1.00 & 2.00 & 0.8442 & 0.8442 & 0.8442 & -3.1845 & -3.1845 & -312 & -312 & -317 & -5 & -2 \\
\hline-0.50 & 2.00 & 0.8442 & 0.8442 & 0.8442 & -2.5922 & -2.5922 & -281 & -281 & -284 & -3 & -1 \\
\hline 0.01 & 2.00 & 0.8442 & 0.8442 & 0.8442 & -1.9882 & -1.9882 & -246 & -246 & -246 & 0 & 0 \\
\hline 0.50 & 2.00 & 0.8442 & 0.8442 & 0.8442 & -1.4078 & -1.4078 & -209 & -209 & -202 & 7 & 3 \\
\hline 1.00 & 2.00 & 0.8442 & 0.8442 & 0.8442 & -0.8155 & -0.8155 & -165 & -165 & -123 & 42 & 29 \\
\hline 1.50 & 2.00 & 0.8442 & 0.8442 & 0.8442 & -0.2233 & -0.2233 & -106 & -106 & -45 & 61 & 81 \\
\hline 2.00 & 2.00 & 0.8442 & 0.8442 & 0.8442 & 0.3690 & 0.3690 & -0 & -0 & 0 & 0 & 0 \\
\hline $\begin{array}{l}2.50 \\
3.00\end{array}$ & $\begin{array}{l}2.00 \\
2.00\end{array}$ & 0.8442 & 0.8442 & 0.8442 & 0.9612 & 0.9612 & $\begin{array}{l}53 \\
95\end{array}$ & 53 & $\begin{array}{l}37 \\
70\end{array}$ & $\begin{array}{l}16 \\
25\end{array}$ & $\begin{array}{l}35 \\
30\end{array}$ \\
\hline $\begin{array}{r}3.00 \\
-3.00\end{array}$ & 3.00 & $\begin{array}{l}0.8442 \\
0.8442\end{array}$ & 0.8442 & $\begin{array}{l}0.8442 \\
0.8442\end{array}$ & $\begin{array}{r}1.5535 \\
-6.5535\end{array}$ & $\begin{array}{r}1.5535 \\
-6.5535\end{array}$ & $\begin{array}{r}95 \\
-481\end{array}$ & $\begin{array}{r}481 \\
-481\end{array}$ & $\begin{array}{r}70 \\
-489\end{array}$ & $\begin{array}{l}25 \\
-8\end{array}$ & $\begin{array}{l}30 \\
-2\end{array}$ \\
\hline-2.50 & 3.00 & 0.8442 & 0.8442 & 0.8442 & -5.9612 & -5.9612 & -457 & -457 & -464 & -8 & -2 \\
\hline-2.00 & 3.00 & 0.8442 & 0.8442 & 0.8442 & -5.3690 & -5.3690 & -432 & -432 & -439 & -7 & -2 \\
\hline-1.50 & 3.00 & 0.8442 & 0.8442 & 0.8442 & -4.7767 & -4.7767 & -406 & -406 & -413 & -6 & -2 \\
\hline-1.00 & 3.00 & 0.8442 & 0.8442 & 0.8442 & -4.1845 & -4.1845 & -379 & -379 & -384 & -5 & -1 \\
\hline-0.50 & 3.00 & 0.8442 & 0.8442 & 0.8442 & -3.5922 & -3.5922 & -351 & -351 & -354 & -3 & -1 \\
\hline 0.01 & 3.00 & 0.8442 & 0.8442 & 0.8442 & -2.9882 & -2.9882 & -321 & -321 & -321 & 0 & $\mathbf{0}$ \\
\hline 0.50 & 3.00 & 0.8442 & 0.8442 & 0.8442 & -2.4078 & -2.4078 & -289 & -289 & -284 & 5 & 2 \\
\hline 1.00 & 3.00 & 0.8442 & 0.8442 & 0.8442 & -1.8155 & -1.8155 & -254 & -254 & -239 & 15 & 6 \\
\hline 1.50 & 3.00 & 0.8442 & 0.8442 & 0.8442 & -1.2233 & -1.2233 & -215 &.-215 & -161 & 54 & 29 \\
\hline 2.00 & 3.00 & 0.8442 & 0.8442 & 0.8442 & -0.6310 & -0.6310 & -168 & -168 & -82 & 86 & 69 \\
\hline 2.50 & 3.00 & 0.8442 & 0.8442 & 0.8442 & -0.0388 & -0.0388 & -95 & -95 & -37 & 57 & 87 \\
\hline 3.00 & 3.00 & 0.8442 & 0.8442 & 0.8442 & 0.5535 & 0.5535 & -0 & -0 & o & 0 & 0 \\
\hline-3.00 & 4.00 & 0.8442 & 0.8442 & 0.8442 & -7.5535 & -7.5535 & -536 & -536 & -545 & -9 & -2 \\
\hline-2.50 & 4.00 & 0.8442 & 0.8442 & 0.8442 & -6.9612 & -6.9612 & -513 & -513 & -522 & -8 & -2 \\
\hline-2.00 & 4.00 & 0.8442 & 0.8442 & 0.8442 & -6.3690 & -6.3690 & -490 & -490 & -498 & -8 & -2 \\
\hline-1.50 & 4.00 & 0.8442 & 0.8442 & 0.8442 & -5.7767 & -5.7767 & -466 & -466 & -472 & -7 & -1 \\
\hline-1.00 & 4.00 & 0.8442 & 0.8442 & 0.8442 & -5.1845 & -5.1845 & -441 & -441 & -446 & -5 & -1 \\
\hline-0.50 & 4.00 & 0.8442 & 0.8442 & 0.8442 & -4.5922 & -4.5922 & -415 & -415 & -418 & -3 & -1 \\
\hline 0.01 & 4.00 & 0.8442 & 0.8442 & 0.8442 & -3.9882 & -3.9882 & -387 & -387 & -387 & 0 & 0 \\
\hline 0.50 & 4.00 & 0.8442 & 0.8442 & 0.8442 & -3.4078 & -3.4078 & -359 & -359 & -354 & 4 & 1 \\
\hline 1.00 & 4.00 & 0.8442 & 0.8442 & 0.8442 & -2.8155 & -2.8155 & -328 & -328 & -317 & 11 & 3 \\
\hline 1.50 & 4.00 & 0.8442 & 0.8442 & 0.8442 & -2.2233 & -2.2233 & -295 & -295 & -272 & 23 & 8 \\
\hline 2.00 & 4.00 & 0.8442 & 0.8442 & 0.8442 & -1.6310 & -1.6310 & -259 & -259 & -194 & 65 & 29 \\
\hline 2.50 & 4.00 & 0.8442 & 0.8442 & 0.8442 & -1.0388 & -1.0388 & -218 & -218 & -115 & 103 & 62 \\
\hline 3.00 & 4.00 & 0.8442 & 0.8442 & 0.8442 & -0.4465 & -0.4465 & -167 & -167 & -70 & 96 & 81 \\
\hline-3.00 & 5.00 & 0.8442 & 0.8442 & 0.8442 & -8.5535 & -8.5535 & -588 & -588 & -598 & -10 & -2 \\
\hline-2.50 & 5.00 & 0.8442 & 0.8442 & 0.8442 & -7.9612 & -7.9612 & -566 & -566 & -575 & -9 & -2 \\
\hline-2.00 & 5.00 & 0.8442 & 0.8442 & 0.8442 & -7.3690 & -7.3690 & -544 & -544 & -552 & -8 & -1 \\
\hline-1.50 & 5.00 & 0.8442 & 0.8442 & 0.8442 & -6.7767 & -6.7767 & -521 & -521 & -528 & -7 & -1 \\
\hline-1.00 & 5.00 & 0.8442 & 0.8442 & 0.8442 & -6.1845 & -6.1845 & -498 & -498 & -502 & -5 & -1 \\
\hline-0.50 & 5.00 & 0.8442 & 0.8442 & 0.8442 & -5.5922 & -5.5922 & -473 & -473 & -476 & -3 & -1 \\
\hline 0.01 & 5.00 & 0.8442 & 0.8442 & 0.8442 & -4.9882 & -4.9882 & -447 & -447 & -447 & 0 & 0 \\
\hline 0.50 & 5.00 & 0.8442 & 0.8442 & 0.8442 & -4.4078 & -4.4078 & -421 & -421 & -418 & 4 & 1 \\
\hline 1.00 & 5.00 & 0.8442 & 0.8442 & 0.8442 & -3.8155 & -3.8155 & -394 & -394 & -384 & 9 & 2 \\
\hline 1.50 & 5.00 & 0.8442 & 0.8442 & 0.8442 & -3.2233 & -3.2233 & -364 & -364 & -347 & 17 & 5 \\
\hline 2.00 & 5.00 & 0.8442 & 0.8442 & 0.8442 & -2.6310 & -2.6310 & -333 & -333 & -303 & 31 & 10 \\
\hline 2.50 & 5.00 & 0.8442 & 0.8442 & 0.8442 & -2.0388 & -2.0388 & -299 & -299 & -224 & 75 & 29 \\
\hline 3.00 & 5.00 & 0.8442 & 0.8442 & 0.8442 & -1.4465 & -1.4465 & -262 & -262 & -145 & 117 & 57 \\
\hline
\end{tabular}




\begin{tabular}{|c|c|c|c|c|c|c|c|c|c|c|c|}
\hline $\begin{array}{l}\text { Ctot= } \\
\text { DPoff }\end{array}$ & $\frac{157.29}{\text { DPon }}$ & $\begin{array}{c}\text { nenve } \\
\text { Zo }\end{array}$ & $\frac{0.65}{21}$ & $22^{c f=}$ & $\frac{0.95}{D P o f t / 2-D P}$ & on $c c=$ & \begin{tabular}{|r|} 
Osr genera \\
Q
\end{tabular} & $\begin{array}{l}C W= \\
\text { ed }\end{array}$ & Qsr 152 & $\begin{array}{l}\text { 1/nenv= } \\
\text { diff }\end{array}$ & $\begin{array}{l}1.538462 \\
\text { \%DIF }\end{array}$ \\
\hline-3.00 & 0.00 & 0.9964 & 0.9952 & 0.9951 & -3.0146 & -3.0149 & -316 & -316 & -252 & 64 & 22 \\
\hline-2.50 & 0.00 & 0.9964 & 0.9952 & 0.9951 & -2.5122 & -2.5124 & -281 & -281 & -224 & 57 & 22 \\
\hline-2.00 & 0.00 & 0.9964 & 0.9952 & 0.9951 & -2.0097 & -2.0099 & -243 & -243 & -194 & 49 & 22 \\
\hline-1.50 & 0.00 & 0.9964 & 0.9952 & 0.9951 & -1.5073 & -1.5074 & -201 & -201 & -161 & 41 & 22 \\
\hline-1.00 & 0.00 & 0.9964 & 0.9952 & 0.9951 & -1.0049 & -1.0050 & -155 & -155 & -123 & 31 & 22 \\
\hline$-0,50$ & 0.00 & 0.9964 & 0.9952 & 0.9951 & -0.5024 & -0.5025 & -99 & -99 & -79 & 20 & 22 \\
\hline 0.01 & 0.00 & 0.9964 & 0.9952 & 0.9951 & 0.0100 & 0.0100 & 8 & 8 & 6 & 2 & 22 \\
\hline 0.50 & 0.00 & 0.9964 & 0.9952 & 0.9951 & 0.5024 & 0.5025 & 99 & 99 & 79 & 20 & 22 \\
\hline 1.00 & 0,00 & 0.9964 & 0.9952 & 0.9951 & 1.0049 & 1.0050 & 155 & 155 & 123 & 31 & 22 \\
\hline 1.50 & 0.00 & 0.9964 & 0.9952 & 0.9951 & 1.5073 & 1.5074 & 201 & 201 & 161 & 41 & 22 \\
\hline 2.00 & 0.00 & 0.9964 & 0.9952 & 0.9951 & 2.0097 & 2.0099 & 243 & 243 & 194 & 49 & 22 \\
\hline 2.50 & 0.00 & 0.9964 & 0.9952 & 0.9951 & 2.5122 & 2.5124 & 281 & 281 & 224 & 57 & 22 \\
\hline 3,00 & 0.00 & 0.9964 & 0.9952 & 0.9951 & 3.0146 & 3.0149 & 316 & 316 & 252 & 64 & 22 \\
\hline$-3,00$ & 1.00 & 0.9964 & 0.9952 & 0.9951 & -4.0146 & -4.0149 & -383 & -383 & -357 & 26 & 7 \\
\hline-2.50 & 1.00 & 0.9964 & 0.9952 & 0.9951 & -3.5122 & -3.5124 & -351 & -351 & -331 & 21 & 6 \\
\hline-2.00 & 1.00 & 0.9964 & 0.9952 & 0.9951 & -3.0097 & -3.0099 & -318 & -318 & -303 & 16 & 5 \\
\hline-1.50 & 1.00 & 0.9964 & 0.9952 & 0.9951 & -2.5073 & -2.5074 & -283 & -283 & -272 & .11 & 4 \\
\hline-1.00 & 1.00 & 0,9964 & 0.9952 & 0.9951 & -2.0049 & -2.0050 & -245 & -245 & -239 & 6[ & 2 \\
\hline$=0.50$ & 1.00 & 0.9964 & 0.9952 & 0.9951 & -1.5024 & -1.5025 & -204 & -204 & -202 & 2 & 1 \\
\hline 0.01 & 1.00 & 0.9964 & 0.9952 & 0.9951 & -0.9900 & -0.9900 & -156 & -156 & -156 & o) & o \\
\hline 0.50 & 1.00 & 0.9964 & 0.9952 & 0.9951 & -0.4976 & -0.4975 & -101 & -101 & -79 & 23 & 25 \\
\hline 1.00 & 1.00 & 0.9964 & 0.9952 & 0.9951 & 0.0049 & 0.0050 & -0 & -0 & 0 & 0 & 0 \\
\hline 1.50 & 1.00 & 0.9964 & 0.9952 & 0.9951 & 0.5073 & 0.5074 & 94 & 94 & 45 & 49 & 71 \\
\hline 2.00 & 1.00 & 0.9964 & 0.9952 & 0.9951 & 1.0097 & 1.0099 & 150 & 150 & 82 & 68 & 59 \\
\hline 2.50 & 1.00 & 0.9964 & 0.9952 & 0.9951 & 1.5122 & 1.5124 & 197 & 197 & 115 & 82 & 53 \\
\hline 3,00 & 1.00 & 0.9964 & 0.9952 & 0.9951 & 2.0146 & 2.0149 & 239 & 239 & 145 & 94 & 49 \\
\hline$-3,00$ & 2.00 & 0.9964 & 0.9952 & 0.9951 & -5.0146 & -5.0149 & -444 & -444 & -427 & 17 & 4 \\
\hline-2.50 & 2.00 & 0.9964 & 0.9952 & 0.9951 & -4.5122 & -4.5124 & -415 & -415 & -402 & 13 & 3 \\
\hline-2.00 & 2.00 & 0.9964 & 0.9952 & 0.9951 & -4.0097 & -4.0099 & -385 & -385 & -375 & 9 & 2 \\
\hline-1.50 & 2.00 & 0.9964 & 0.9952 & 0.9951 & -3.5073 & -3.5074 & -353 & -353 & -347 & 6 & 2 \\
\hline-1.00 & 2.00 & 0.9964 & 0.9952 & 0.9951 & -3.0049 & -3.0050 & -320 & -320 & -317 & 3 & 1 \\
\hline-0.50 & 2.00 & 0.9964 & 0.9952 & 0.9951 & -2.5024 & -2.5025 & -285 & -285 & -284 & 1 & 0 \\
\hline 0.01 & 2.00 & 0.9964 & 0.9952 & 0.9951 & -1.9900 & -1.9900 & -246 & -246 & -246 & o) & 0 \\
\hline 0.50 & 2.00 & 0.9964 & 0.9952 & 0.9951 & -1.4976 & -1.4975 & -206 & -206 & -202 & 4 & 2 \\
\hline 1.00 & 2.00 & 0.9964 & 0.9952 & 0.9951 & -0.9951 & -0.9950 & -159 & -159 & -123 & 36 & 25 \\
\hline 1.50 & 2.00 & 0.9964 & 0.9952 & 0.9951 & -0.4927 & -0.4926 & -103 & -103 & -45 & 58 & 79 \\
\hline 2.00 & 2.00 & 0.9964 & 0.9952 & 0.9951 & 0.0097 & 0.0099 & -0 & -0 & 0 & 0 & 0 \\
\hline 2.50 & 2.00 & 0.9964 & 0.9952 & 0.9951 & 0.5122 & 0.5124 & 91 & 91 & 37 & 54 & 84 \\
\hline 3.00 & 2.00 & 0.9964 & 0.9952 & 0.9951 & 1.0146 & 1.0149 & 147 & 148 & 70 & 77 & 71 \\
\hline-3.00 & 3.00 & 0.9964 & 0.9952 & 0.9951 & -6.0146 & -6.0149 & -500 & -500 & -489 & 12 & 2 \\
\hline-2.50 & 3.00 & 0.9964 & 0.9952 & 0.9951 & -5.5122 & -5.5124 & -473 & -473 & -464 & 9 & 2 \\
\hline-2.00 & 3.00 & 0.9964 & 0.9952 & 0.9951 & -5.0097 & -5.0099 & -445 & -445 & -439 & 6 & 1 \\
\hline-1.50 & 3.00 & 0.9964 & 0.9952 & 0.9951 & -4.5073 & -4.5074 & -416 & -416 & -413 & 4 & 1 \\
\hline$-1,00$ & 3.00 & 0.9964 & 0.9952 & 0.9951 & -4.0049 & -4.0050 & -386 & -386 & -384 & 1 & 0 \\
\hline-0.50 & 3.00 & 0.9964 & 0.9952 & 0.9951 & -3.5024 & -3.5025 & -354 & -354 & -354 & 0 & 0 \\
\hline 0.01 & 3.00 & 0.9964 & 0.9952 & 0.9951 & -2.9900 & -2.9900 & -321 & -321 & -321 & o) & 0 \\
\hline 0.50 & 3.00 & 0.9964 & 0.9952 & 0.9951 & -2.4976 & -2.4975 & -286 & -286 & -284 & 2 & 1 \\
\hline 1.00 & 3.00 & 0.9964 & 0.9952 & 0.9951 & -1.9951 . & -1.9950 & -248 & -248 & -239 & 9 & 4 \\
\hline 1.50 & 3.00 & 0.9964 & 0.9952 & 0.9951 & -1.4927 & -1.4926 & -207 & -207 & -161 & 46 & 25 \\
\hline 2.00 & 3.00 & 0.9964 & 0.9952 & 0.9951 & -0.9903 & -0.9901 & -161 & -161 & -82 & 79 & 65 \\
\hline 2.50 & 3.00 & 0.9964 & 0.9952 & 0.9951 & -0.4878 & -0.4876 & -105 & -105 & -37 & 68 & 95 \\
\hline 3,00 & 3.00 & 0.9964 & 0.9952 & 0.9951 & 0.0146 & 0.0149 & -0 & -0 & 0 & 0 & 1 \\
\hline-3.00 & 4.00 & 0.9964 & 0.9952 & 0.9951 & -7.0146 & -7.0149 & -554 , & -554 & -545 & 9 & 2 \\
\hline-2.50 & 4.00 & 0.9964 & 0.9952 & 0.9951 & -6.5122 & -6.5124 & -528 & -528 & -522 & 6 & 1 \\
\hline-2.00 & 4.00 & 0.9964 & 0.9952 & 0.9951 & -6.0097 & -6.0099 & -502 & -502 & -498 & 4 & 1 \\
\hline-1.50 & 4.00 & 0.9964 & 0.9952 & 0.9951 & -5.5073 & -5.5074 & -475 & -475 & -472 & 2 & 0 \\
\hline-1.00 & 4.00 & 0.9964 & 0.9952 & 0.9951 & -5.0049 & -5.0050 & -447 & -447 & -446 & 1 & 0 \\
\hline-0.50 & 4.00 & 0.9964 & 0.9952 & 0.9951 & -4.5024 & -4.5025 & -417 & -417 & -418 & -0 & -0 \\
\hline 0.01 & 4.00 & 0.9964 & 0.9952 & 0.9951 & -3.9900 & -3.9900 & -387 & -387 & -387 & o) & 0 \\
\hline 0.50 & 4.00 & 0.9964 & 0.9952 & 0.9951 & -3.4976 & -3.4975 & -356 & -356 & -354 & 1 & o \\
\hline 1.00 & 4.00 & 0.9964 & 0.9952 & 0.9951 & -2.9951 & -2.9950 & -323 & -323 & -317 & 6[ & 2 \\
\hline 1.50 & 4.00 & 0.9964 & 0.9952 & 0.9951 & -2.4927 & -2.4926 & -287 & -287 & -272 & 15 & 5 \\
\hline 2.00 & 4.00 & 0.9964 & 0.9952 & 0.9951 & -1.9903 & -1.9901 & -250 & -250 & -194 & 56 & 25 \\
\hline 2.50 & 4.00 & 0.9964 & 0.9952 & 0.9951 & -1.4878 & -1.4876 & -208 & -208 & -115 & 93 & 58 \\
\hline 3,00 & 4.00 & 0.9964 & 0.9952 & 0.9951 & -0.9854 & -0.9851 & -162 & -162 & -70 & 92 & 79 \\
\hline-3.00 & 5.00 & 0.9964 & 0.9952 & 0.9951 & -8.0146 & -8.0149 & -605 & -605 & -598 & 7 & 1 \\
\hline-2.50 & 5.00 & 0.9964 & 0.9952 & 0.9951 & -7.5122 & -7.5124 & -580 & -580 & -575 & 5 & 1 \\
\hline-2.00 & 5.00 & 0.9964 & 0.9952 & 0.9951 & -7.0097 & -7.0099 & -555 & -555 & -552 & 3 & 1 \\
\hline-1.50 & 5.00 & 0.9964 & 0.9952 & 0.9951 & -6.5073 & -6.5074 & -529 & -529 & -528 & 2 & 0 \\
\hline-1.00 & 5.00 & 0.9964 & 0.9952 & 0.9951 & -6.0049 & -6.0050 & -503 & -503 & -502 & of & 0 \\
\hline-0.50 & 5.00 & 0.9964 & 0.9952 & 0.9951 & -5.5024 & -5.5025 & -476 & -476 & -476 & -0 & -0 \\
\hline 0.01 & 5.00 & 0.9964 & 0.9952 & 0.9951 & -4.9900 & -4.9900 & -447 & -447 & -447 & o. & 0 \\
\hline 0.50 & 5.00 & 0.9964 & 0.9952 & 0.9951 & -4.4976 & -4.4975 & -419 & -419 & -418 & 1 & o) \\
\hline 1.00 & 5.00 & 0.9964 & 0.9952 & 0.9951 & -3.9951 & -3.9950 & -389 & -389 & -384 & 4 & 1 \\
\hline 1.50 & 5.00 & 0.9964 & 0.9952 & 0.9951 & -3.4927 & -3.4926 & -357 & -357 & -347 & 10 & 3 \\
\hline 2.00 & 5.00 & 0.9964 & 0.9952 & 0.9951 & -2.9903 & -2.9901 & -324 & -324 & -303 & 21 & 7 \\
\hline 2.50 & 5.00 & 0.9964 & 0.9952 & 0.9951 & -2.4878 & -2.4876 & -289 & -289 & -224 & 65 & 25 \\
\hline 3,00 & 5.00 & 0.9964 & 0.9952 & 0.9951 & -1.9854 & -1.9851 & -251 & -251 & -145 & 106 & 53 \\
\hline
\end{tabular}

